\title{
ENHANCED UNCERTAINTY ANALYSIS FOR SRS COMPOSITE ANALYSIS
}

\author{
F. G. Smith, III \\ M. A. Phifer
}

JUNE, 2011

Savannah River National Laboratory

Savannah River Nuclear Solutions

Savannah River Site

Aiken, SC 29808

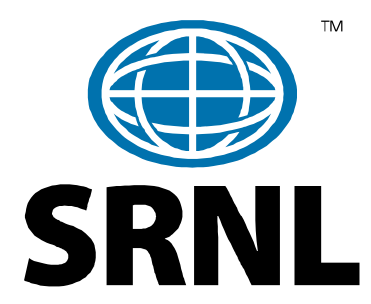


SRNL-STI-2011-00365, Rev. 0

\section{DISCLAIMER}

This work was prepared under an agreement with and funded by the U.S. Government. Neither the U. S. Government or its employees, nor any of its contractors, subcontractors or their employees, makes any express or implied:

1. warranty or assumes any legal liability for the accuracy, completeness, or for the use or results of such use of any information, product, or process disclosed; or

2. representation that such use or results of such use would not infringe privately owned rights; or

3. endorsement or recommendation of any specifically identified commercial product, process, or service.

Any views and opinions of authors expressed in this work do not necessarily state or reflect those of the United States Government, or its contractors, or subcontractors.

Printed in the United States of America

Prepared For

\section{U.S. Department of Energy}


Key Words:

CA, Modeling,

Uncertainty Analysis, GoldSim

Retention:

Permanent

\title{
ENHANCED UNCERTAINTY ANALYSIS FOR SRS COMPOSITE ANALYSIS
}

\author{
F. G. Smith, III
}

M. A. Phifer

JUNE, 2011

Savannah River National Laboratory

Savannah River Nuclear Solutions

Savannah River Site

Aiken, SC 29808

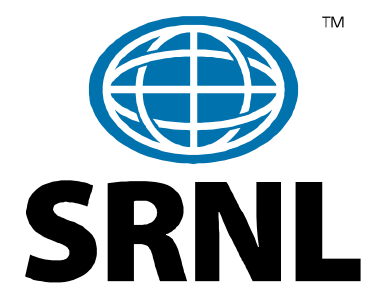


SRNL-STI-2011-00365, Rev. 0

\section{REVIEWS AND APPROVALS}

\section{Authors}

F. G. Smith, III, Process Modeling and Computational Chemistry

Date

M. A. Phifer, Environmental Remediation Technology

Date

\section{Design Check}

G. A. Taylor, Radiological Performance Assessment

Date

\section{Approval}

D. A. Crowley, Manager, Radiological Performance Assessment

Date

R. S. Aylward Manager, Environmental Restoration Technology

Date

W. T. Goldston, Manager, Regulatory Integration

Date 


\section{TABLE OF CONTENTS}

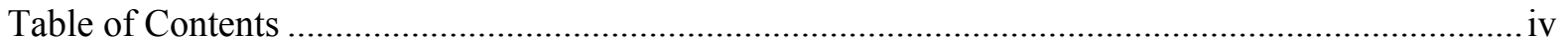

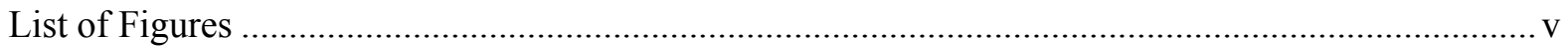

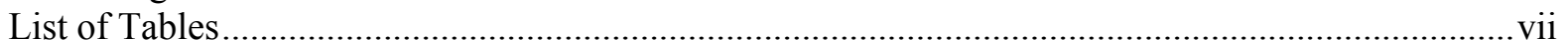

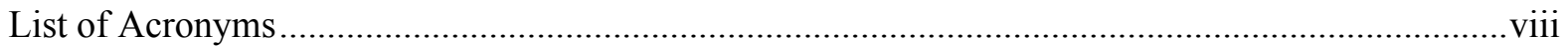

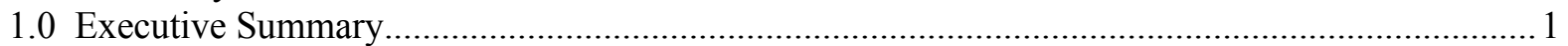

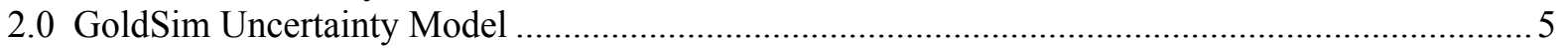

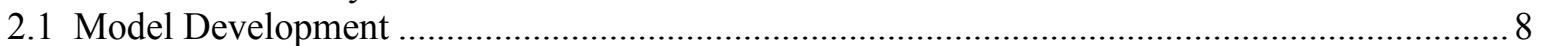

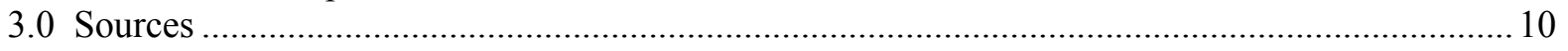

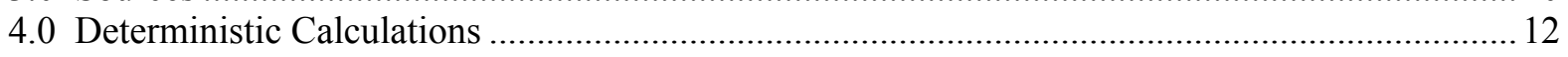

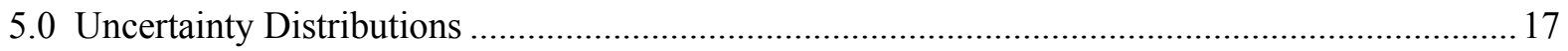

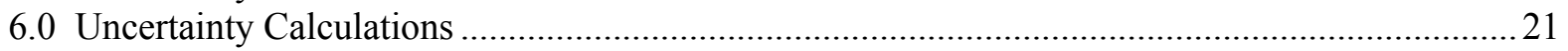

6.1 Dose Uncertainty over 10,000 Year Simulation ................................................................ 23

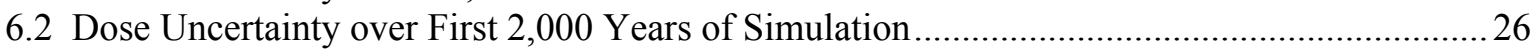

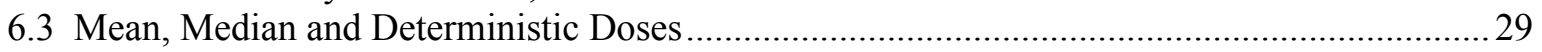

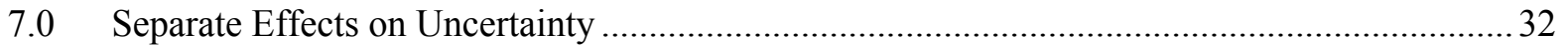

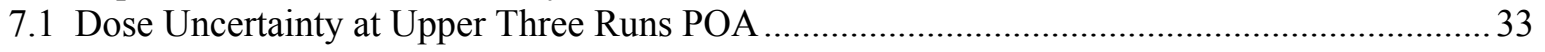

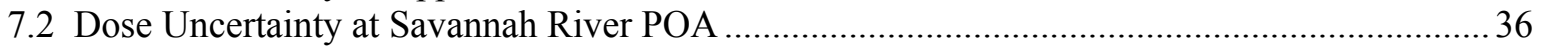

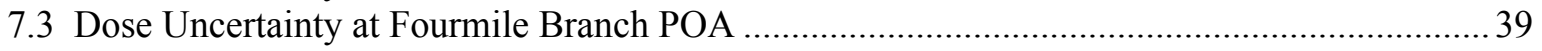

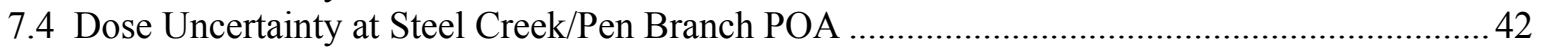

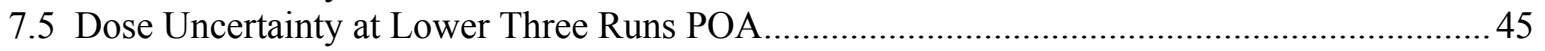

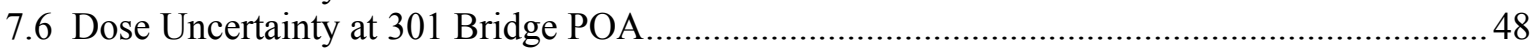

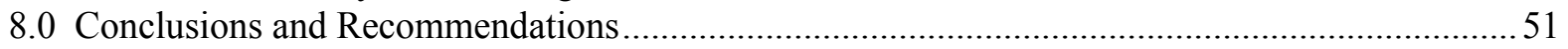

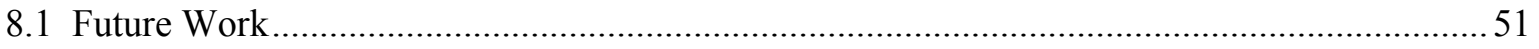

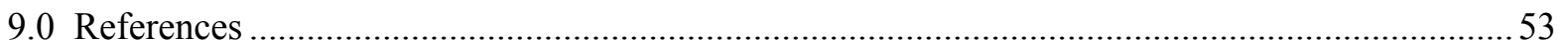




\section{LIST OF FIGURES}

Figure 2-1. View of sources in GoldSim model used for enhanced CA uncertainty analysis.............. 6 Figure 2-2. GoldSim transport model used for each of the 32 sources. .............................................. 6 Figure 2-3. View of POAs in GoldSim model used for enhanced CA uncertainty analysis................ 7 Figure 2-4. GoldSim model of Steel Creek/Pen Branch POA........................................................... 8

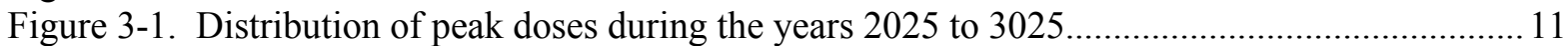

Figure 4-1. CA deterministic calculation of cumulative doses at each POA from all sources over 10,000 year time period.

Figure 4-2. CA deterministic calculation of cumulative doses at each POA from all sources over 2,000 year time period.

Figure 4-3. Deterministic calculation of cumulative doses at each POA over 10,000 year time period using multi-source model with 39 sources.

Figure 4-4. Deterministic calculation of cumulative doses at each POA over 2,000 year time period using multi-source model with 39 sources. ............................................................... 14

Figure 4-5. Comparison of deterministic doses calculated at each POA over 10,000 years using the CA model with all 152 sources and the multi-source model with 39 sources................ 15

Figure 4-6. Comparison of deterministic doses calculated at each POA over 2,000 years using the CA model with all 152 sources and the multi-source model with 39 sources. ..................... 16

Figure 6.1-1. Uncertainty in dose at Upper Three Runs POA over 10,000 years. ............................ 23

Figure 6.1-2. Uncertainty in cumulative dose at Savannah River POA over 10,000 years............... 23

Figure 6.1-3. Uncertainty in cumulative dose at Fourmile Branch POA over 10,000 years..............24

Figure 6.1-4. Uncertainty in cumulative dose at Steel Creek/Pen Branch POA over 10,000 years.... 24

Figure 6.1-5. Uncertainty in cumulative dose at Lower Three Runs POA over 10,000 years........... 25

Figure 6.1-6. Uncertainty in cumulative dose at 301 Bridge POA over 10,000 years. ..................... 25

Figure 6.2-1. Uncertainty in dose at Upper Three Runs POA over 2,000 years. ............................. 26

Figure 6.2-2. Uncertainty in cumulative dose at Savannah River POA over 2,000 years.................. 26

Figure 6.2-3. Uncertainty in cumulative dose at Fourmile Branch POA over 2,000 years................ 27

Figure 6.2-4. Uncertainty in cumulative dose at Steel Creek/Pen Branch POA over 2,000 years...... 27

Figure 6.2-5. Uncertainty in cumulative dose at Lower Three Runs POA over 2,000 years............. 28

Figure 6.2-6. Uncertainty in cumulative dose at 301 Bridge POA over 2,000 years....................... 28

Figure 6.3-1. Mean, median and deterministic doses at Upper Three Runs POA.............................29

Figure 6.3-2. Mean, median and deterministic doses at Savannah River POA.................................29

Figure 6.3-3. Mean, median and deterministic doses at Fourmile Branch POA.............................. 30

Figure 6.3-4. Mean, median and deterministic doses at Steel Creek/Pen Branch POA..................... 30

Figure 6.3-5. Mean, median and deterministic doses at Lower Three Runs POA. ........................... 31

Figure 6.3-6. Mean, median and deterministic doses at 301 Bridge POA. ........................................ 31

Figure 7.1-1. Overall uncertainty in dose at Upper Three Runs POA............................................ 33

Figure 7.1-2. Uncertainty in dose at Upper Three Runs POA from variation in $\mathrm{K}_{\mathrm{d}} \ldots \ldots \ldots \ldots \ldots \ldots \ldots \ldots \ldots . . . . . . . . . . . .33$

Figure 7.1-3. Uncertainty in dose at Upper Three Runs POA from variation in dose parameters...... 34

Figure 7.1-4. Uncertainty in dose at Upper Three Runs POA from variation in material properties.. 34

Figure 7.1-5. Uncertainty in dose at Upper Three Runs POA from variation in surface water flow.. 35

Figure 7.1-6. Uncertainty in dose at Upper Three Runs POA from variation in infiltration and aquifer

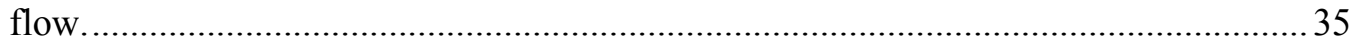

Figure 7.2-1. Overall uncertainty in dose at Savannah River POA.................................................. 36

Figure 7.2-2. Uncertainty in dose at Savannah River POA from variation in $\mathrm{K}_{\mathrm{d} \cdot \ldots \ldots \ldots \ldots \ldots \ldots \ldots \ldots . . . . . . . . . . . . . . . . .36}$

Figure 7.2-3. Uncertainty in dose at Savannah River POA from variation in dose parameters.......... 37

Figure 7.2-4. Uncertainty in dose at Savannah River POA from variation in material properties...... 37

Figure 7.2-5. Uncertainty in dose at Savannah River POA from variation in surface water flow...... 38

Figure 7.2-6. Uncertainty in dose at Savannah River POA from variation in infiltration and aquifer flow. 
Figure 7.3-1. Overall uncertainty in dose at Fourmile Branch POA. 39

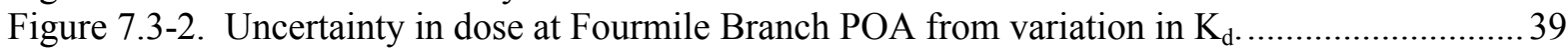

Figure 7.3-3. Uncertainty in dose at Fourmile Branch POA from variation in dose parameters. ....... 40

Figure 7.3-4. Uncertainty in dose at Fourmile Branch POA from variation in material properties.... 40

Figure 7.3-5. Uncertainty in dose at Fourmile Branch POA from variation in surface water flow. ... 41

Figure 7.3-6. Uncertainty in dose at Fourmile Branch POA from variation in infiltration and aquifer

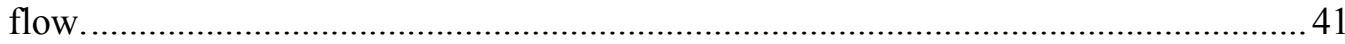

Figure 7.4-1. Overall uncertainty in dose at Steel Creek/Pen Branch POA.................................... 42

Figure 7.4-2. Uncertainty in dose at Steel Creek/Pen Branch POA from variation in $\mathrm{K}_{\mathrm{d}} \ldots \ldots \ldots \ldots \ldots \ldots . . . . . . .42$

Figure 7.4-3. Uncertainty in dose at Steel Creek/Pen Branch POA from variation in dose parameters.

Figure 7.4-4. Uncertainty in dose at Steel Creek/Pen Branch POA from variation in material properties.

Figure 7.4-5. Uncertainty in dose at Steel Creek/Pen Branch POA from variation in surface water

Figure 7.4-6. Uncertainty in dose at Steel Creek/Pen Branch POA from variation in infiltration and

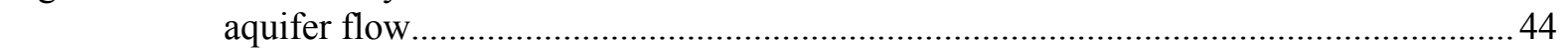

Figure 7.5-1. Overall uncertainty in dose at Lower Three Runs POA. ........................................... 45

Figure 7.5-2. Uncertainty in dose at Lower Three Runs POA from variation in $\mathrm{K}_{\mathrm{d}}$........................ 45

Figure 7.5-3. Uncertainty in dose at Lower Three Runs POA from variation in dose parameters...... 46

Figure 7.5-4. Uncertainty in dose at Lower Three Runs POA from variation in material properties. 46

Figure 7.5-5. Uncertainty in dose at Lower Three Runs POA from variation in surface water flow.. 47

Figure 7.5-6. Uncertainty in dose at Lower Three Runs POA from variation in infiltration and aquifer

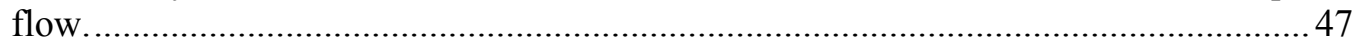

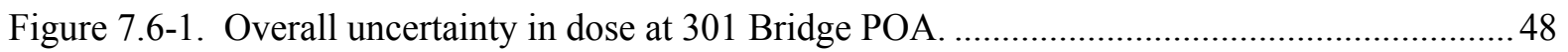

Figure 7.6-2. Uncertainty in dose at 301 Bridge POA from variation in $\mathrm{K}_{\mathrm{d}}$................................. 48

Figure 7.6-3. Uncertainty in dose at 301 Bridge POA from variation in dose parameters.................. 49

Figure 7.6-4. Uncertainty in dose at 301 Bridge POA from variation in material properties. ............ 49

Figure 7.6-5. Uncertainty in dose at 301 Bridge POA from variation in surface water flow............. 50

Figure 7.6-6. Uncertainty in dose at 301 Bridge POA from variation in infiltration and aquifer flow.

Figure 8-1. Cumulative distribution of peak doses from all CA sources during the years $2025-3025$. 


\section{LIST OF TABLES}

Table 1-1 Items in CA maintenance program addressed through this work. .................................... 3

Table 3-1. 39 Sources Included in Extended CA Uncertainty Analysis............................................ 10

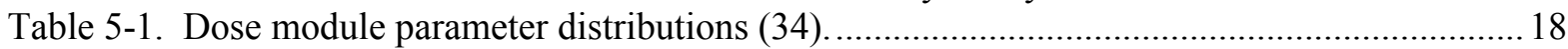

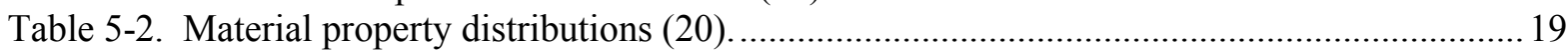

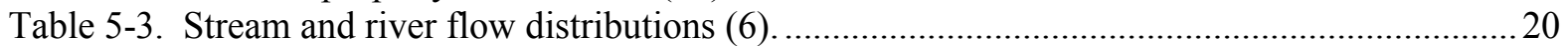

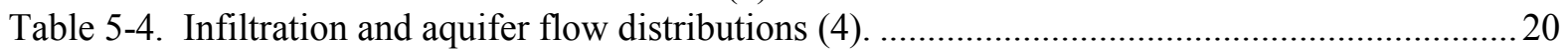

Table 6-1. Peak values of statistical parameters for total dose at each POA over the CA assessment period from 2025 to 3025 produced from the multi-source, multi-POA model. .............. 22

Table 6-2. Peak values of statistical parameters for total dose at each POA over the CA assessment period from 2025 to 3025 produced from the original CA uncertainty analysis. .............. 22 
SRNL-STI-2011-00365, Rev. 0

\section{LIST OF ACRONYMS}

\begin{tabular}{|c|c|}
\hline $\mathrm{ACP}$ & Area Completion Projects \\
\hline $\mathrm{BCF}$ & Bioaccumulation Factor \\
\hline $\mathrm{CA}$ & Composite Analysis \\
\hline CIG & Components in Grout \\
\hline DOE & Department of Energy \\
\hline DWPF & Defense Waste Processing Facility \\
\hline ET & Engineered Trench \\
\hline FAMS & F-Area Material Storage \\
\hline FMB & Fourmile Branch \\
\hline FTF & F-Area Tank Farm \\
\hline GOU & Groundwater Operable Unit \\
\hline GSA & General Separations Area \\
\hline HANM & H-Area New Manufacturing \\
\hline HAOM & H-Area Old Manufacturing \\
\hline HTF & H-Area Tank Farm \\
\hline HWMF & Hazardous Waste Management Facility \\
\hline ILV & Intermediate Level Vault \\
\hline IOU & Integrator Operable Unit \\
\hline IPSL & Inoperative Process Sewer Line \\
\hline $\mathrm{KAC}$ & K-Area Complex \\
\hline LAC & L-Area Complex \\
\hline LAWV & Low Activity Waste Vault \\
\hline LFRG & Low Level Waste Disposal Facility Federal Review Group \\
\hline LLRWDF & Low Level Radioactive Waste Disposal Facility \\
\hline LLWF & Low Level Waste Facility \\
\hline LPPP & Low Point Pump Pit \\
\hline LTR & Lower Three Runs \\
\hline MWMF & Mixed Waste Management Facility \\
\hline NR & Naval Reactor \\
\hline NRCDA & Naval Reactor Components Disposal Area \\
\hline ORWBG & Old Radioactive Waste Burial Ground \\
\hline PB & Pen Branch \\
\hline POA & Point of Assessment \\
\hline $\mathrm{SC}$ & Steel Creek \\
\hline SDF & Saltstone Disposal Facility \\
\hline SR & Savannah River \\
\hline SRS & Savannah River Site \\
\hline SS & Stainless Steel \\
\hline SWPF & Salt Waste Processing Facility \\
\hline $\mathrm{TEF}$ & Tritium Extraction Facility \\
\hline TPBAR & Tritium Producing Burnable Absorber Rods \\
\hline TRU & Transuranic \\
\hline UTR & Upper Three Runs \\
\hline
\end{tabular}


SRNL-STI-2011-00365, Rev. 0

(This Page Intentionally Left Blank) 
SRNL-STI-2011-00365, Rev. 0

\subsection{Executive Summary}

The Composite Analysis (CA) performed for the Savannah River Site (SRS) in 2009 (SRS CA 2009 ) included a simplified uncertainty analysis. The uncertainty analysis in the CA (Smith et al. 2009b) was limited to considering at most five sources in a separate uncertainty calculation performed for each POA. To perform the uncertainty calculations in a reasonable amount of time, the analysis was limited to using 400 realizations, 2,000 years of simulated transport time, and the time steps used for the uncertainty analysis were increased from what was used in the CA base case analysis. As part of the CA maintenance plan, the Savannah River National Laboratory (SRNL) committed to improving the CA uncertainty/sensitivity analysis.

The previous uncertainty analysis was constrained by the standard GoldSim licensing which limits the user to running at most four Monte Carlo uncertainty calculations (also called realizations) simultaneously. Some of the limitations on the number of realizations that could be practically run and the simulation time steps were removed by building a cluster of three HP Proliant windows servers with a total of 36 64-bit processors and by licensing the GoldSim DPPlus distributed processing software. This allowed running as many as 35 realizations simultaneously (one processor is reserved as a master process that controls running the realizations). These enhancements to SRNL computing capabilities ${ }^{1}$ made uncertainty analysis: using 1000 realizations, using the time steps employed in the base case CA calculations, with more sources, and simulating radionuclide transport for 10,000 years feasible ${ }^{2}$.

In addition, an importance screening analysis was performed to identify the class of stochastic variables that have the most significant impact on model uncertainty. This analysis ran the uncertainty model separately testing the response to variations in the following five sets of model parameters:

a. $\mathrm{K}_{\mathrm{d}}$ values (72 parameters for the $36 \mathrm{CA}$ elements in sand and clay),

b. Dose Parameters (34 parameters),

c. Material Properties (20 parameters),

d. Surface Water Flows (6 parameters),

e. Vadose and Aquifer Flow (4 parameters).

Results provided an assessment of which group of parameters is most significant in the dose uncertainty ${ }^{3}$. It was found that $\mathrm{K}_{\mathrm{d}}$ and the vadose/aquifer flow parameters, both of which impact transport timing, had the greatest impact on dose uncertainty. Dose parameters had an intermediate level of impact while material properties and surface water flows had little impact on dose uncertainty. Results of the importance analysis are discussed further in Section 7 of this report.

\footnotetext{
${ }^{1}$ This addresses Item 15 in SRS CA Table 11-2 and partially addresses LFRG Review Team Observation 21 in SRS CA Appendix H.

2 This partially addresses Item 14 in SRS CA Table 11-3 and the review comment in Appendix G Section 3.3.8.1.

${ }^{3}$ This more structured uncertainty analysis partially addresses Items 16 and 17 in SRS CA Table 11-2; review comments in Appendix G Section 3.3.8.1; Appendix G "General Comments from Bruce Crowe" 1.d; and LFRG Review Team Observation 21 in Appendix H. However this uncertainty analysis did not include inventory and bioaccumulation factor (transfer factor) distributions, which will need to be included in the next $\mathrm{CA}$ revision.
} 
The objectives of this work were to address comments received during the CA review on the uncertainty analysis and to demonstrate an improved methodology for CA uncertainty calculations as part of CA maintenance. This report partially addresses the LFRG Review Team issue of producing an enhanced CA sensitivity and uncertainty analysis. This is described in Table 1-1 which provides specific responses to pertinent CA maintenance items extracted from Section 11 of the SRS CA (2009). As noted above, the original uncertainty analysis looked at each POA separately and only included the effects from at most five sources giving the highest peak doses at each POA. Only 17 of the 152 CA sources were used in the original uncertainty analysis and the simulation time was reduced from 10,000 to 2,000 years. A major constraint on the original uncertainty analysis was the limitation of only being able to use at most four distributed processes. This work expanded the analysis to 10,000 years using 39 of the CA sources, included cumulative dose effects at downstream POAs, with more realizations $(1,000)$ and finer time steps. This was accomplished by using the GoldSim DP-Plus module and the 36 processors available on a new windows cluster. The last part of the work looked at the contribution to overall uncertainty from the main categories of uncertainty variables: $K_{d} s$, dose parameters, flow parameters, and material properties. This was not intended to be a detailed sensitivity analysis but only to see in very general terms what broad category of parameters contributes most significantly to overall uncertainty in the CA dose. This analysis was not intended to be a final CA uncertainty calculation and there was no intent to revise the stochastic distributions as part of this work. 
Table 1-1 Items in CA maintenance program addressed through this work.

\begin{tabular}{|c|c|c|}
\hline \multicolumn{3}{|c|}{$\begin{array}{l}\text { Priority Future Work Category: } \\
\text { SRS CA Sensitivity and Uncertainty Analysis (Table 11-2, SRS CA, 2009) }\end{array}$} \\
\hline Item & Description & As Addressed by This Work \\
\hline 15 & $\begin{array}{l}\text { GoldSim }{ }^{\mathrm{TM}} \text { has a distributed processing (DP) capability that can be used when } \\
\text { performing probabilistic calculations. Using this feature, individual realizations can be } \\
\text { run on as many processors as the master GoldSim }{ }^{\mathrm{TM}} \text { simulation can be linked to. The } \\
\text { basic GoldSim } \\
\text { for the mastware is limited to using four processors one of which is reserved } \\
\text { capability was utilized in performing the CA uncertainty calculations which reduced } \\
\text { the simulation run time by a factor of three. However, by adding the GoldSim }{ }^{\mathrm{TM}} \mathrm{DP} \\
\text { module, available from GoldSim Technology Group at a nominal cost, a probabilistic } \\
\text { GoldSim }{ }^{\mathrm{TM}} \text { simulation can be connected to as many processors as are available. This } \\
\text { offers the possibility of dramatically decreasing probabilistic simulation run times and } \\
\text { increasing the capability of performing uncertainty calculations including more sources } \\
\text { with more realizations. Utilizing this approach is currently limited by our inability to } \\
\text { access other computers through the SRS network primarily from computer security } \\
\text { concerns. If a large cluster of Windows machines could be assembled off the SRS } \\
\text { network, all of the processors could be accessed by GoldSim } \\
\text { calculations. This item was probabilistic } \\
\text { plan, and work on this item has been initiated. (Smith } 2009 \mathrm{~b} \text { ) }\end{array}$ & $\begin{array}{l}\text { The computing capability proposed in Item } 15 \text { was created as } \\
\text { a part of the work described in this report. A cluster of three } \\
\text { HP Proliant windows servers having a total of } 36 \text { 64-bit } \\
\text { processors were purchased and the GoldSim DP-Plus } \\
\text { distributed processing software was licensed. This gives } \\
\text { SRNL the capability of running as many as } 35 \text { simultaneous } \\
\text { GoldSim realizations which allowed uncertainty calculations } \\
\text { to be run over } 10,000 \text { years including more sources and using } \\
\text { finer time steps. Item } 15 \text { is therefore complete as a result of } \\
\text { the work described in this report. }\end{array}$ \\
\hline 16 & $\begin{array}{l}\text { A systematic sensitivity analysis should be performed to identify the model parameters } \\
\text { that have the greatest impact on CA results. This analysis should investigate the } \\
\text { additive and multiplicative effects of parameters on the CA results. This analysis } \\
\text { should investigate parameters in the transport model and in the dose model separately. } \\
\text { This systematic sensitivity analysis along with a more structured uncertainty analysis } \\
\text { (Item 17) will assist in future work prioritization. Expertise in the SRNL statistical } \\
\text { group should be utilized to help structure this investigation and interpret the results. }\end{array}$ & $\begin{array}{l}\text { Item } 16 \text { is partially addressed by the work described in this } \\
\text { report. As part of the enhanced uncertainty analysis a limited } \\
\text { sensitivity analysis was performed to determine what general } \\
\text { categories of uncertainty parameters }\left(\mathrm{K}_{\mathrm{d}} \text {, material properties, }\right. \\
\text { water flow, and dose parameters) had the greatest impact on } \\
\text { uncertainty in the calculated dose. Final sensitivity analysis } \\
\text { work must await development of inventory uncertainty } \\
\text { distributions from the remaining significant radionuclide } \\
\text { source locations under CA maintenance. }\end{array}$ \\
\hline
\end{tabular}




\begin{tabular}{|c|c|c|}
\hline \multicolumn{3}{|c|}{$\begin{array}{l}\text { Priority Future Work Category: } \\
\text { SRS CA Sensitivity and Uncertainty Analysis (Table 11-2, SRS CA, 2009) }\end{array}$} \\
\hline Item & Description & $\begin{array}{l}\text { As Addressed by This Work } \\
\end{array}$ \\
\hline 17 & $\begin{array}{l}\text { A more structured uncertainty analysis should be performed to identify both those } \\
\text { stochastic variables that have the greatest impact on model results and stochastic } \\
\text { variables that have an insignificant impact on model results and can be eliminated from } \\
\text { the uncertainty analysis. In particular inventory uncertainty distributions developed } \\
\text { from Items } 4,5,6 \text {, and } 7 \text { should be included in the uncertainty analysis. This } \\
\text { structured uncertainty analysis along with a more systematic sensitivity analysis (Item } \\
\text { 16) will assist in future work prioritization. Expertise in the SRNL statistical group } \\
\text { should be utilized to help structure this investigation and interpret the results. }\end{array}$ & $\begin{array}{l}\text { Item } 17 \text { is partially addressed by the work described in this } \\
\text { report. A methodology to conduct a more structured } \\
\text { uncertainty analysis was demonstrated and preliminary } \\
\text { results obtained. However, this work did not include } \\
\text { developing inventory uncertainty distributions or } \\
\text { distributions for bioaccumulation factors which were not } \\
\text { included in the dose module. Items } 16 \text { and } 17 \text { can be } \\
\text { completed when these distributions are available. }\end{array}$ \\
\hline \multicolumn{3}{|c|}{$\begin{array}{c}\text { Potential Future Work Category: } \\
\text { SRS CA Model Improvements (Table 11-3, SRS CA, 2009) }\end{array}$} \\
\hline Item & \begin{tabular}{l|l} 
Description &
\end{tabular} & As Addressed by This Work \\
\hline 14 & $\begin{array}{l}\text { After Item } 15 \text { in Error! Reference source not found. is completed, a fully } \\
\text { probabilistic analysis should be conducted over 10,000 years both at the base case } \\
\text { POAs and at the Alternate Industrial POAs. }\end{array}$ & $\begin{array}{l}\text { Item } 14 \text { is partially addressed by the work described in this } \\
\text { report. A methodology capable of conducting a full } \\
\text { probabilistic analysis over } 10,000 \text { years at the base case } \\
\text { POAs was developed and demonstrated. Lack of inventory } \\
\text { and bioaccumulation factor distributions prevented } \\
\text { conducting a final CA uncertainty analysis. Alternative } \\
\text { Industrial POAs were not considered in this work. }\end{array}$ \\
\hline
\end{tabular}


SRNL-STI-2011-00365, Rev. 0

\subsection{GoldSim Uncertainty Model}

To further enhance CA uncertainty analysis capabilities, a new GoldSim model was created. Some basic features of this model are shown in Figures 2-1 through 2-4 which are graphic displays copied directly from the model. As indicated in Figure 2-1, the model can use as many as 32 individual sources in a single calculation. Each source models the release of radionuclides from the source material and transport through the waste zone, vadose zone and aquifer to the stream outfall. Figure 2-2 shows the contents of a single source model container. The basic transport calculations are unchanged from those in the original CA model as described by Smith, et al. (2009a). Each source is automatically linked to its corresponding Point of Assessment (POA) using the source stream number which is an input parameter to the model. The user can connect as many as 32 sources to a single POA or distribute the 32 sources among some or all of the POAs. As illustrated in Figure 2-3, the model automatically includes the impact from upstream POAs on downstream locations which adds a new capability to the CA uncertainty analysis.

The original CA deterministic calculations were performed for each source individually and composite results were collected and further analyzed in a series of Excel spreadsheets. A simplification realized in constructing the multi-source uncertainty model was that an Integrator Operable Unit (IOU), which represents a source of radionuclides released from stream bed sediment directly to the stream, can be modeled without using the full transport model shown in Figure 2-2. With a slight loss of generality, models for the IOU sources were embedded in the POA containers. This is illustrated in Figure 2-4 which shows the model for the Steel Creek/Pen Branch POA. Two IOU sources, one from each stream, contribute to the dose at this POA. Therefore, two sediment release models are included with this POA. In this way, the multisource model also included seven specific IOU sources along with the 32 surface sources for a total of 39 sources. Figure 2-4 also shows that each POA has a separate dose calculation.

The original CA uncertainty calculations considered a total of only 17 sources. Therefore, it is possible to duplicate the full extent of the previous CA uncertainty calculations with a single run of the multi-source, multi-POA model which also includes the impact from upstream POAs on downstream locations. However, the 32 source, multiple POA model is about $226 \mathrm{Mb}$ in size versus the $13 \mathrm{Mb}$ size of the original CA model. Run time scales linearly with the number of sources so that, whereas the original CA model typically ran one source calculation in about one minute, the multi-source, multi-POA model runs using 32 sources typically take about 30 minutes. When using the full multi-source, multi-POA model for Monte-Carlo uncertainty analysis, saving the data from all realizations creates very large GoldSim files from 10 to $20 \mathrm{~Gb}$ in size. To reduce the file size as much as possible, output provided by the original CA model to trace the dose results to individual sources, radionuclides, and pathways is not saved in the multisource, multi-POA model.

GoldSim run settings used in the uncertainty analysis were: 1,000 realizations, a 10,100 year simulation (running from 1950 to 12050), and 2,600 time steps. The uncertainty calculations used the same time period and time steps used for in the original CA deterministic calculations. The uncertainty runs were made on the GoldSim servers typically using 30 slave processes. Each calculation took about 20 hours to complete. 
SRNL-STI-2011-00365, Rev. 0

Mutt-source model that can be used to evaluate up to 32 surface release sources plus 7 lou sources simultaneousy. The surface release sources automatically connect to their poA based on the source

uncertainty analysis.

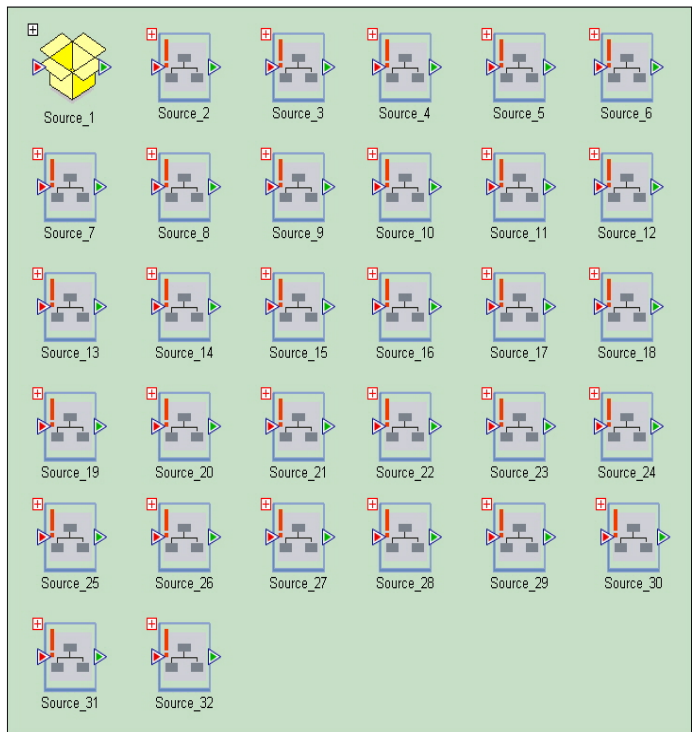

Figure 2-1. View of sources in GoldSim model used for enhanced CA uncertainty analysis.

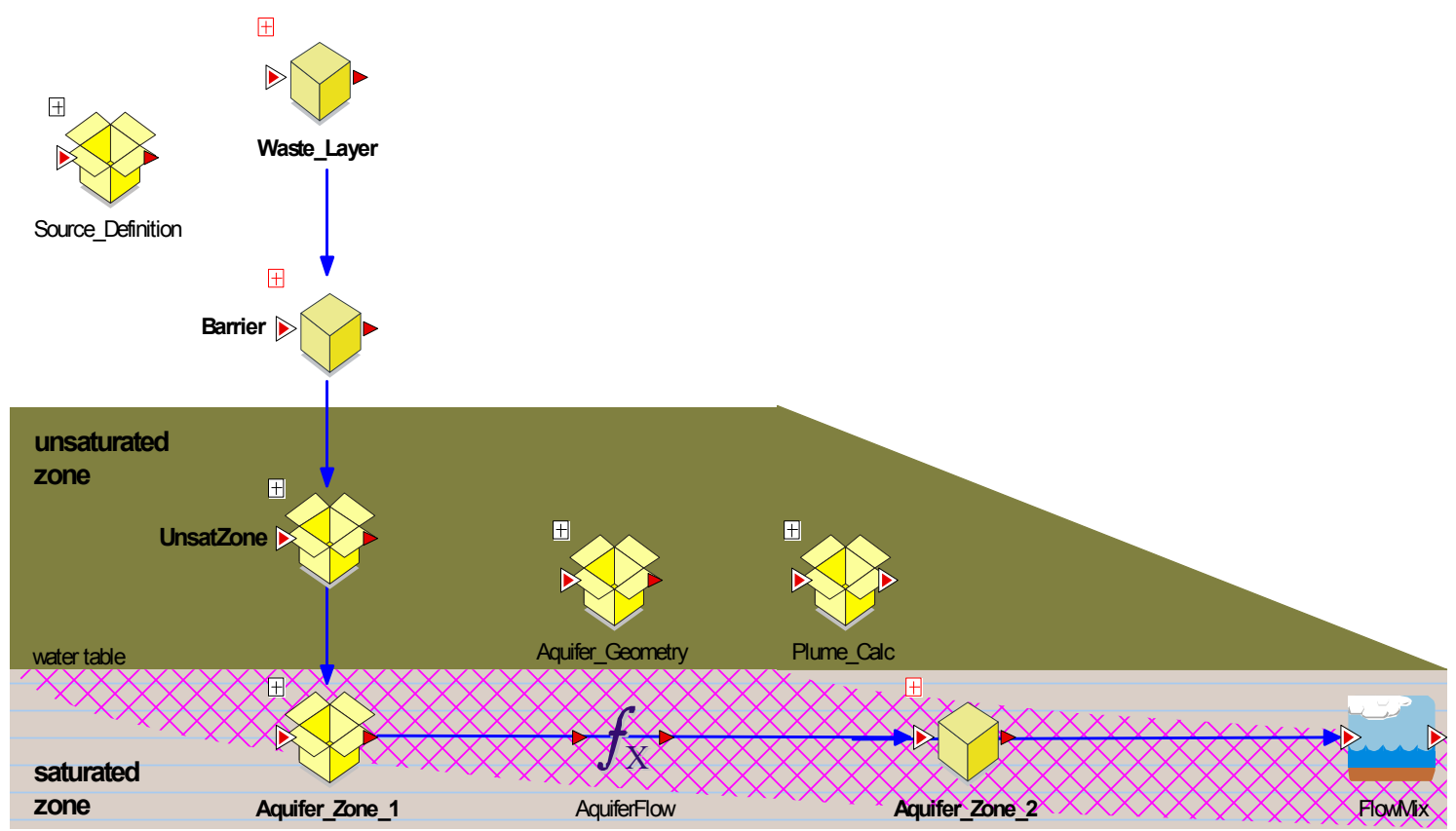

Figure 2-2. GoldSim transport model used for each of the 32 sources. 
SRNL-STI-2011-00365, Rev. 0

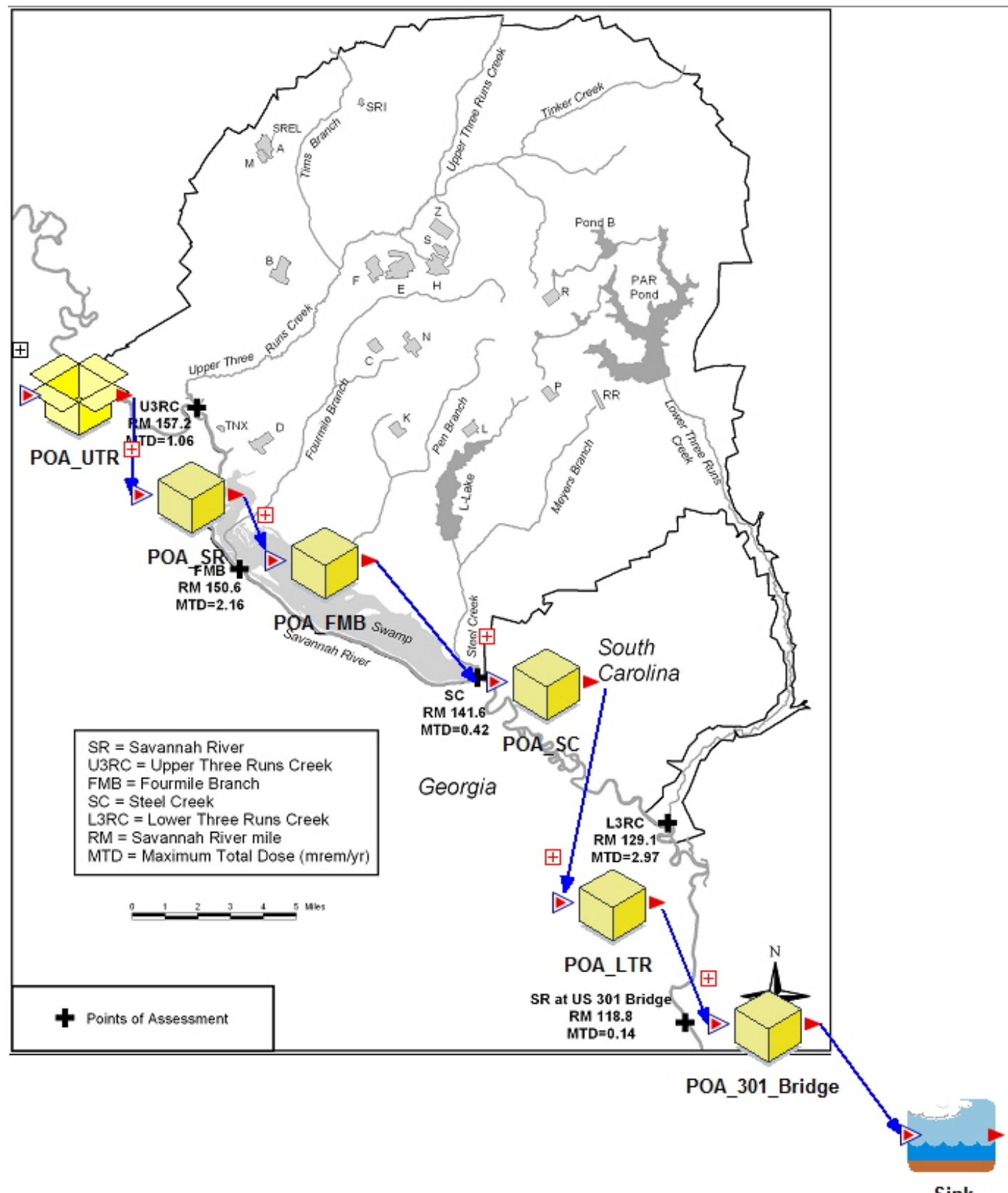

Sink

Figure 2-3. View of POAs in GoldSim model used for enhanced CA uncertainty analysis. 


\section{Concentrations at a Point of Assessment}

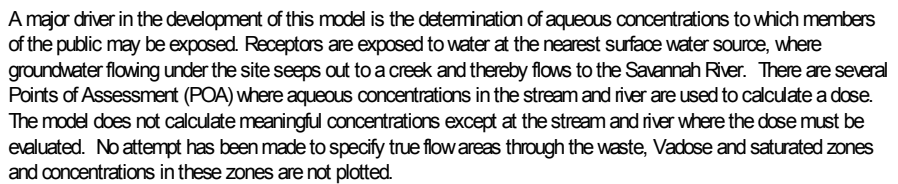
and concentrations in these zones are not plotted.
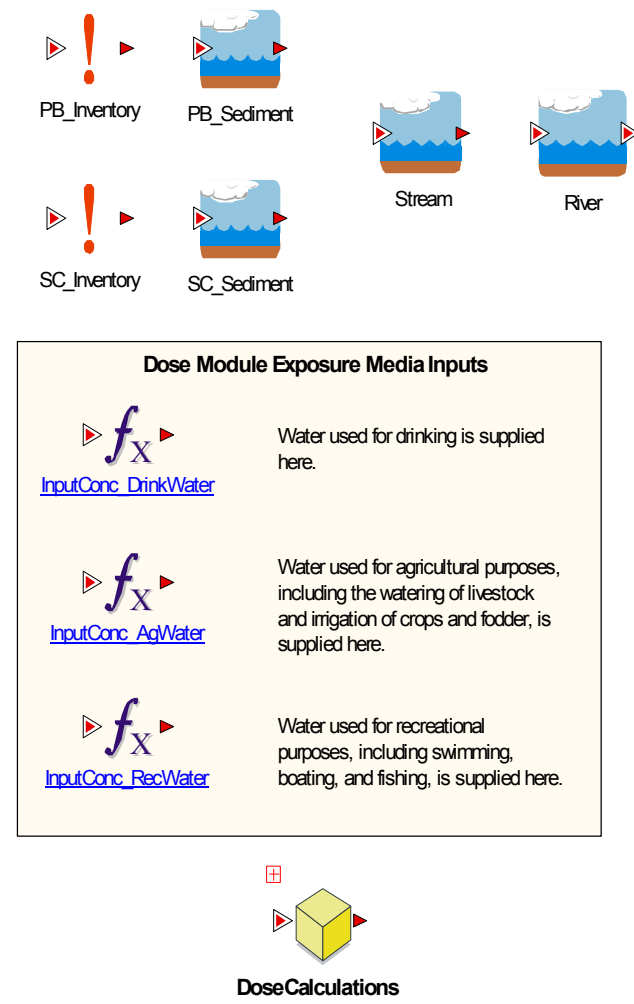

Figure 2-4. GoldSim model of Steel Creek/Pen Branch POA.

\subsection{Model Development}

The multi-source, multi-POA uncertainty model was developed in several stages. Initially a 16 source model was created and tested. In the second stage of development, the model was expanded to 24 sources and retested. Finally, in the last stage, the model with 32 surface sources and 7 IOU sources that was used for the final uncertainty analysis was created. The staged approach was useful in that it allowed testing and the correction of coding errors as development progressed. Initially, there was some concern that the overhead associated with the GoldSim master process managing as many as 30 slave processes would decrease model performance as the model was enlarged. The large size of the output files was also of concern. However, in practice, it was found that GoldSim using the DP-Plus module performed very well on the Windows servers. Both run time and output file size scaled approximately linearly as sources were added to the model and no serious problems were encountered in running the final model.

During development of the enhanced uncertainty model, two relatively minor errors in the original CA uncertainty analysis were discovered and corrected. These errors were: 
SRNL-STI-2011-00365, Rev. 0

1. The original CA uncertainty model connected five sources to a single POA. Sandy soil $\mathrm{K}_{\mathrm{d}}$ 's used in the dose module in the original uncertainty analysis had CDP on or off depending on the setting used in the first of the five sources. In the new uncertainty analysis, sandy soil $\mathrm{K}_{\mathrm{d}}$ 's in the dose module always use CDP off values.

2. Saturations of clayey soil and sandy soil in the original CA uncertainty analysis were calculated for all sources using the Darcy velocity from the first source. In the new uncertainty analysis, soil saturation is calculated as a function of infiltration separately for each source.

Other modifications made in new uncertainty analysis are:

1. The Eta $\mathrm{clay}_{\text {and }}$ and $\mathrm{Etand}_{\text {sand }}$ factors that determined aquifer flow distributions are the same for each source in the new uncertainty model. These factors varied for each source in the original CA uncertainty model. This approach was changed in the new model to reduce the number of uncertainty parameters. Aquifer flow velocities themselves are still source dependent.

2. The cap infiltration distribution factor is the same for each source. This factor varied for each source in the original CA uncertainty model and was changed in the new model to reduce the number of uncertainty parameters. The infiltration flow itself is still source dependent.

These corrections and modifications mean that the new uncertainty analysis model will not give exactly the same results as the original five-source, single-POA CA uncertainty model used for uncertainty analysis in the CA. However, the changes are relatively minor and the results should be comparable to those obtained previously.

The output file for a 1,000 realization uncertainty analysis with 39 sources is about $16 \mathrm{~Gb}$ in size. Not only is this a significant amount of storage space but the GoldSim model file takes about 2.5 hours to save. GoldSim has the option to save a limited number of realization results to reduce the output file size. However, when this option was tested, it was found that different results were obtained than when all realizations were saved. Therefore, all realizations were saved for the uncertainty runs made in this study. With results from all of the realizations available, it is possible to extract more information from the results. For example, the uncertainty results show that the most extreme case produces high doses. When all realizations are saved, it is possible to scan through the results and identify the realization producing the maximum dose. GoldSim has the option of running a specific realization. Rerunning the extreme realization would identify the parameter settings producing this result. 


\subsection{Sources}

The 39 sources used in the new uncertainty analysis are listed in Table 3-1. Sources added to the original CA uncertainty analysis are highlighted in the table. These 39 sources were chosen such that $99 \%$ of the sum of the peak doses found at each POA during the years 2025 to 3025 was included in the analysis. This time period was used because it is the 1,000 year CA compliance period. To achieve this, the sources used in the uncertainty analysis include all sources that produced peak doses during the years 2025 to 3025 greater than $0.005 \mathrm{mrem} / \mathrm{yr}$.

Table 3-1. 39 Sources Included in Extended CA Uncertainty Analysis

\begin{tabular}{|c|c|c|c|c|c|}
\hline \multicolumn{2}{|c|}{ Upper Three Runs (20) } & \multicolumn{2}{|c|}{ Fourmile Branch (7) } & \multicolumn{2}{|c|}{ Steel Creek / Pen Branch (7) } \\
\hline Source & MaxDose & Source & MaxDose & Source & MaxDose \\
\hline TEF & $3.38 \mathrm{E}-03$ & FMB GOU & $6.81 \mathrm{E}-03$ & LAC Con & $8.24 \mathrm{E}-03$ \\
\hline NR Pad 1 Part 6 & $3.66 \mathrm{E}-03$ & ORWBG & $7.28 \mathrm{E}-03$ & 105-P Con & $1.54 \mathrm{E}-02$ \\
\hline H-Area IPSL UTR & $3.69 \mathrm{E}-03$ & LLRWDF FMB & $1.79 \mathrm{E}-02$ & KAC Surf & $5.3 \mathrm{E}-02$ \\
\hline $234-7 \mathrm{H}$ & $4.21 \mathrm{E}-03$ & $105-\mathrm{C}$ Surf & $5.75 \mathrm{E}-02$ & PB IOU & $6.00 \mathrm{E}-02$ \\
\hline Z-Area Vault 1 & $7.71 \mathrm{E}-03$ & H Area Seep & $1.03 \mathrm{E}-01$ & LAC Surf & $7.57 \mathrm{E}-02$ \\
\hline $281-3 \mathrm{~F}$ & $8.34 \mathrm{E}-03$ & ORWBG AgI & $1.63 \mathrm{E}-01$ & 105-P Surf & $1.14 \mathrm{E}-01$ \\
\hline $232-\mathrm{H}$ & $1.11 \mathrm{E}-02$ & FMB IOU & $1.97 \mathrm{E}+00$ & SC IOU & $2.43 \mathrm{E}-01$ \\
\hline F-Area Old Seep & $1.16 \mathrm{E}-02$ & & & & \\
\hline E-Area ST Cent & $1.33 \mathrm{E}-02$ & \multicolumn{2}{|c|}{ Lower Three Runs (2) } & \multicolumn{2}{|c|}{ Savannah River (3) } \\
\hline $264-2 \mathrm{H}$ & $1.48 \mathrm{E}-02$ & Source & MaxDose & Source & MaxDose \\
\hline LLRWDF UTR & $1.80 \mathrm{E}-02$ & 105-R Surf S & $4.68 \mathrm{E}-02$ & TNX Outfall & $4.61 \mathrm{E}-04$ \\
\hline HAOM & $2.02 \mathrm{E}-02$ & LTR IOU & $2.94 \mathrm{E}+00$ & SR-B IOU & $1.38 \mathrm{E}-02$ \\
\hline E-Area CIG & $2.09 \mathrm{E}-02$ & & & SR-A IOU & $1.76 \mathrm{E}-02$ \\
\hline TPBAR & $2.44 \mathrm{E}-02$ & & & & \\
\hline NR Pad 2 & $3.65 \mathrm{E}-02$ & & & & \\
\hline Z-Area Vault 4 & $4.93 \mathrm{E}-02$ & & & & \\
\hline HANM & $6.07 \mathrm{E}-02$ & & & & \\
\hline UTR IOU & $7.19 \mathrm{E}-02$ & & & & \\
\hline MWMF & $1.35 \mathrm{E}-01$ & & & & \\
\hline H-Canyon & $1.04 \mathrm{E}+00$ & & & & \\
\hline
\end{tabular}

For reference, a histogram showing the distribution of peak doses in the years $2025-3025$ calculated for all 152 CA sources is shown in Figure 3-1. The category for each bar is labeled with the log to the base 10 of the maximum peak dose for that category. The first bar then shows that there are three peak doses greater than $1.0 \mathrm{mrem} / \mathrm{yr}$, the second bar shows there are five peak doses less than 1.0 and greater than $0.1 \mathrm{mrem} / \mathrm{yr}$, and so forth. The 39 sources used in the uncertainty analysis represent the first three bars of the histogram and part of the fourth.

In fact, the 39 sources used in the uncertainty analysis are not exactly the same as those giving the highest 39 peak doses since the criterion of representing $99 \%$ of the sum of the peak does at each POA was also used in the selection. However, there are only two differences in these lists. The highest 39 peak doses include the H-Area IPSL FMB and HTF Type IIIA FMB sources while the uncertainty analysis list includes TEF and TNX Outfall instead.

If peak doses from all $152 \mathrm{CS}$ sources are ranked for the 1,000 year period from the years 2025 to 3025 and for the 10,000 year period from the years 2025 to 12025 , and these lists are compared to that used in the uncertainty analysis, the top 14 sources are the same in all cases. There are only 
four differences between the lists of the 39 sources producing the highest peak doses in the 1,000 year and 10,000 year time periods. For the 1,000 year time period, the sources H-Area IPSL

FMB, HTF Type IIIA FMB, 234-7H, and H-Area IPSL UTR appear while in the 10,000 year list the sources E-Area ILV, NR Pad 1 Part 5, 105-C SS, and KAC SS appear instead.

Distribution of Peak Doses in Years 2025 - 3025

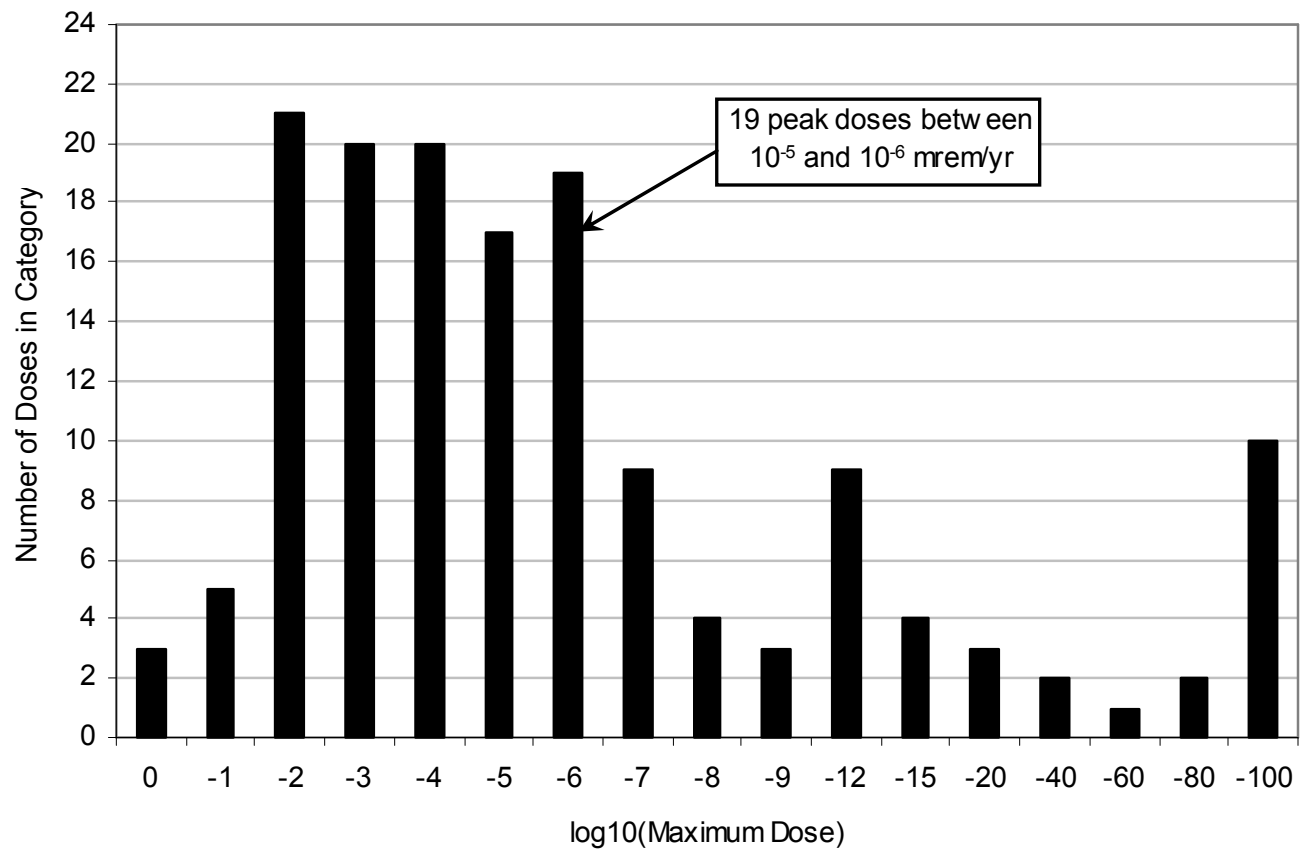

Figure 3-1. Distribution of peak doses during the years 2025 to 3025. 
SRNL-STI-2011-00365, Rev. 0

\subsection{Deterministic Calculations}

Deterministic results obtained with the multi-source, multi-POA uncertainty model were compared to those obtained with the original single-source CA deterministic model to verify that the multi-source, multi-POA model was functioning correctly. Simulations were performed using the uncertainty model with the stochastic variables set to their deterministic values. The majority of the deterministic value settings were set to the mean of the stochastic variable distribution. However, for some of the stochastic variables associated with the dose calculation, their deterministic (most likely) values were set to the minimum or maximum extreme values of their distributions. The original CA model calculations considered all 152 sources, whereas the multisource, multi-POA model considers 39 sources as discussed in Section 3.0.

Figure 4-1 shows the cumulative doses calculated at each POA over 10,000 years from all 152 sources while Figure 4-2 shows the cumulative doses for the first 2,000 years from the original CA deterministic model. The original CA GoldSim calculations ran each source separately and cumulative doses were obtained from the results using an Excel spreadsheet. As described in Section 2.0, the multi-source, multi-POA model automatically calculates cumulative doses at each POA but only uses the 39 sources listed in Table 3-1. Figure 4-3 shows the cumulative doses calculated at each POA over 10,000 years using the multi-source, multi-POA model, while Figure 4-4 shows the cumulative doses for the first 2,000 years of the simulation. Comparison of Figure 4-3 with 4-1 and Figure 4-4 with 4-2 shows that the results obtained using the 39 sources having peak doses greater than $0.005 \mathrm{mrem} / \mathrm{yr}$ compare favorably to the results obtained using all 152 CA sources.

Direct comparisons of the two calculations of cumulative doses at each POA are shown in Figures 4-5 and 4-6 for 10,000 and 2,000 years, respectively. As expected, the results of the multi-source, multi-POA model (39 source) compare favorably with the 152 CA source model, particularly with respect to the peak values. Greater deviation between the 39 source model and the $152 \mathrm{CA}$ source model is seen in the valleys and after 1,000 years. In all cases, doses greater than $0.1 \mathrm{mrem} / \mathrm{yr}$ are reproduced accurately with the new model. As noted in Section 3, the 39 sources used for the uncertainty analysis were based on peak doses during the years 2025 to 3025 and the additional criterion that at least $99 \%$ of the sum of the peak doses at each POA be represented. This choice of sources based upon peak values explains why there is greater deviation in the valleys. Additionally, if the 39 sources were chosen based on peak doses over the entire 10,000 year simulation four different sources would have been used. This choice of sources based upon peaks and to best represent the CA period of performance explains why the 39 source deterministic results deviate from the results obtained using all 152 sources beyond 1,000 years. 
SRNL-STI-2011-00365, Rev. 0

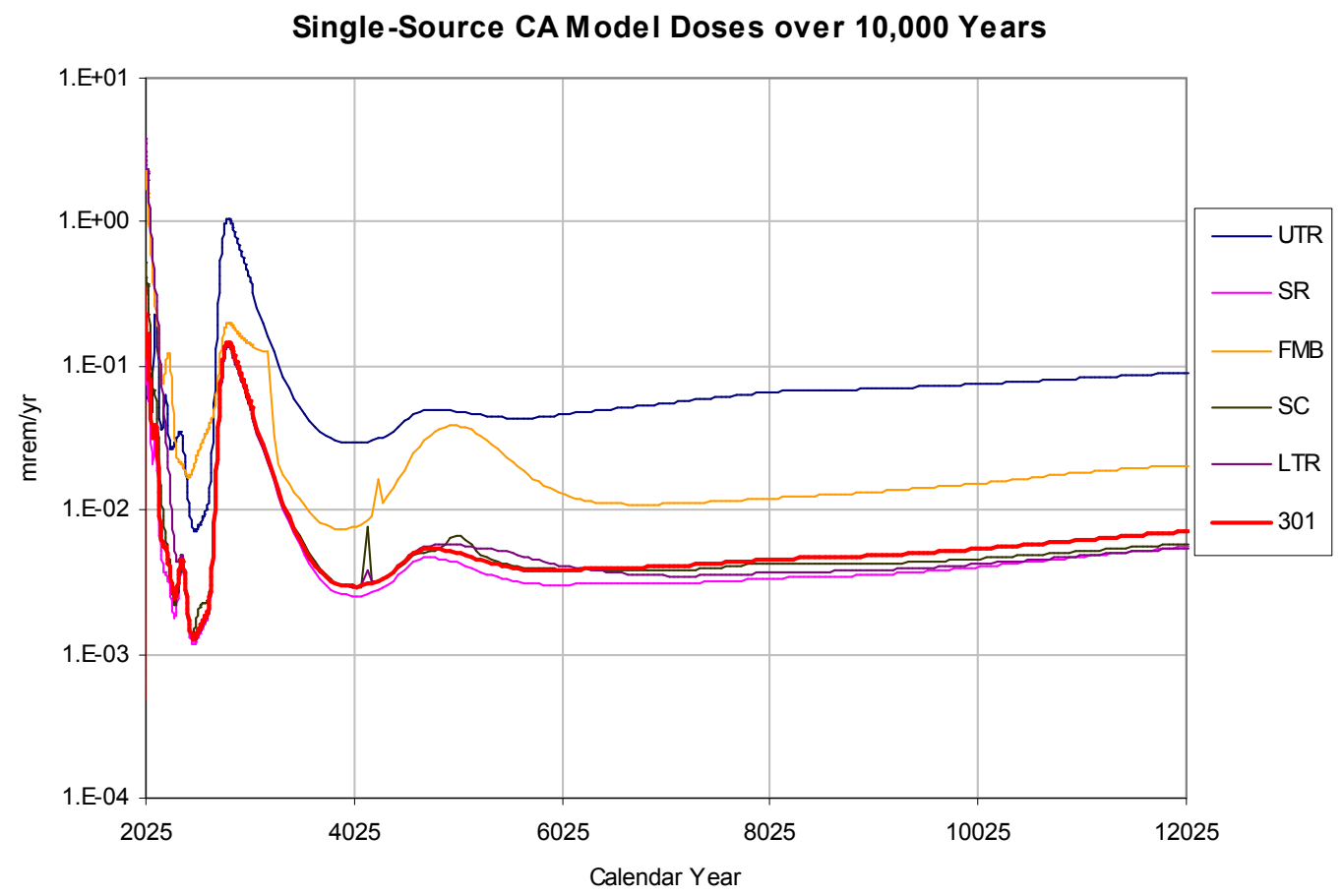

Figure 4-1. Original CA deterministic calculation of cumulative doses at each POA from all sources over 10,000 year time period.

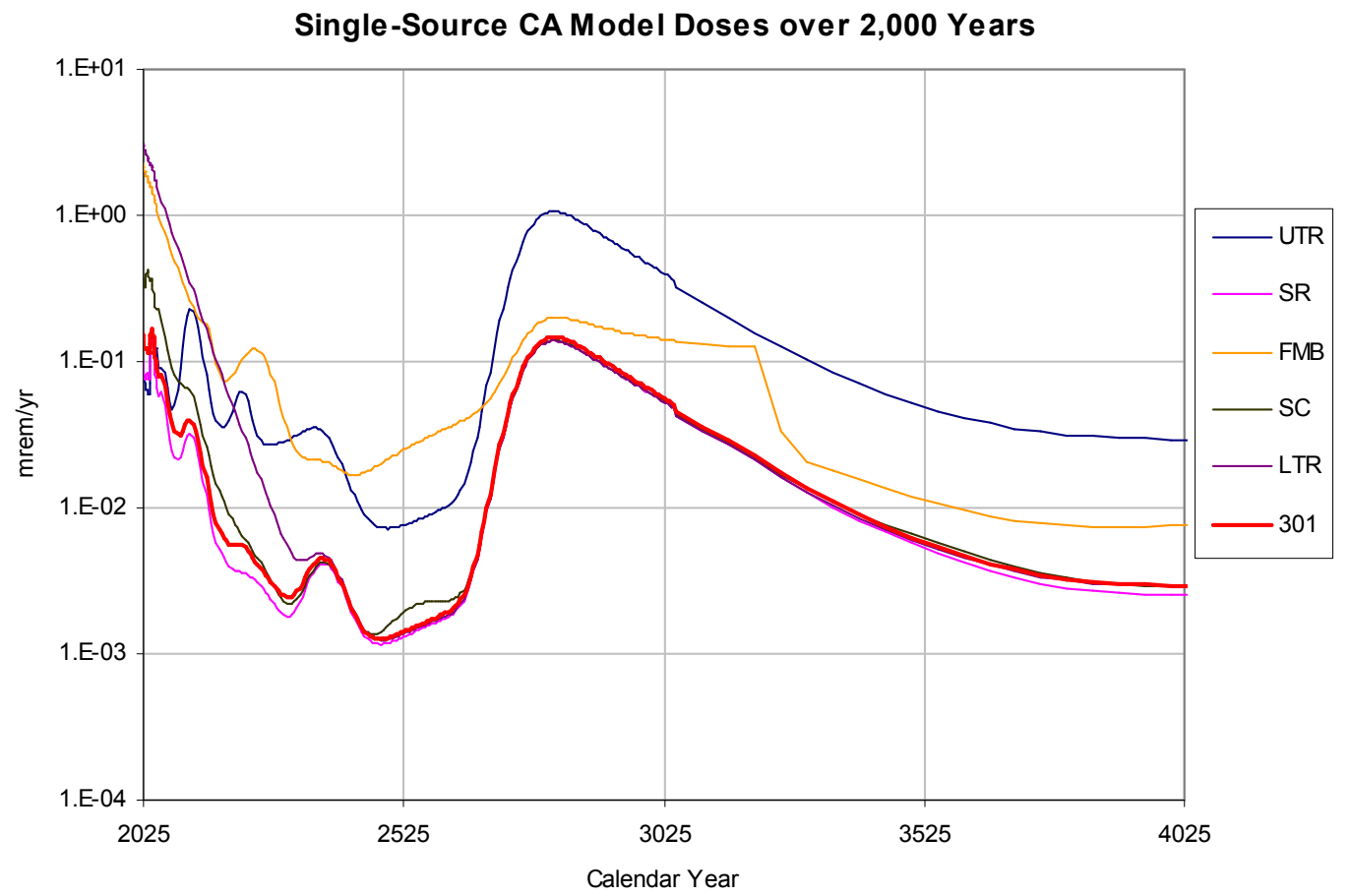

Figure 4-2. Original CA deterministic calculation of cumulative doses at each POA from all sources over 2,000 year time period. 
SRNL-STI-2011-00365, Rev. 0

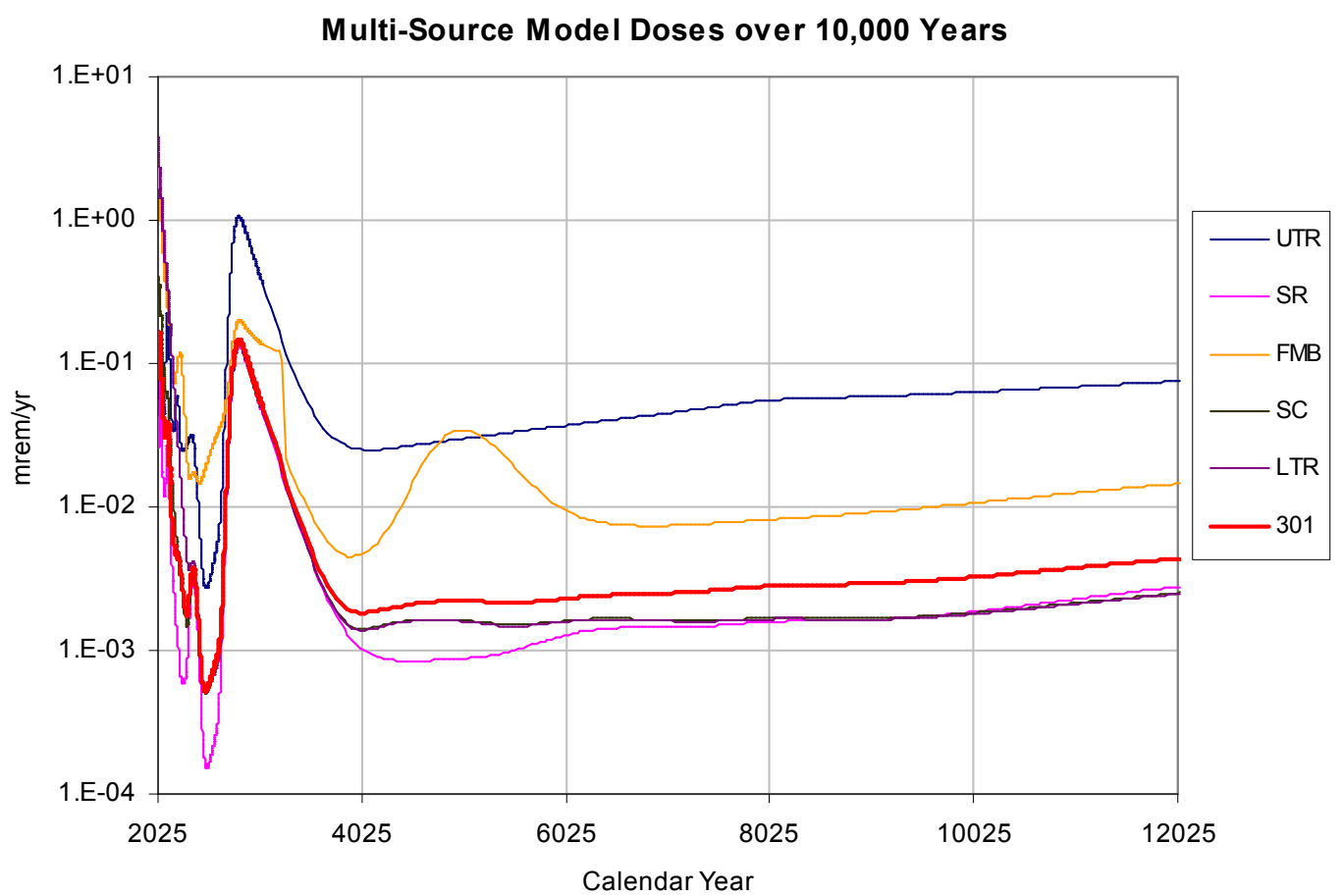

Figure 4-3. Deterministic calculation of cumulative doses at each POA over 10,000 year time period using multi-source, multi-POA model with 39 sources.

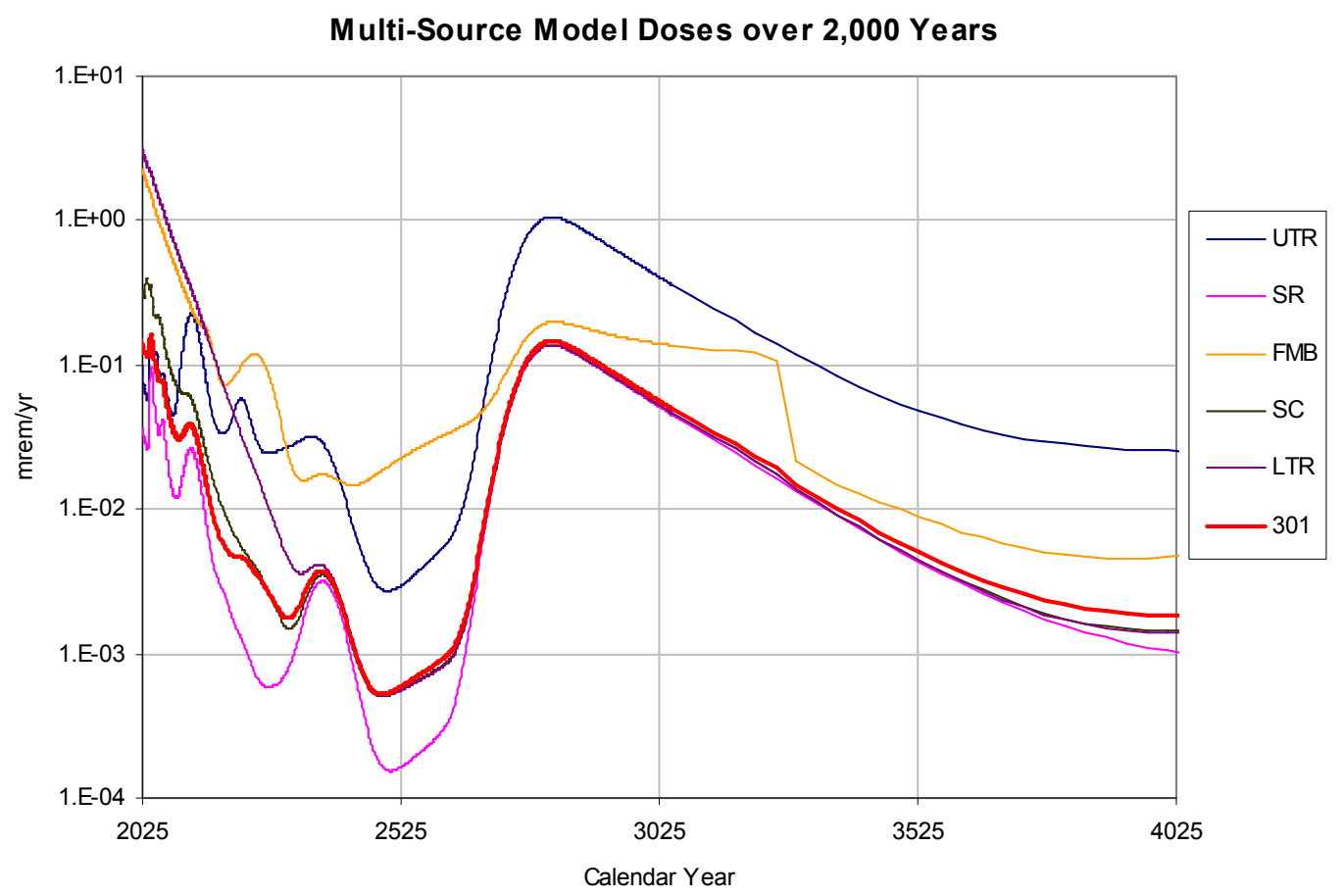

Figure 4-4. Deterministic calculation of cumulative doses at each POA over 2,000 year time period using multi-source, multi-POA model with 39 sources. 
SRNL-STI-2011-00365, Rev. 0
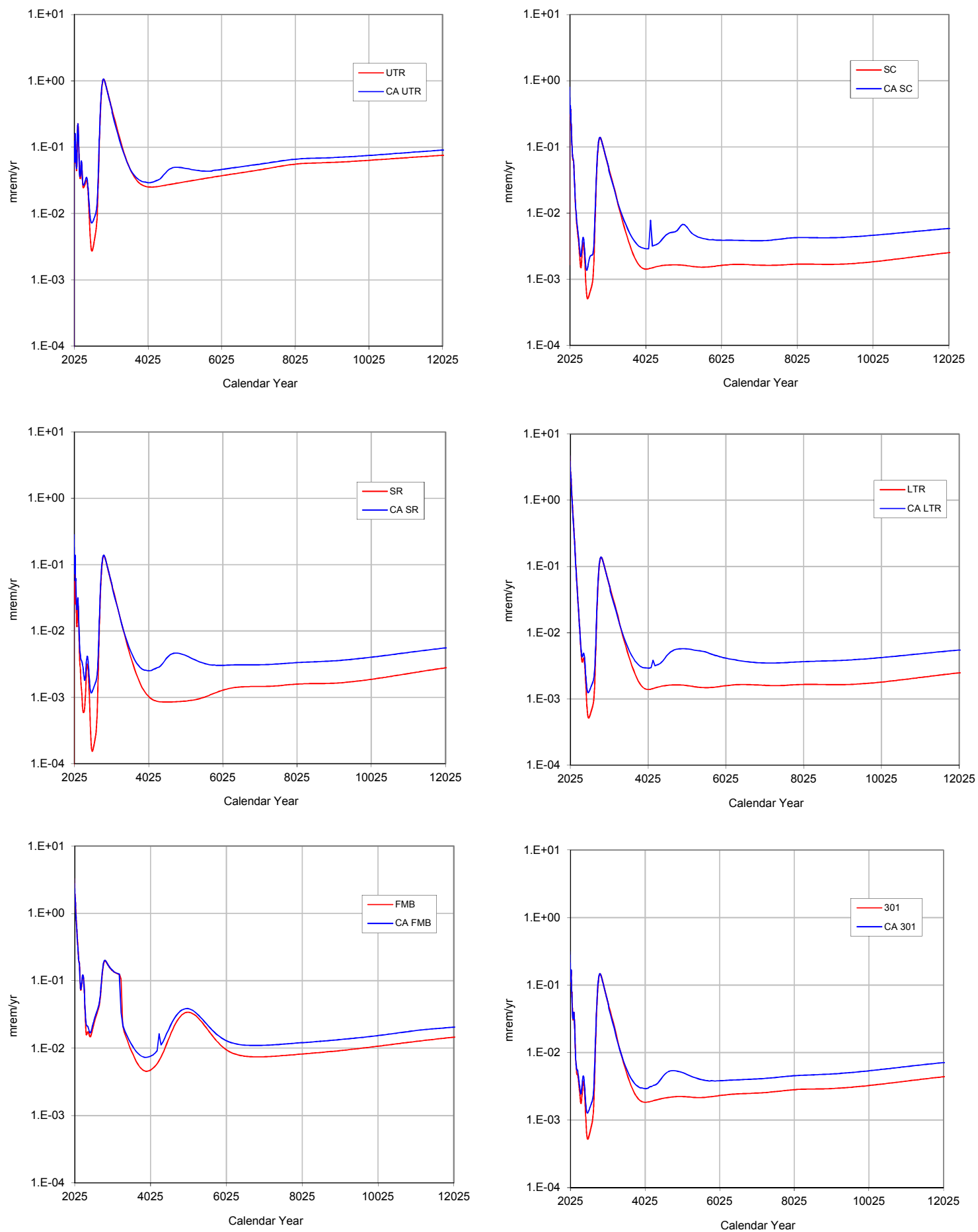

Figure 4-5. Comparison of deterministic doses calculated at each POA over 10,000 years using the original CA model with all 152 sources and the multi-source, multi-POA model with 39 sources. 
SRNL-STI-2011-00365, Rev. 0
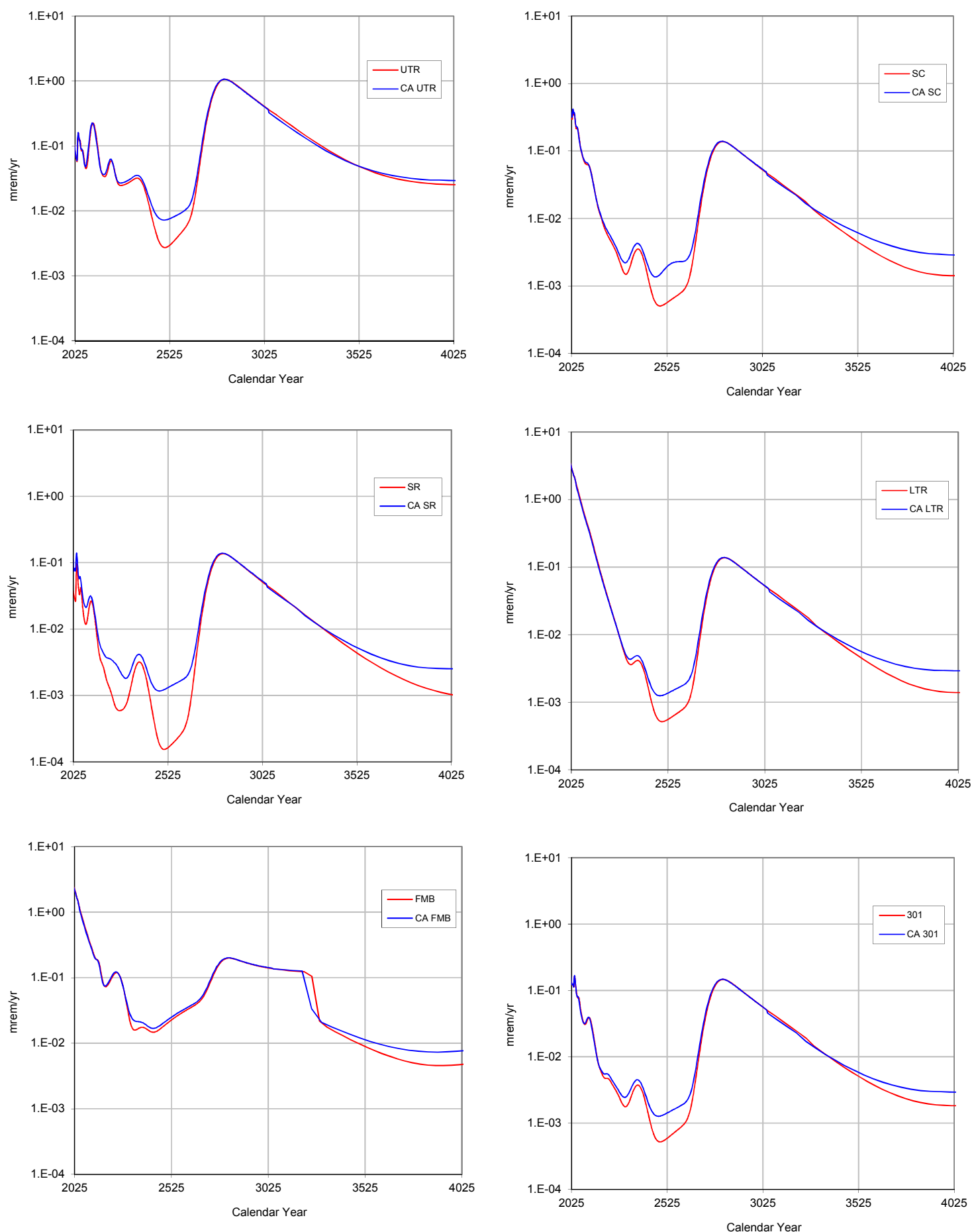

Figure 4-6. Comparison of deterministic doses calculated at each POA over 2,000 years using the original CA model with all 152 sources and the multi-source, multi-POA model with 39 sources. 


\subsection{Uncertainty Distributions}

Parameters in the CA model that were assigned stochastic distributions are listed in Tables 5-1 through 5-4. For probabilistic Monte-Carlo calculations, GoldSim randomly chooses a value for each of these parameters from the associated distribution. Stochastic distributions that appear in the dose module (Phifer et al. 2009) are given in Table 5-1, distributions for material property values (Phifer and Dixon 2009) are listed in Table 5-2, and distributions for flow parameters (Phifer and Dixon 2009, Shine 2009, and Hamm et al. 2009) are listed in Table 5-3 and Table 5-4. In all cases, the mean or, for triangular distributions, the most likely value was the value used for base case deterministic calculations (Smith et al. 2009a). The cap infiltration distributions listed in Table 5-4 are applied as multipliers to the nominal cap infiltration flow calculated as a function of time (Smith et al. 2009a). Similarly, the aquifer sand and clay velocity distributions shown in Table 5-4 are factors applied to the nominal Darcy velocities. The nominal aquifer velocities are divided by these flow factors to obtain a revised estimate of the velocity (Hamm et al. 2009). The only other distributions used in the CA model were applied to $\mathrm{K}_{\mathrm{d}}$ values. Following McDowellBoyer and Kaplan (2009), it was assumed that $\mathrm{K}_{\mathrm{d}}$ values have log-normal distributions and that for sandy soil and cement the standard deviation is $75 \%$ of the mean value and for clayey soil the standard deviation is $50 \%$ of the mean value. Neither the original CA model nor this multisource, multi-POA uncertainty model included inventory and bioaccumulation factor (transfer factor) distributions. Inventory and bioaccumulation factor (transfer factor) distributions will need to be included in the next CA revision. 
Table 5-1. Dose module parameter distributions (34).

\begin{tabular}{|c|c|c|c|c|c|c|}
\hline Parameter & Units & Distribution & $\begin{array}{c}\text { Mean or } \\
\text { Most } \\
\text { Likely } \\
\text { Value }\end{array}$ & 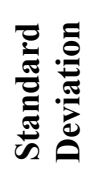 & 主 & $\underset{\Xi}{\Xi}$ \\
\hline \multicolumn{7}{|c|}{ Exposures } \\
\hline Irrigation rate & $\mathrm{L} / \mathrm{d} / \mathrm{m}^{2}$ & Triangular & 3.6 & & 2.08 & 5.5 \\
\hline retention leaf & & Triangular & 0.25 & & 0.2 & 0.25 \\
\hline soil_depth & $\mathrm{m}$ & Triangular & 0.15 & & 0.15 & 0.61 \\
\hline holdup_vegetable ${ }^{1}$ & $\mathrm{hr}$ & Normal & 8.7 & 1 & 1 & $1.0 \mathrm{E}+40$ \\
\hline Irrigation_time_garden & $\mathrm{d}$ & Normal & 70 & 7 & & \\
\hline Weathering loss & $1 / \mathrm{d}$ & Triangular & 0.0495 & & 0.03 & 0.0495 \\
\hline Vegetable_Yield & $\mathrm{kg} / \mathrm{m}^{2}$ & Triangular & 0.7 & & 0.2 & 4 \\
\hline Buildup_Time_Soil & $\mathrm{d}$ & Triangular & 183 & & 60 & 365 \\
\hline Irrigation time pasture $^{1}$ & $\mathrm{~d}$ & Normal & 70 & 7 & & \\
\hline Fodder intake beef & $\mathrm{kg} / \mathrm{d}$ & Normal & 36 & 8 & & \\
\hline Fodder_intake_milk & $\mathrm{kg} / \mathrm{d}$ & Normal & 52 & 11 & & \\
\hline Frac_Pasture beef & & Triangular & 0.75 & & 0.5 & 1 \\
\hline Frac Pasture milk & & Triangular & 0.56 & & 0.5 & 1 \\
\hline Water_intake_beef & $\mathrm{L} / \mathrm{d}$ & Triangular & 28 & & 28 & 50 \\
\hline Water_intake_milk & $\mathrm{L} / \mathrm{d}$ & Triangular & 50 & & 50 & 60 \\
\hline holdup_beef & $\mathrm{d}$ & Triangular & 6 & & 6 & 20 \\
\hline holdup_milk & $\mathrm{d}$ & Triangular & 3 & & 1 & 4 \\
\hline \multicolumn{7}{|c|}{ Behaviors } \\
\hline Soil_Ing_Rate & $\mathrm{kg} / \mathrm{yr}$ & Triangular & 0.0365 & & 0.0008 & 0.05 \\
\hline Inhalation Rate & $\mathrm{m}^{3} / \mathrm{yr}$ & Triangular & 5,548 & & 1,267 & 11,600 \\
\hline Dust_Loading_Garden & $\mathrm{kg} / \mathrm{m}^{3}$ & Triangular & $1.0 \mathrm{E}-07$ & & $1.0 \mathrm{E}-08$ & $3.0 \mathrm{E}-07$ \\
\hline Water_Ing_Rate & $\mathrm{L} / \mathrm{yr}$ & Triangular & 337 & & 184 & 730 \\
\hline Garden Time frac & & Triangular & 0.01 & & 0.01 & 0.08 \\
\hline $\begin{array}{l}\text { Veg_Ing_Rate } \\
\text { nonleafy }\end{array}$ & $\mathrm{kg} / \mathrm{yr}$ & Triangular & 163 & & 90 & 276 \\
\hline Veg_Ing_Rate_leafy & $\mathrm{kg} / \mathrm{yr}$ & Triangular & 21 & & 18 & 43 \\
\hline Meat Ing Rate & $\mathrm{kg} / \mathrm{yr}$ & Triangular & 43 & & 26 & 81 \\
\hline Milk_Ing_Rate & $\mathrm{L} / \mathrm{yr}$ & Triangular & 120 & & 73.7 & 230 \\
\hline Frac_Local_Veg leafy & & Triangular & 0.173 & & 0 & 0.5 \\
\hline $\begin{array}{l}\text { Frac_Local_Veg } \\
\text { nonleafy }\end{array}$ & & Triangular & 0.173 & & 0 & 0.5 \\
\hline Frac_Local_Meat & & Triangular & 0.306 & & 0 & 0.5 \\
\hline Frac_Local_Milk & & Triangular & 0.207 & & 0 & 0.5 \\
\hline Fish_Ing_Rate & $\mathrm{kg} / \mathrm{yr}$ & Triangular & 9 & & 2.2 & 19 \\
\hline Shoreline_Time & $\mathrm{hr} / \mathrm{yr}$ & Triangular & 23 & & 11 & 35 \\
\hline Swimming_Time & $\mathrm{hr} / \mathrm{yr}$ & Triangular & 8.9 & & 8.9 & 13 \\
\hline Boating_Time & $\mathrm{hr} / \mathrm{yr}$ & Triangular & 21 & & 9.1 & 31.5 \\
\hline
\end{tabular}

${ }^{1}$ For the following two parameters the deterministic value was not equal to the mean or most likely value: the deterministic value for holdup_vegetable was $6 \mathrm{hr}$, and the deterministic value for Irrigation_time_pasture was $30 \mathrm{~d}$. 
SRNL-STI-2011-00365, Rev. 0

Table 5-2. Material property distributions (20).

\begin{tabular}{|c|c|c|c|c|c|c|}
\hline Parameter & Units & Distribution & $\begin{array}{c}\text { Mean } \\
\text { or Most } \\
\text { Likely }\end{array}$ & 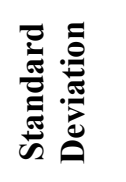 & 車 & 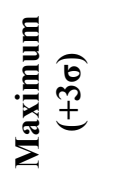 \\
\hline \multicolumn{7}{|c|}{ Sandy Soil } \\
\hline Dry Bulk Density & $\mathrm{g} / \mathrm{cm}^{3}$ & Normal & 1.650 & 0.022 & 1.590 & 1.710 \\
\hline Porosity & & Normal & 0.380 & 0.008 & 0.360 & 0.400 \\
\hline Water Saturation ${ }^{1}$ & & Triangular & 1.000 & & 0.968 & 1.032 \\
\hline Tortuosity & & Triangular & 0.500 & & 0.227 & 1.000 \\
\hline \multicolumn{7}{|c|}{ Clayey Soil } \\
\hline Dry Bulk Density & $\mathrm{g} / \mathrm{cm}^{3}$ & Normal & 1.680 & 0.028 & 1.600 & 1.760 \\
\hline Porosity & & Normal & 0.370 & 0.011 & 0.340 & 0.400 \\
\hline Water Saturation ${ }^{1}$ & & Triangular & 1.000 & & 0.982 & 1.018 \\
\hline Tortuosity & & Triangular & 0.331 & & 0.202 & 0.557 \\
\hline \multicolumn{7}{|c|}{ Intact Concrete } \\
\hline Dry Bulk Density & $\mathrm{g} / \mathrm{cm}^{3}$ & Normal & 2.060 & 0.100 & 1.760 & 2.360 \\
\hline Porosity & & Normal & 0.221 & 0.013 & 0.172 & 0.250 \\
\hline Tortuosity & & Triangular & 0.050 & & 0.011 & 0.217 \\
\hline \multicolumn{7}{|c|}{ Saturated Sandy Soil } \\
\hline Dry Bulk Density & $\mathrm{g} / \mathrm{cm}^{3}$ & Normal & 1.040 & 0.024 & 0.968 & 1.112 \\
\hline Porosity & & Normal & 0.250 & 0.009 & 0.225 & 0.276 \\
\hline Tortuosity & & Triangular & 0.331 & & 0.202 & 0.557 \\
\hline \multicolumn{7}{|c|}{ Saturated Clayey Soil } \\
\hline Dry Bulk Density & $\mathrm{g} / \mathrm{cm}^{3}$ & Normal & 1.040 & 0.024 & 0.968 & 1.112 \\
\hline Porosity & & Normal & 0.250 & 0.009 & 0.225 & 0.276 \\
\hline Tortuosity & & Triangular & 0.250 & & 0.176 & 0.368 \\
\hline \multicolumn{7}{|c|}{ Concrete Aging Pore Volume Flushes } \\
\hline $1^{\text {st }}$ Flush & & Triangular & 50 & & 1 & 100 \\
\hline $2^{\text {nd }}$ Flush & & Triangular & 500 & & 100 & 1000 \\
\hline $3^{\text {rd }}$ Flush & & Triangular & 7000 & & 1000 & 10000 \\
\hline
\end{tabular}

${ }^{1}$ Variation in water saturation is calculated as the deviation about the nominal value.

The evaluation of concrete aging using the pore flush distributions, listed in the bottom of Table 5-2 requires some explanation. The first flush (nominally 50 pore volumes) sets the point of transition from applying young to middle-age concrete $\mathrm{K}_{\mathrm{d}}$ values. The second flush sets the point of transition from using middle-age to old concrete $\mathrm{K}_{\mathrm{d}}$ values. The third flush sets the point of transition from using old concrete $\mathrm{K}_{\mathrm{d}}$ values to using $\mathrm{K}_{\mathrm{d}}$ values for sandy soil. When uncertainty in material properties alone was tested, the distributions shown in Table 5-2 were applied using nominal $\mathrm{K}_{\mathrm{d}}$ values for each element for the concrete age indicated. When uncertainty in $\mathrm{K}_{\mathrm{d}}$ alone was tested, nominal flush volumes were used and the $\mathrm{K}_{\mathrm{d}}$ values varied as described above. 
SRNL-STI-2011-00365, Rev. 0

Table 5-3. Stream and river flow distributions (6).

\begin{tabular}{|c|c|c|c|c|c|c|}
\hline Parameter & Units & Distribution & $\begin{array}{c}\text { Mean } \\
\text { or } \\
\text { Most } \\
\text { Likely }\end{array}$ & 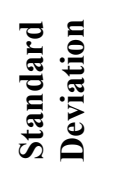 & $\stackrel{\Xi}{\Xi} \underset{\Xi}{E}$ & 罵 \\
\hline Upper Three Runs Flow & $\mathrm{cfs}$ & Normal & 237 & 1.35 & 232.94 & 241.06 \\
\hline Fourmile Branch Flow & $\mathrm{cfs}$ & Normal & 32 & 0.41 & 30.78 & 33.22 \\
\hline Pen Branch / Steel Creek Flow & $\mathrm{cfs}$ & Normal & 89 & 1.32 & 85.04 & 92.96 \\
\hline Lower Three Runs Flow & $\mathrm{cfs}$ & Normal & 164 & 1.91 & 158.28 & 169.72 \\
\hline $\begin{array}{l}\text { Savannah River Augusta Flow } \\
\text { Savannah River U.S. } 301 \text { Bridge }\end{array}$ & $\mathrm{cfs}$ & Normal & 9198 & 86.00 & 8940.00 & 9456.00 \\
\hline Flow & $\mathrm{cfs}$ & Normal & 10175 & 102.63 & 9867.11 & 10482.89 \\
\hline
\end{tabular}

Table 5-4. Infiltration and aquifer flow distributions (4).

\begin{tabular}{|c|c|c|c|c|c|c|}
\hline Parameter & Units & Distribution & $\begin{array}{c}\text { Mean } \\
\text { or } \\
\text { Most } \\
\text { Likely }\end{array}$ & D̃ & 志 & 声昰 \\
\hline Natural Infiltration Flow & in/yr & Normal & 15 & 0.17 & 14.48 & 15.52 \\
\hline Cap Infiltration & & Normal & 1 & 0.01133 & 0.966 & 1.034 \\
\hline Aquifer Sand Velocity & & Log-normal & 1 & 0.869 & 0.1 & 10 \\
\hline Aquifer Clay Velocity & & Log-normal & 1 & 1.31 & 0.1 & 10 \\
\hline
\end{tabular}


SRNL-STI-2011-00365, Rev. 0

\subsection{Uncertainty Calculations}

Probabilistic simulations were performed with GoldSim using the codes Monte-Carlo algorithm with the following options:

- Stochastic variables were chosen using a Latin Hypercube sampling algorithm.

- Sampling sequences are repeatable with the initial random seed set to one.

Results from this new uncertainty analysis are presented graphically in the following subsections. Section 6.1 shows plots of dose uncertainty at each POA over the entire 10,000 year simulation (Figures 6.1-1 through 6.1-6). To better see details during the 1,000 year CA period of compliance from 2025 to 3025 , Section 6.2 presents the same plots for the first 2,000 years of the simulation (Figures 6.2-1 through 6.2-6). The plots are extended over 2,000 years to be certain that nothing unusual happens just beyond the assessment period.

Section 6.3 plots mean and median doses from this new multi-source, multi-POA stochastic analysis against the new deterministic value obtained with the multi-source, multi-POA model and the deterministic value obtained previously with the original CA deterministic model considering all $152 \mathrm{CA}$ sources for the first 2,000 years of the simulation. There are significant differences between the mean and median results from the uncertainty analysis and the deterministic result, although the magnitude of the peaks are similar. As shown in Section 7.0, this is a result of sampling from the $\mathrm{K}_{\mathrm{d}}$, infiltration, and aquifer flow distributions. Different values for these parameters change the timing of dose peaks and thereby introduce some distortion into the dose profile. The abbreviated legends on the figures in Section 6.3 can be read more explicitly as, for example on Figure 6.3-1:

- $\quad \mathrm{UTR}=$ Multi-source, multi-POA deterministic result

- CA UTR = Original CA deterministic result

- $\quad$ Mean $=$ Multi-source, multi-POA stochastic analysis mean

- Median $=$ Multi-source, multi-POA stochastic analysis median

Table 6-1 summarizes the results by listing the peak value of each statistic over the CA assessment period from 2025 to 3025 . These results compare very closely to those obtained in the original limited CA uncertainty analysis shown in Table 6-2 (Smith et al. 2009b) with the single exception of the peak upper bound for the Upper Three Runs POA, which is much higher in this study. The origin of this high upper bound value, which, as shown in Figure 6.2-1, occurs in the year 2110, has not been traced. GoldSim offers some ability to determine the origin of this upper bound. Graphical results from all 1,000 realizations can be scanned to identify the one producing the upper bound. GoldSim then allows calculation of a specific realization. Running the realization that produced the upper bound result would allow identification of the stochastic parameters used and possibly identify the cause of the high dose. At each POA, the upper bound is much larger than the $95^{\text {th }}$ percentile value which would typically be used as a $95 \%$ confidence bound on the median. None of the $95^{\text {th }}$ percentile values challenge the $30 \mathrm{mrem} / \mathrm{yr}$ dose constraint. All other results in Table 6-2, including the deterministic values obtained from the multi-source, multi-POA model, are comparable to those obtained previously. 
Table 6-1. Peak values of statistical parameters for total dose at each POA over the CA assessment period from 2025 to 3025 produced from the multi-source, multi-POA model.

\begin{tabular}{c||cccccc}
\hline $\begin{array}{c}\text { Dose } \\
\text { (mrem/yr) }\end{array}$ & $\begin{array}{c}\text { Upper } \\
\text { Three Runs }\end{array}$ & $\begin{array}{c}\text { Savannah } \\
\text { River }\end{array}$ & $\begin{array}{c}\text { Fourmile } \\
\text { Branch }\end{array}$ & $\begin{array}{c}\text { Steel } \\
\text { Creek/Pen } \\
\text { Branch }\end{array}$ & $\begin{array}{c}\text { Lower } \\
\text { Three Runs }\end{array}$ & 301 Bridge \\
\hline \hline Deterministic $^{2}$ & 1.06 & 0.14 & 2.19 & 0.40 & 3.01 & 0.16 \\
\hline Mean & 0.73 & 0.11 & 3.48 & 0.59 & 4.95 & 0.23 \\
Lower Bound $^{1}$ & 0.02 & 0.02 & 0.38 & 0.07 & 0.50 & 0.06 \\
5th Percentile & 0.06 & 0.03 & 0.87 & 0.17 & 1.24 & 0.10 \\
25th Percentile & 0.15 & 0.06 & 1.80 & 0.32 & 2.51 & 0.15 \\
Median & 0.53 & 0.10 & 2.73 & 0.50 & 3.88 & 0.20 \\
75th Percentile & 1.14 & 0.16 & 4.35 & 0.74 & 6.26 & 0.28 \\
95th Percentile & 4.44 & 0.63 & 8.71 & 1.40 & 12.49 & 0.65 \\
Upper Bound $^{1}$ & 60.20 & 11.01 & 22.33 & 11.05 & 30.99 & 10.61 \\
\hline
\end{tabular}

Table 6-2. Peak values of statistical parameters for total dose at each POA over the CA assessment period from 2025 to 3025 produced from the original CA uncertainty analysis.

\begin{tabular}{|c|c|c|c|c|c|c|}
\hline $\begin{array}{c}\text { Dose } \\
(\mathrm{mrem} / \mathrm{yr})\end{array}$ & $\begin{array}{c}\text { Upper } \\
\text { Three Runs }\end{array}$ & $\begin{array}{c}\text { Savannah } \\
\text { River }\end{array}$ & $\begin{array}{c}\text { Fourmile } \\
\text { Branch }\end{array}$ & $\begin{array}{c}\text { Steel } \\
\text { Creek/Pen } \\
\text { Branch }\end{array}$ & $\begin{array}{c}\text { Lower } \\
\text { Three Runs }\end{array}$ & $\begin{array}{c}301 \\
\text { Bridge }^{4}\end{array}$ \\
\hline Deterministic $^{2}$ & 1.04 & 0.03 & 2.14 & 0.46 & 2.95 & \\
\hline Cumulative $^{3}$ & 1.06 & 0.14 & 2.16 & 0.42 & 2.97 & \\
\hline Mean & 0.60 & 0.05 & 3.25 & 0.72 & 4.64 & \\
\hline Lower Bound ${ }^{1}$ & 0.01 & 0.01 & 0.33 & 0.06 & 0.43 & \\
\hline 5th Percentile & 0.04 & 0.02 & 0.78 & 0.17 & 1.08 & \\
\hline 25th Percentile & 0.08 & 0.03 & 1.62 & 0.35 & 2.33 & \\
\hline Median & 0.37 & 0.04 & 2.48 & 0.56 & 3.58 & \\
\hline 75th Percentile & 0.92 & 0.06 & 4.14 & 0.91 & 6.02 & \\
\hline 95th Percentile & 2.43 & 0.10 & 8.16 & 1.75 & 11.55 & \\
\hline Upper Bound $^{1}$ & 5.59 & 0.20 & 17.99 & 3.71 & 24.78 & \\
\hline
\end{tabular}

${ }^{1}$ The upper bound is the envelope of maximum values at each point in time that bounds all of the 1,000 realizations. Similarly, the lower bound is the envelope of minimum values at each point in time that bounds all of the 1,000 realizations. All of the doses calculated in the uncertainty analysis fall within the upper and lower bounds.

${ }^{2}$ Deterministic doses calculated using the uncertainty model. In the original CA these were not cumulative doses at each POA but only considered direct discharges to the POA.

${ }^{3}$ Cumulative doses calculated from the original CA deterministic results. These agree very well with the cumulative deterministic doses calculated with the multi-source multi-POA uncertainty model.

${ }^{4}$ The dose at the 301 Bridge could not be assessed with the original CA uncertainty model. 
SRNL-STI-2011-00365, Rev. 0

\subsection{Dose Uncertainty over 10,000 Year Simulation}

UTR Dose 1000 Realizations

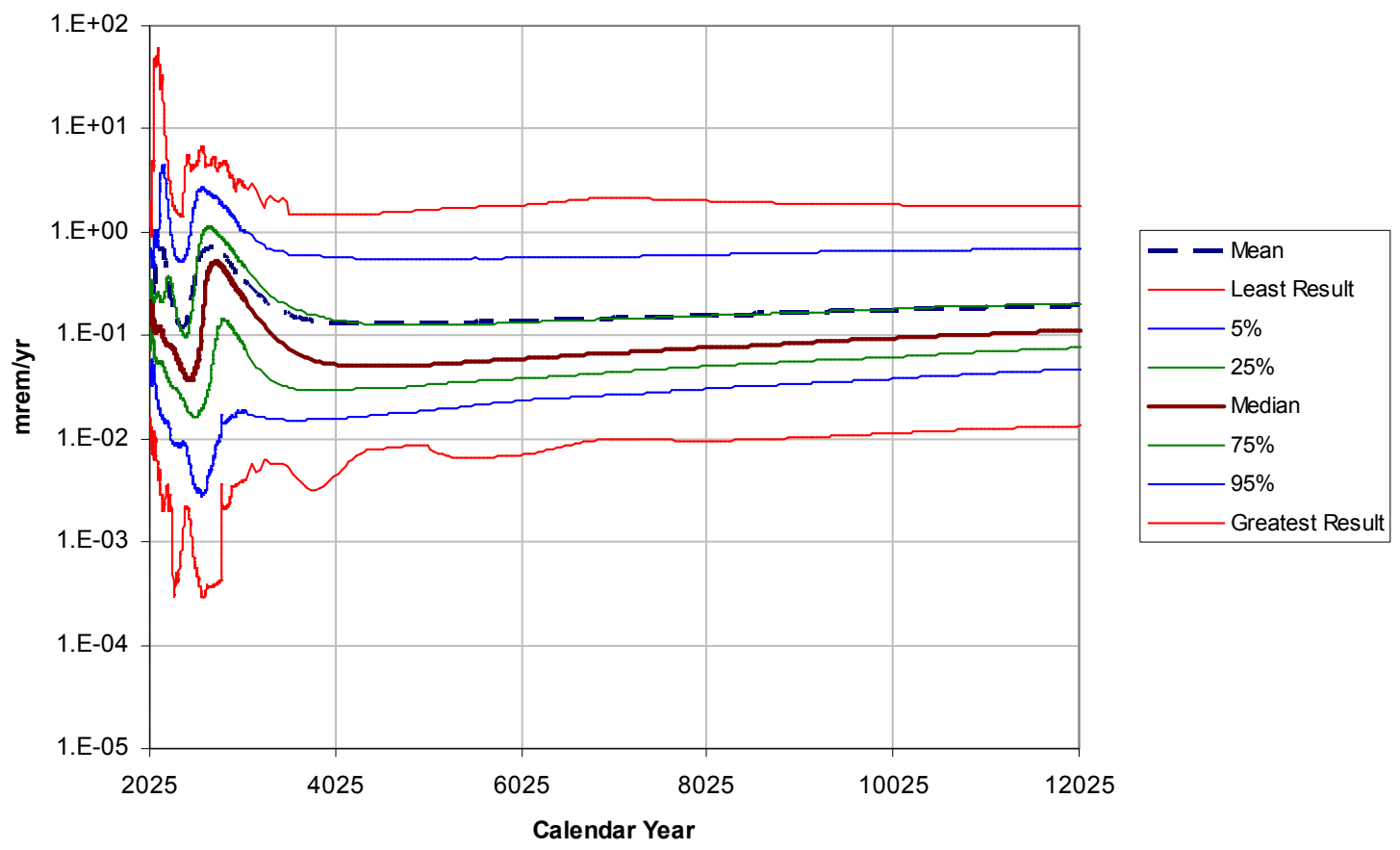

Figure 6.1-1. Uncertainty in dose at Upper Three Runs POA over 10,000 years.

\section{SR Dose 1000 Realizations}

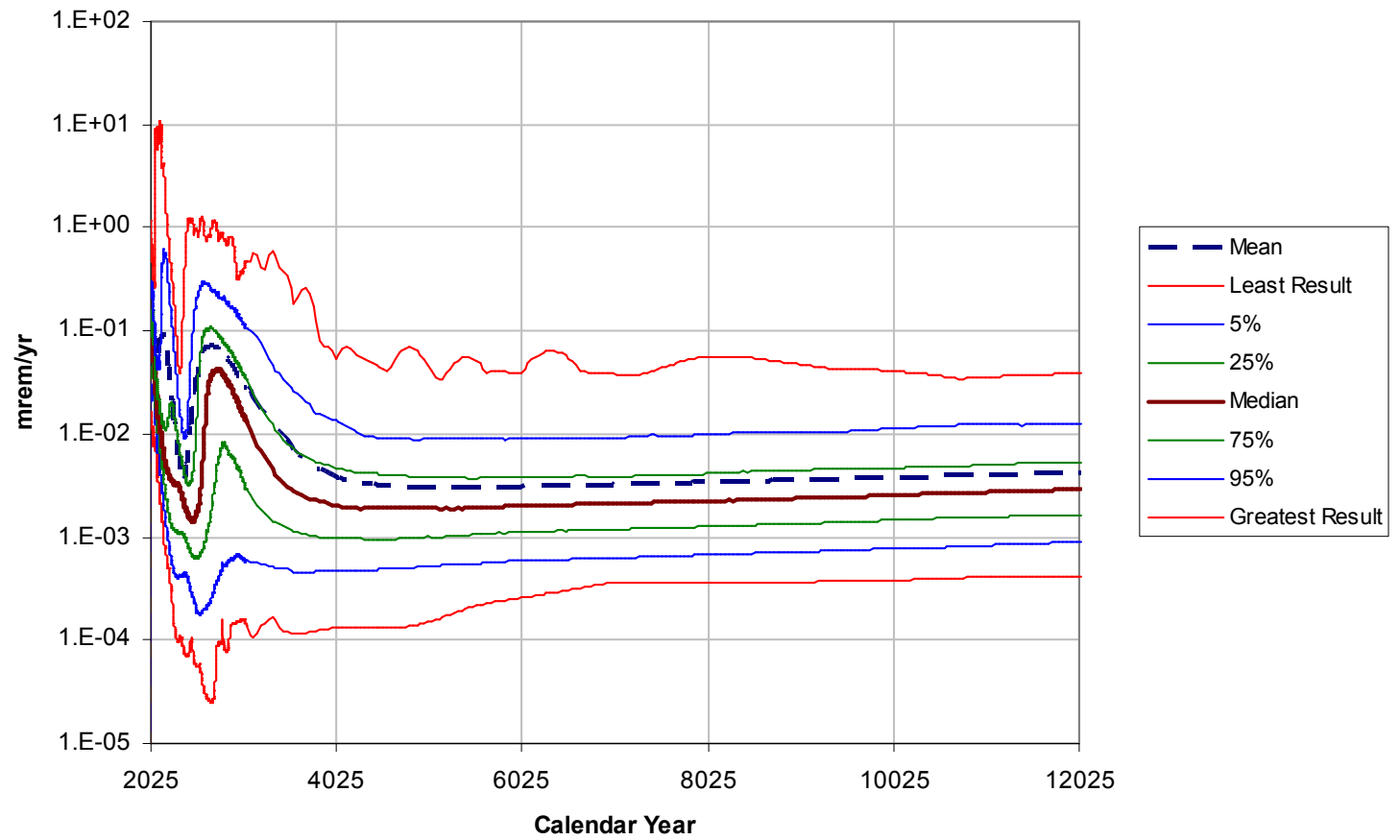

Figure 6.1-2. Uncertainty in cumulative dose at Savannah River POA over 10,000 years. 
SRNL-STI-2011-00365, Rev. 0

FMB Dose 1000 Realizations

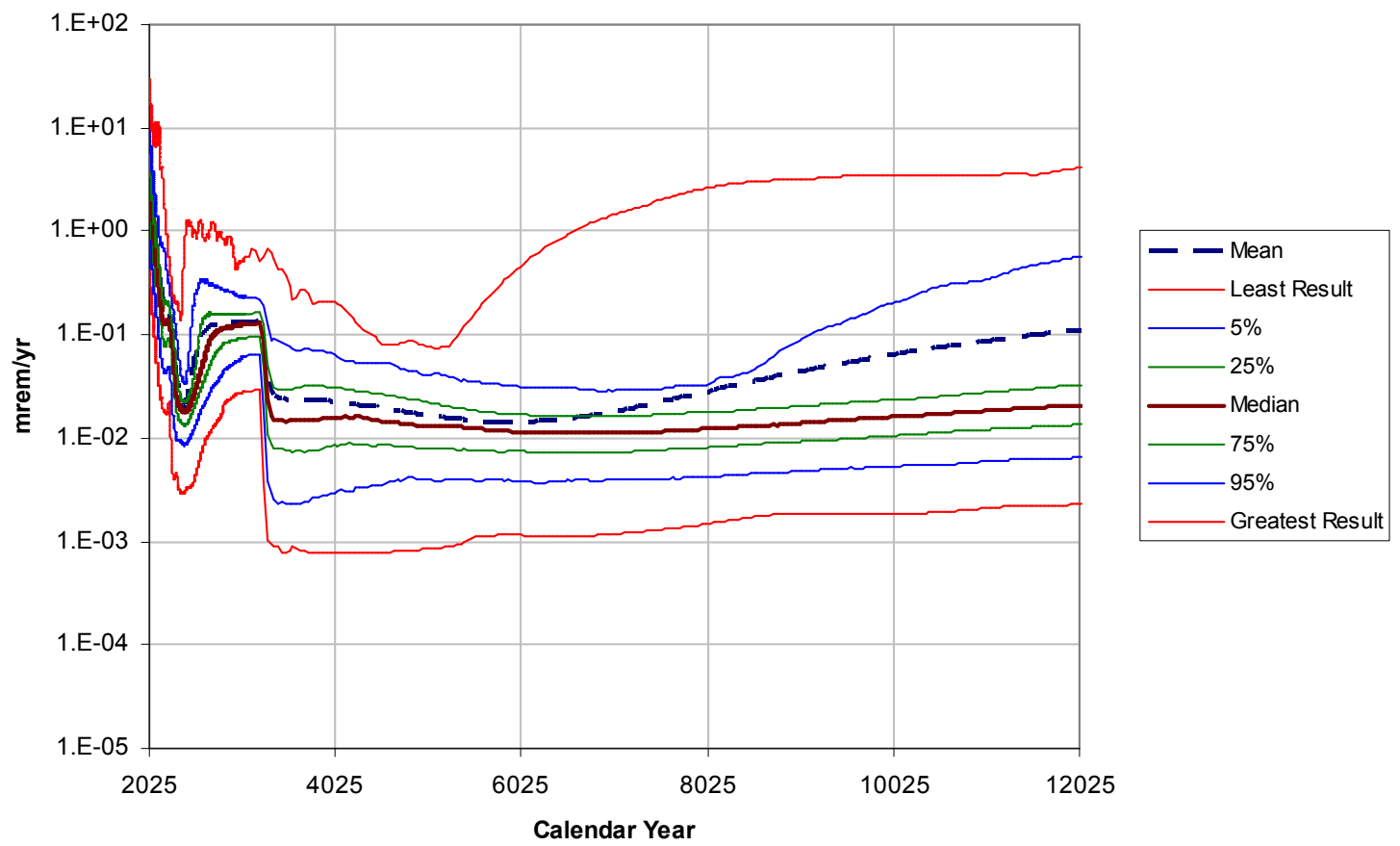

Figure 6.1-3. Uncertainty in cumulative dose at Fourmile Branch POA over 10,000 years.

SC Dose 1000 Realizations

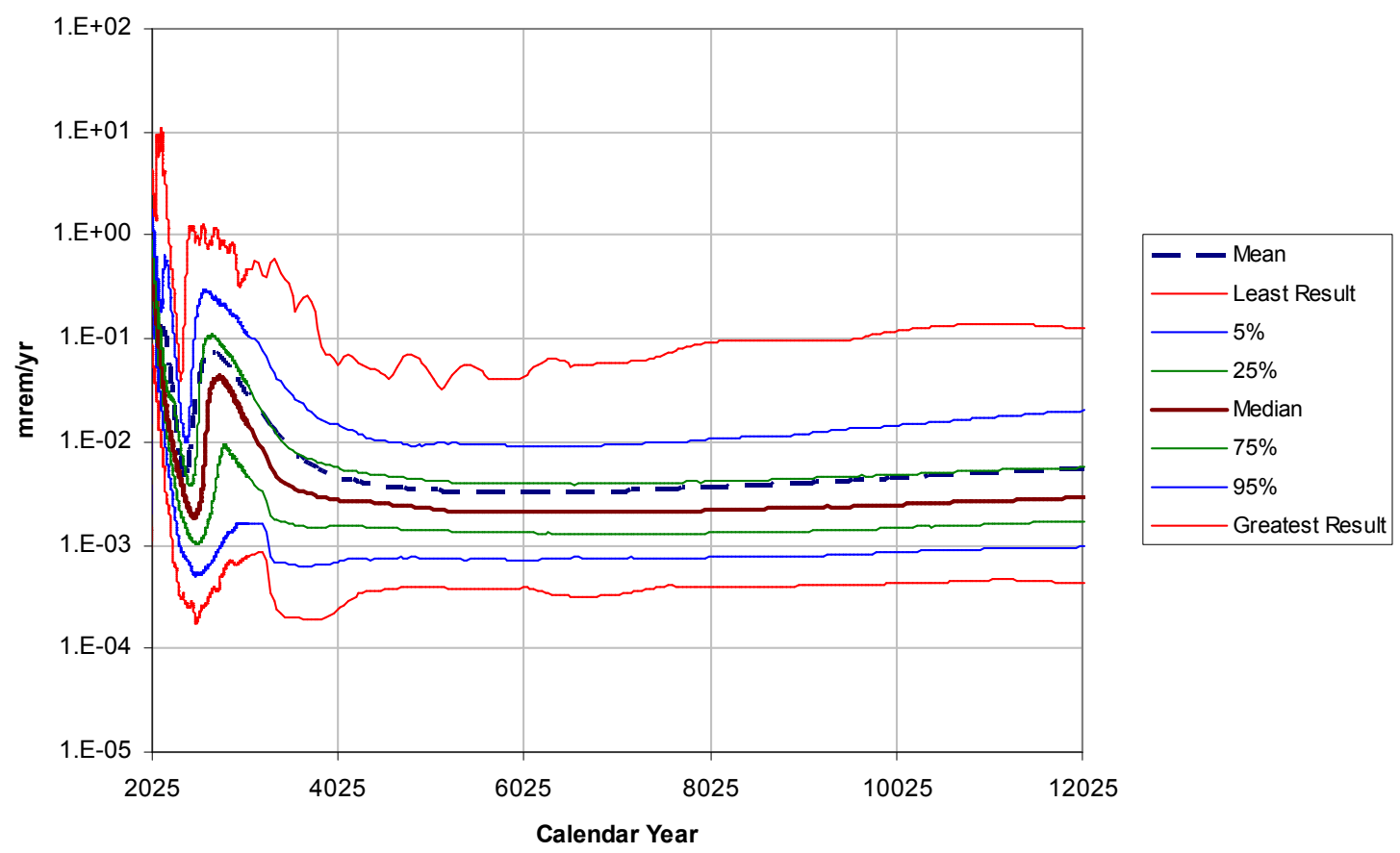

Figure 6.1-4. Uncertainty in cumulative dose at Steel Creek/Pen Branch POA over 10,000 years. 


\section{LTR Dose 1000 Realizations}

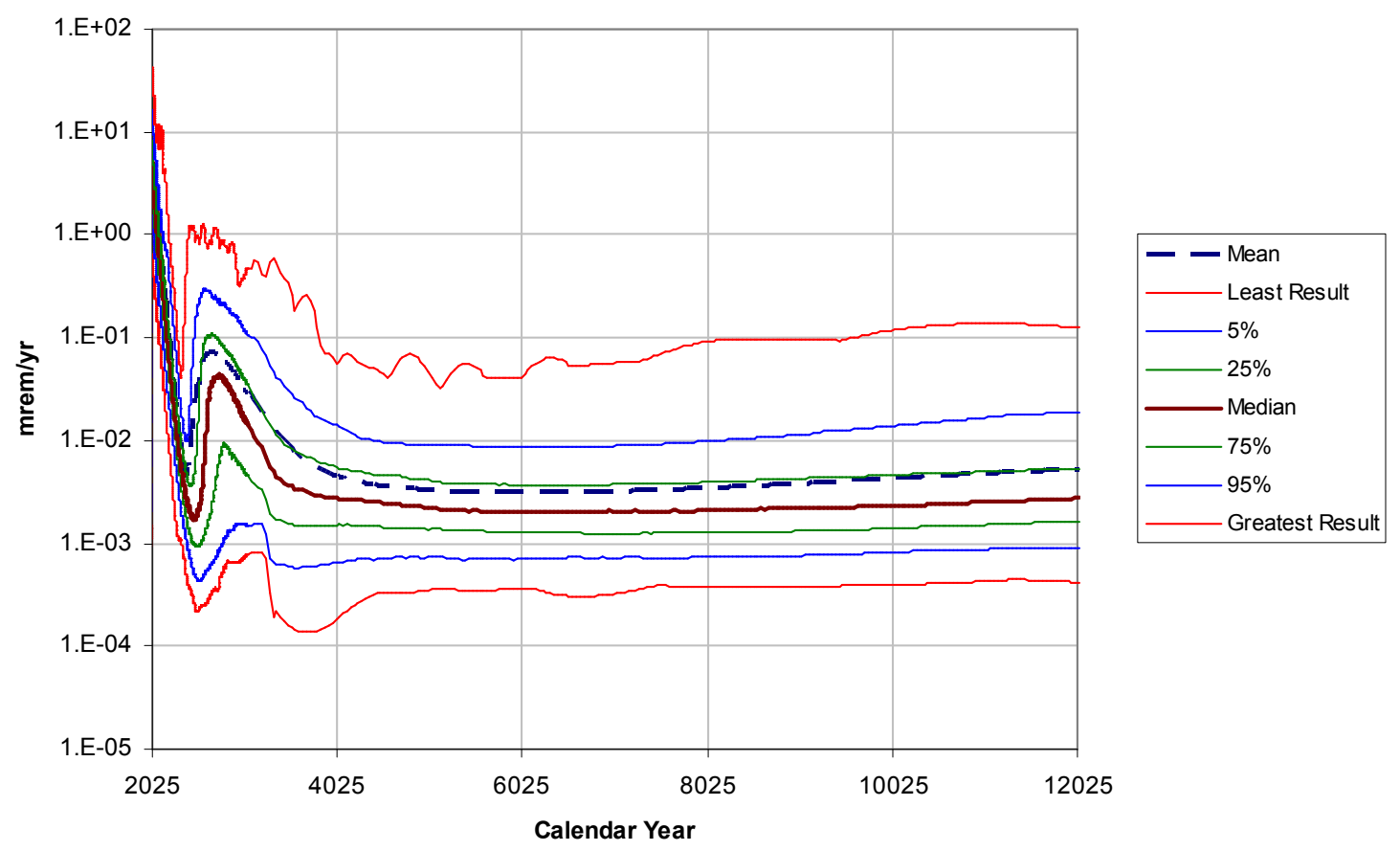

Figure 6.1-5. Uncertainty in cumulative dose at Lower Three Runs POA over 10,000 years.

301 Bridge Dose 1000 Realizations

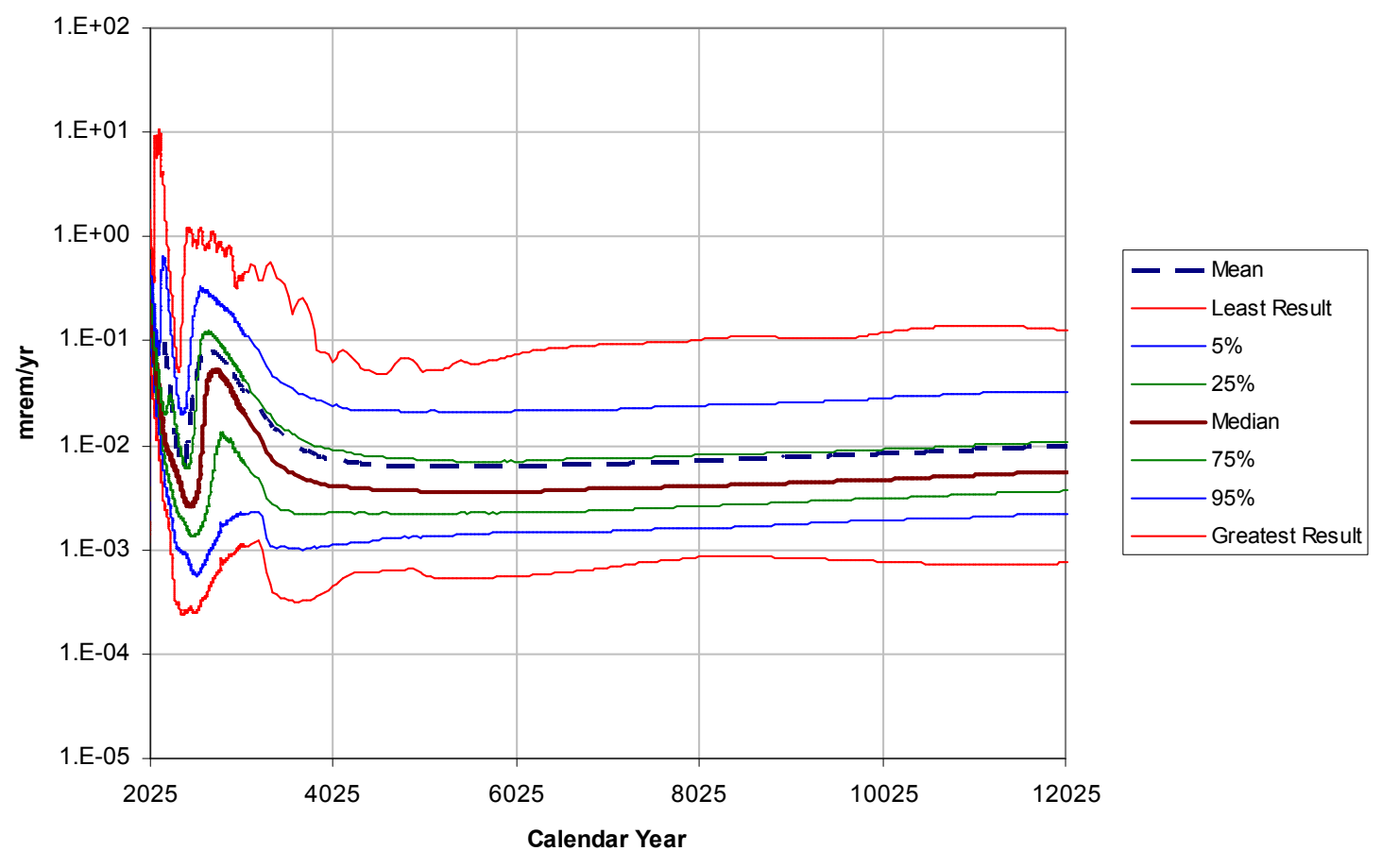

Figure 6.1-6. Uncertainty in cumulative dose at 301 Bridge POA over 10,000 years. 
SRNL-STI-2011-00365, Rev. 0

\subsection{Dose Uncertainty over First 2,000 Years of Simulation}

UTR Dose 1000 Realizations

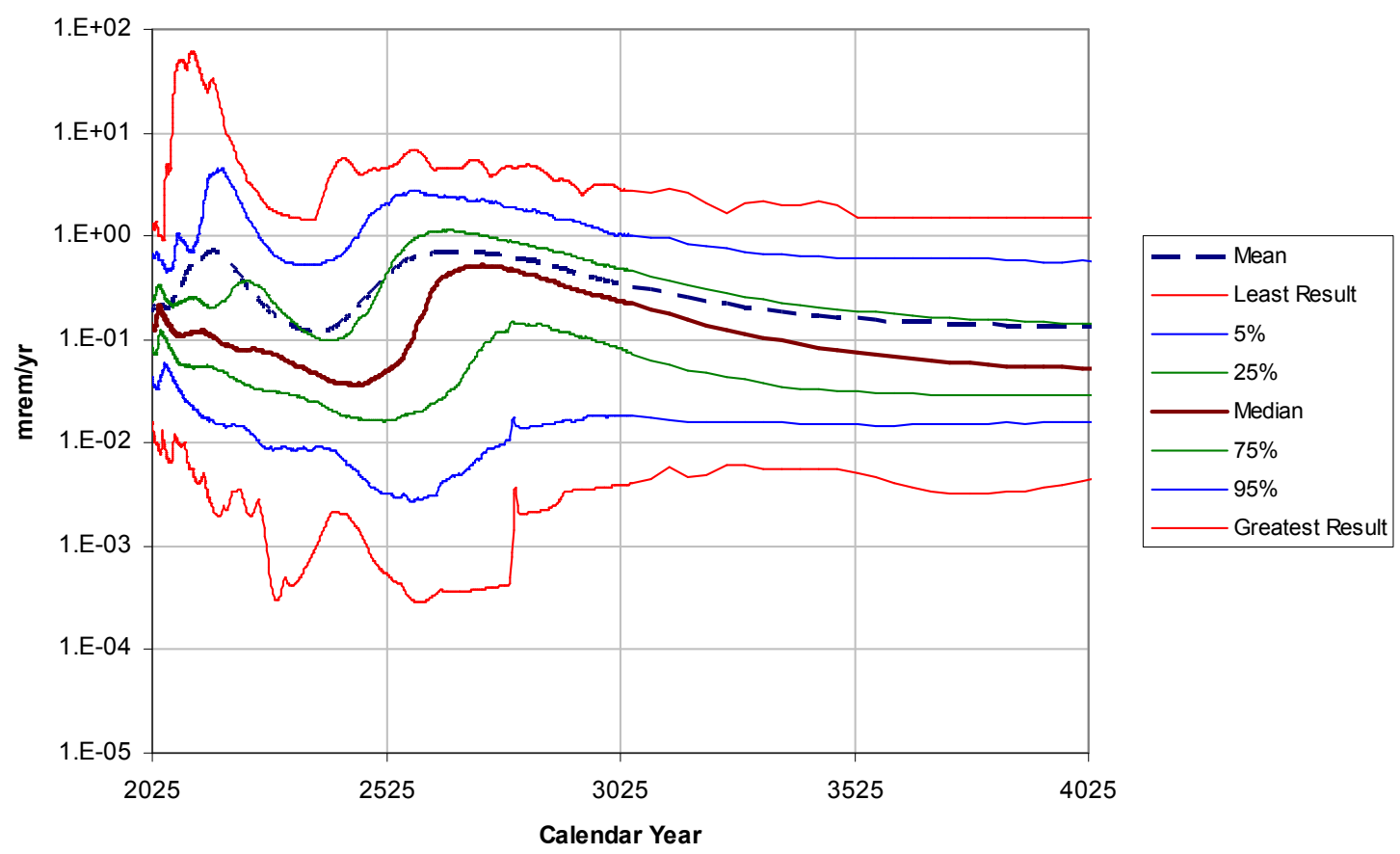

Figure 6.2-1. Uncertainty in dose at Upper Three Runs POA over 2,000 years.

\section{SR Dose 1000 Realizations}

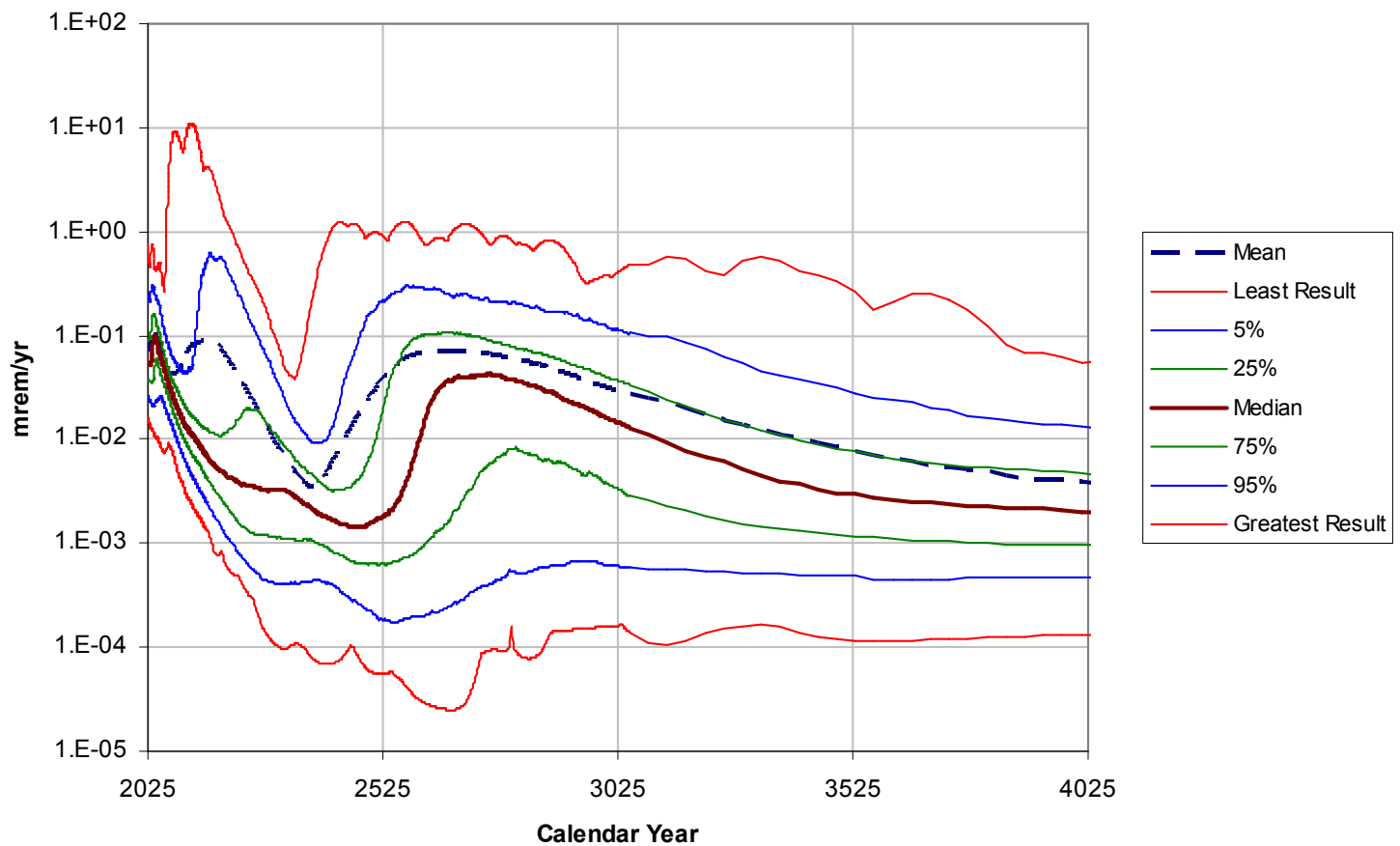

Figure 6.2-2. Uncertainty in cumulative dose at Savannah River POA over 2,000 years. 
FMB Dose 1000 Realizations

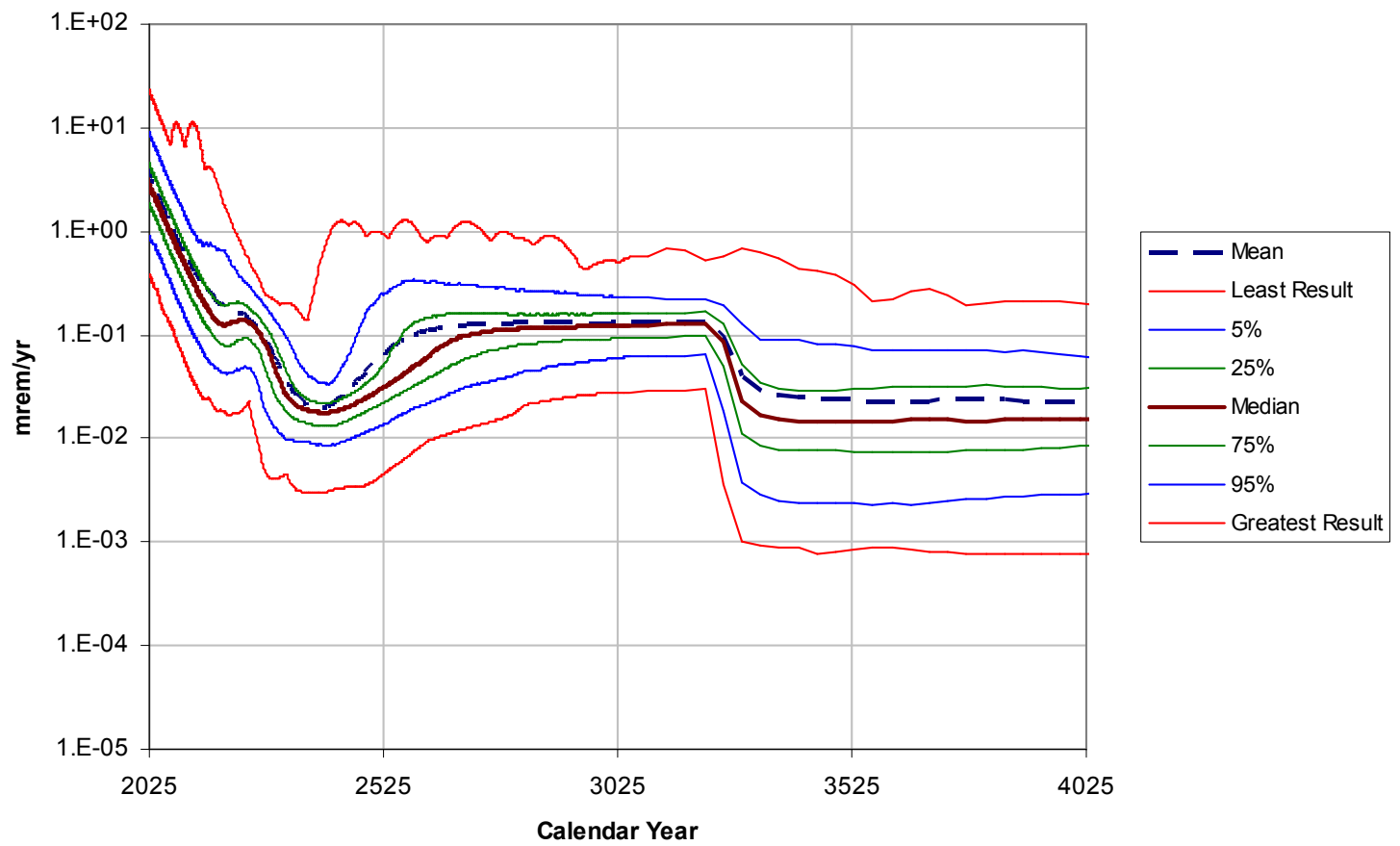

Figure 6.2-3. Uncertainty in cumulative dose at Fourmile Branch POA over 2,000 years.

SC Dose 1000 Realizations

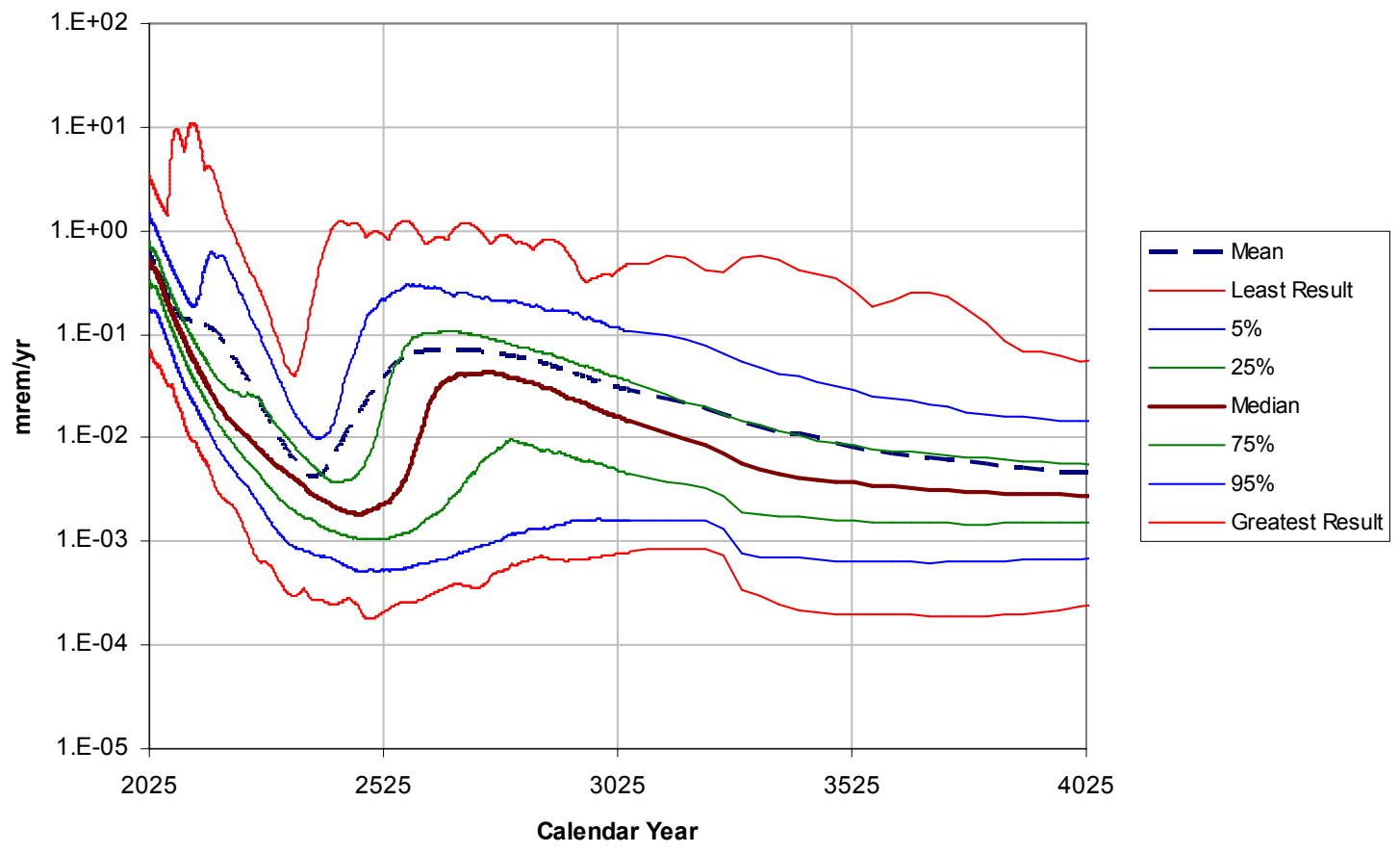

Figure 6.2-4. Uncertainty in cumulative dose at Steel Creek/Pen Branch POA over 2,000 years. 


\section{LTR Dose 1000 Realizations}

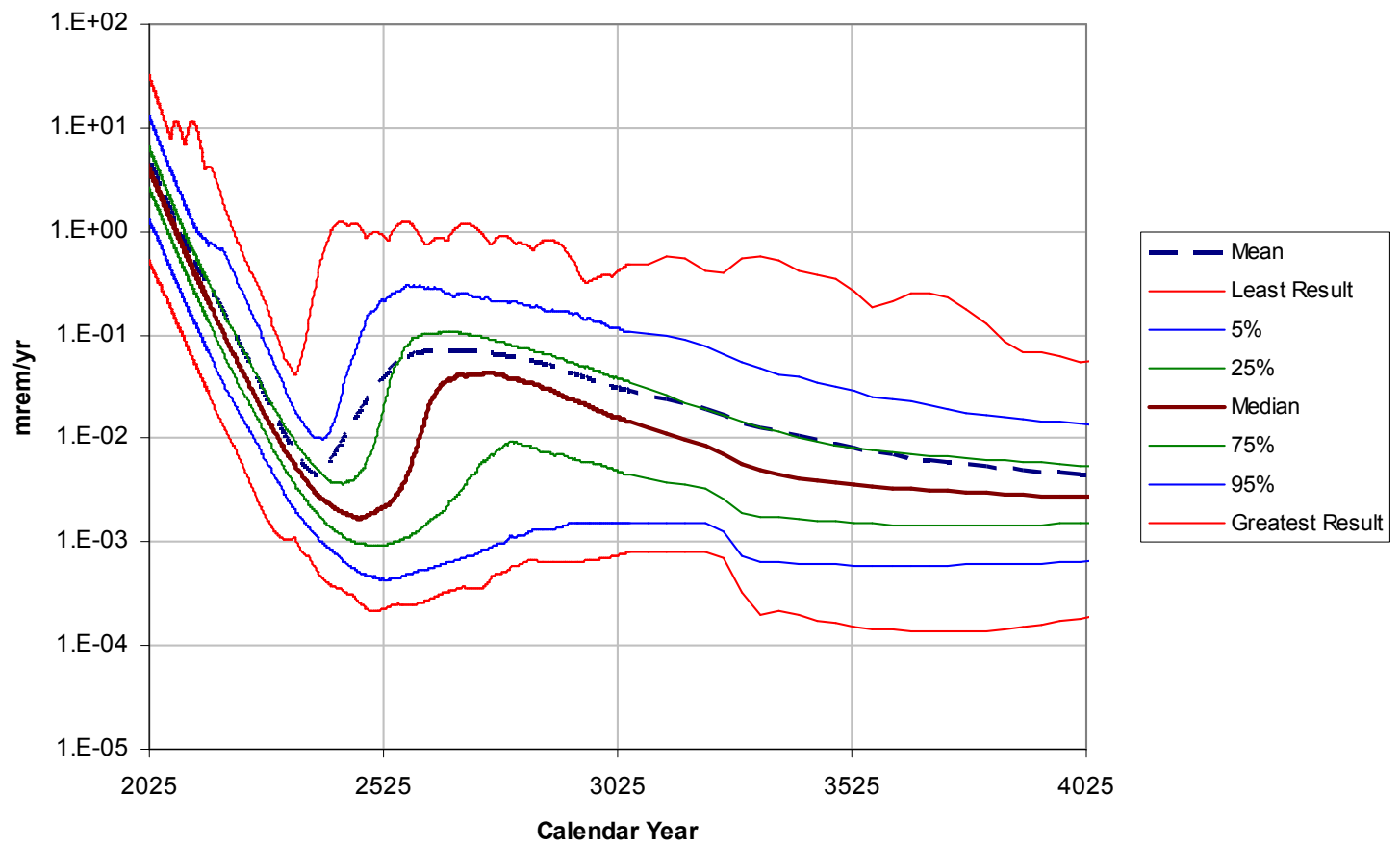

Figure 6.2-5. Uncertainty in cumulative dose at Lower Three Runs POA over 2,000 years.

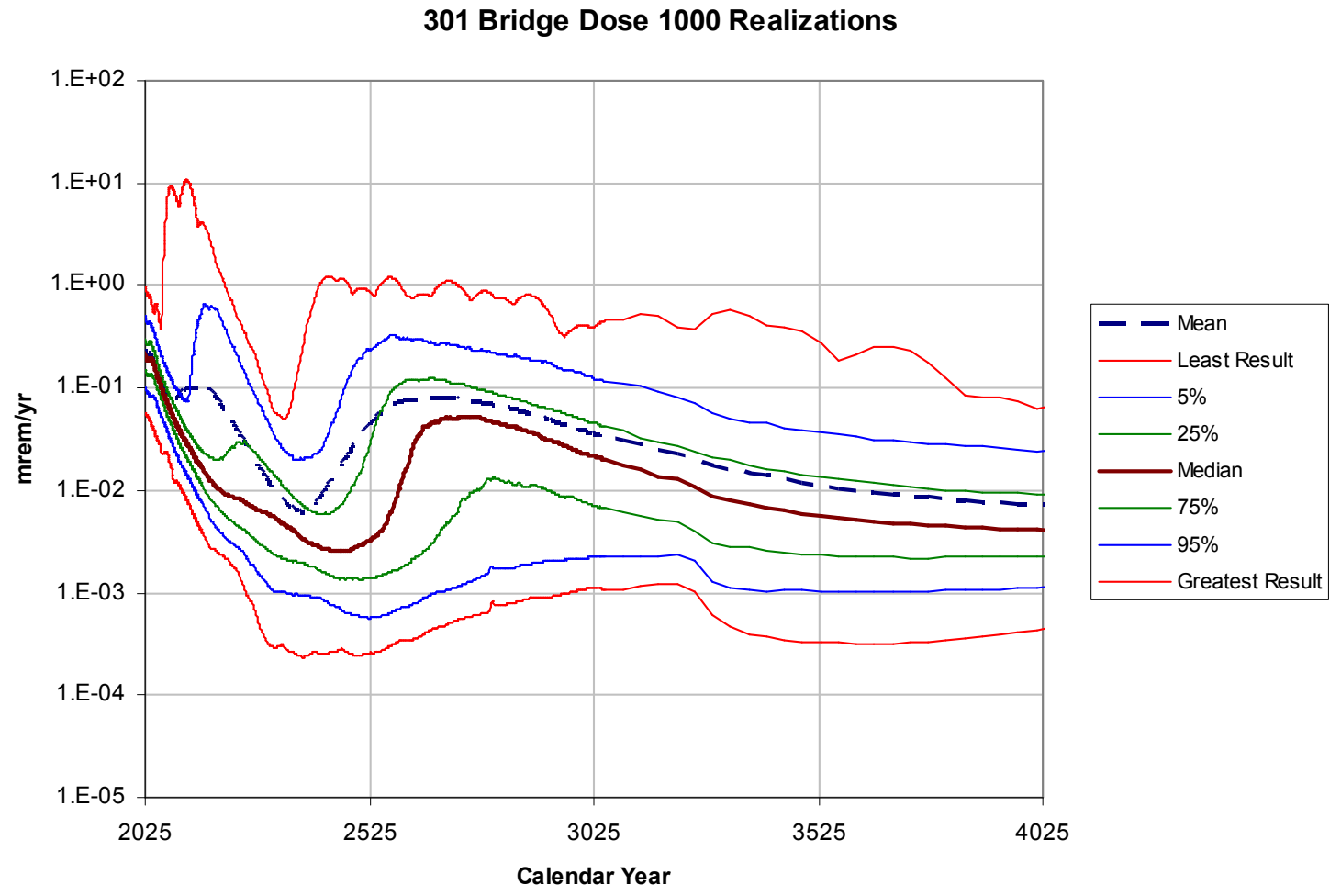

Figure 6.2-6. Uncertainty in cumulative dose at 301 Bridge POA over 2,000 years. 


\subsection{Mean, Median and Deterministic Doses}

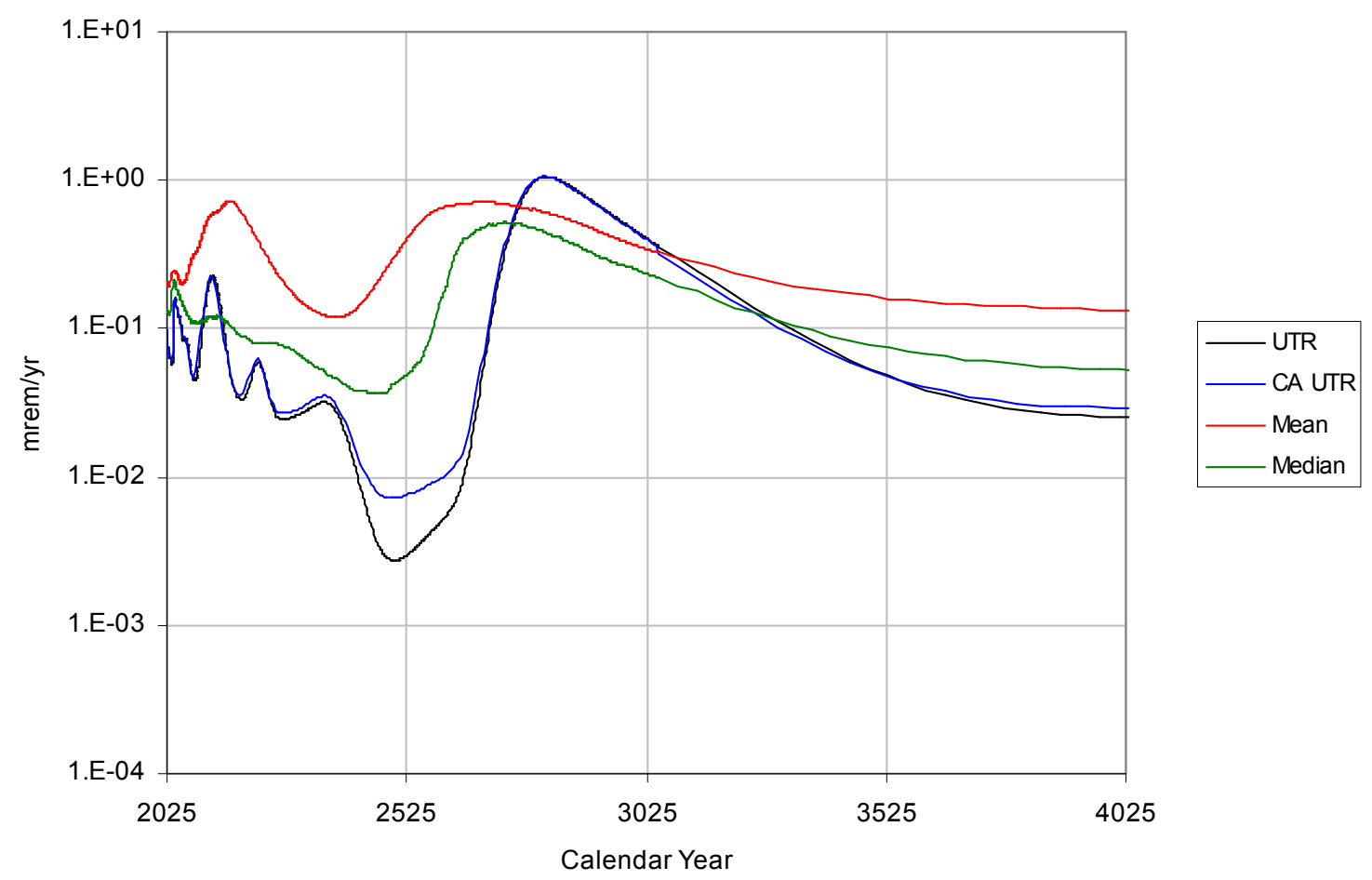

Figure 6.3-1. Mean, median and deterministic doses at Upper Three Runs POA.
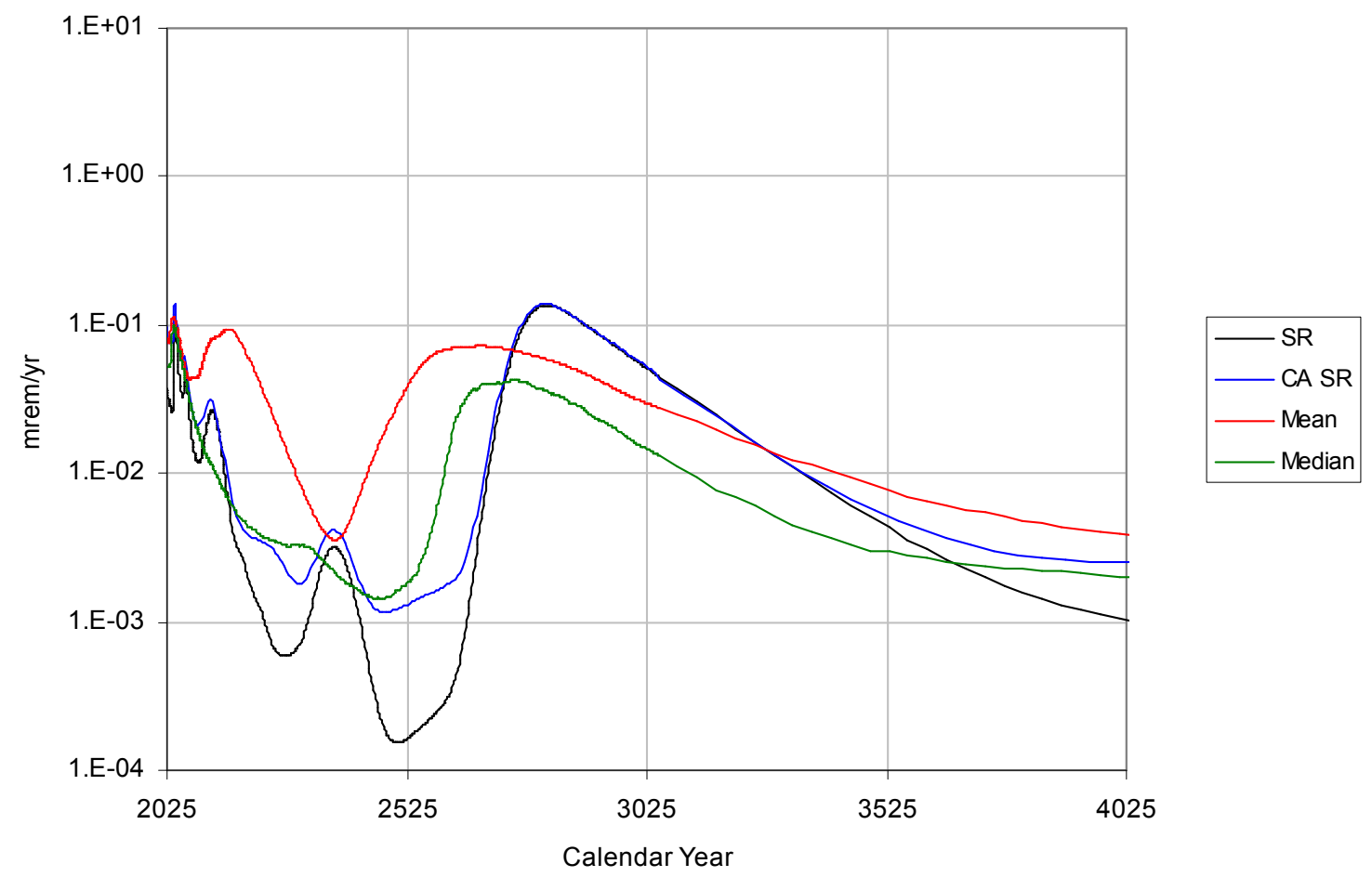

Figure 6.3-2. Mean, median and deterministic doses at Savannah River POA. 
SRNL-STI-2011-00365, Rev. 0

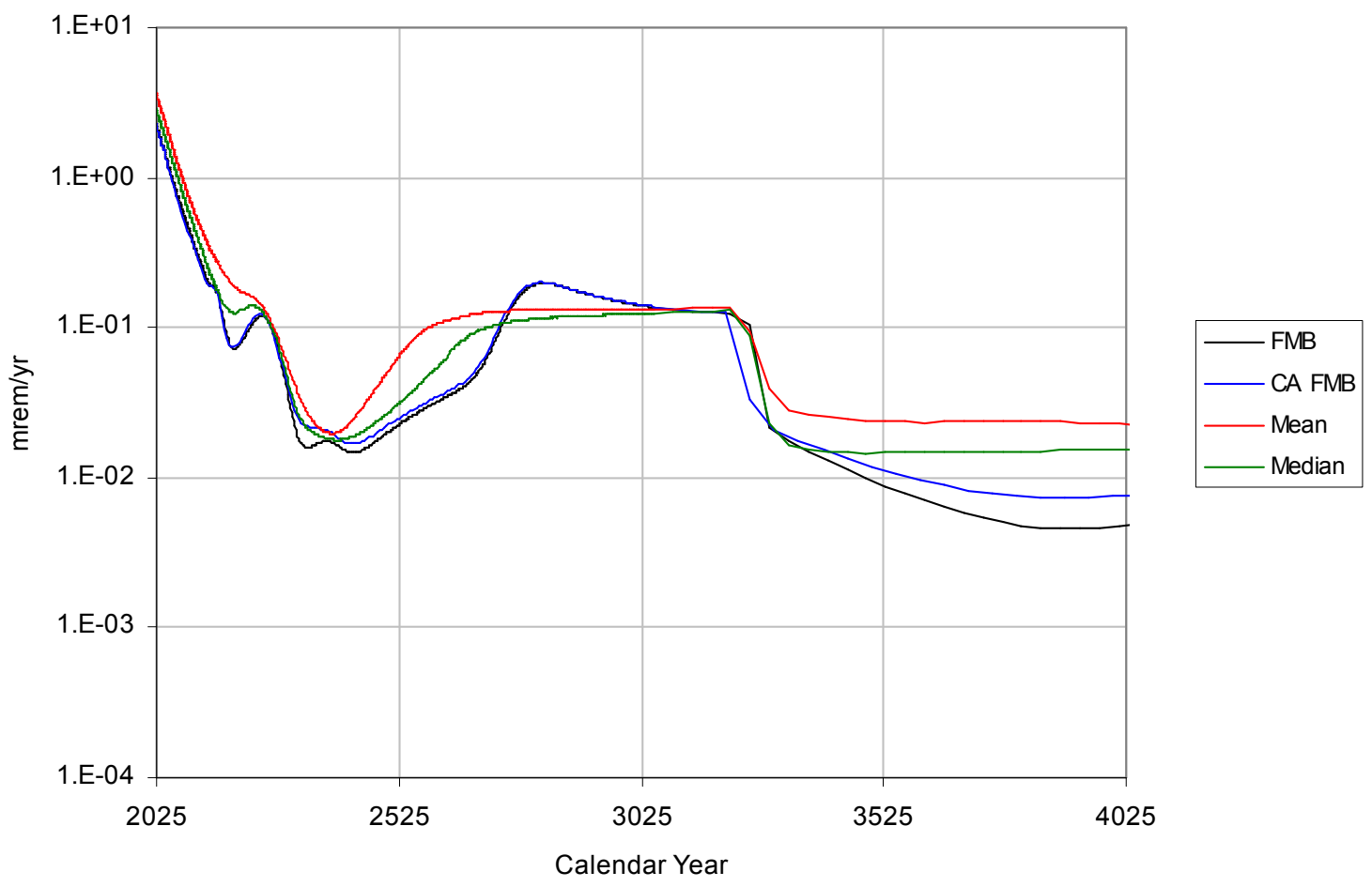

Figure 6.3-3. Mean, median and deterministic doses at Fourmile Branch POA.

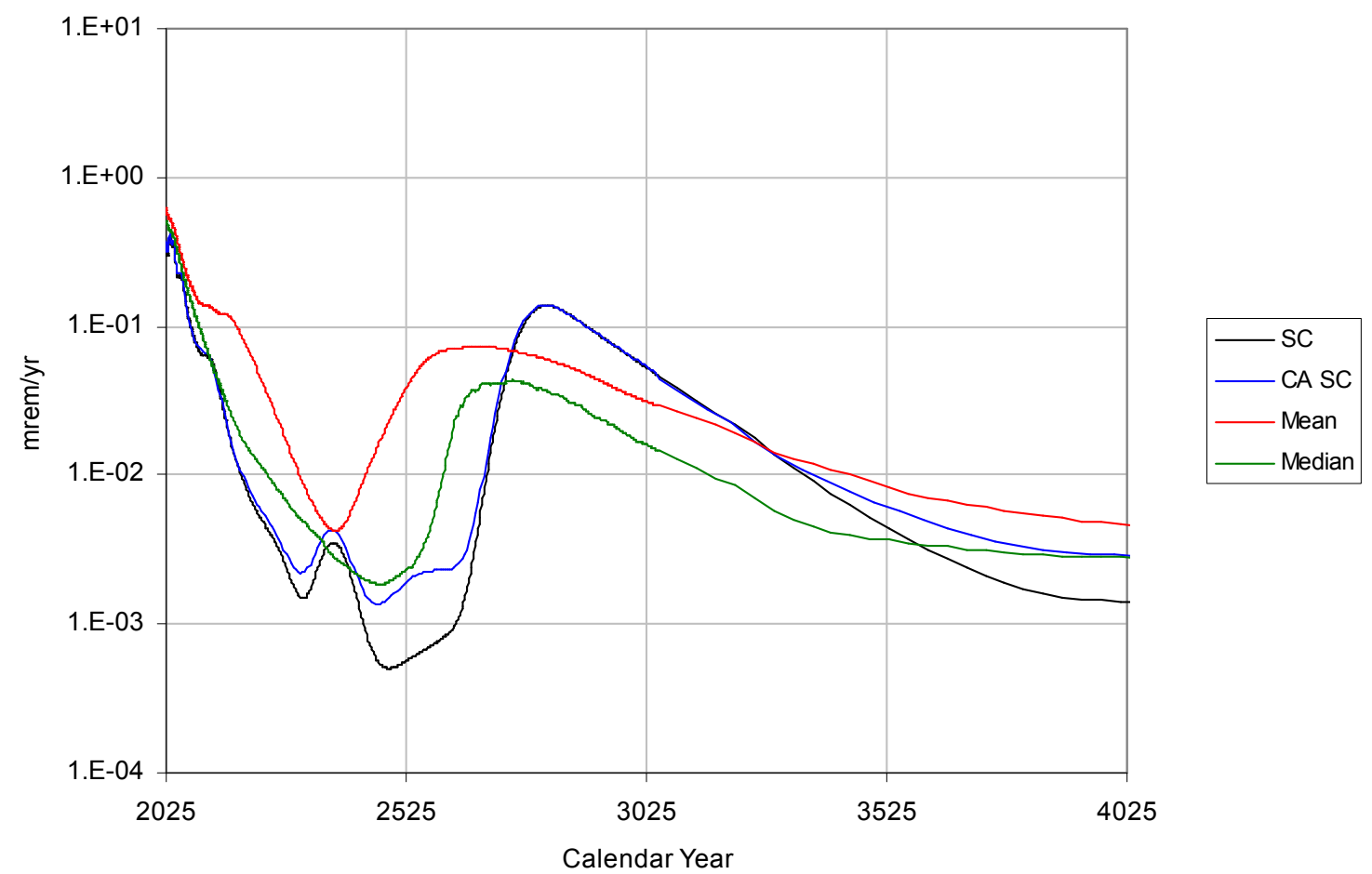

Figure 6.3-4. Mean, median and deterministic doses at Steel Creek/Pen Branch POA. 
SRNL-STI-2011-00365, Rev. 0

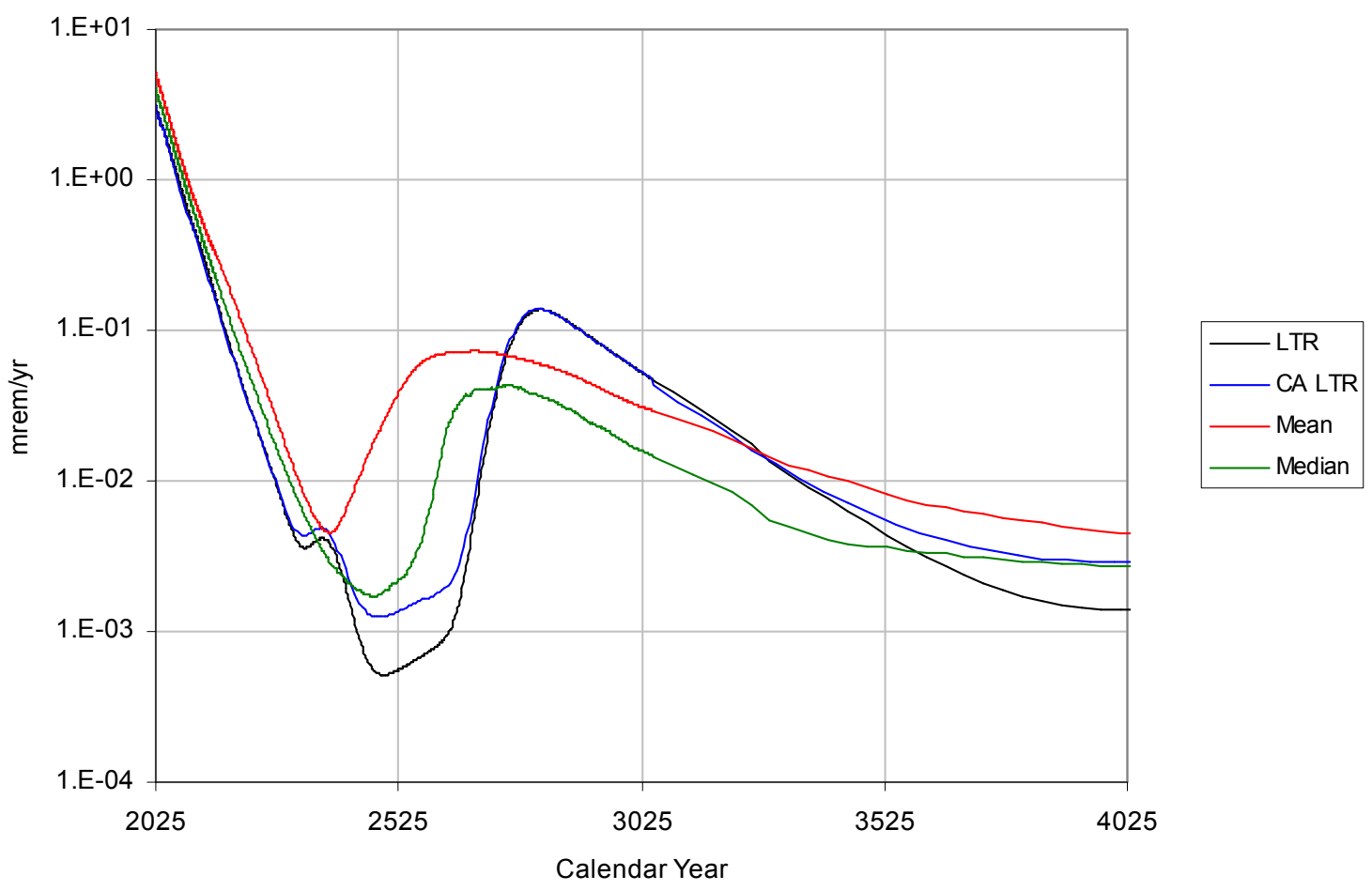

Figure 6.3-5. Mean, median and deterministic doses at Lower Three Runs POA.

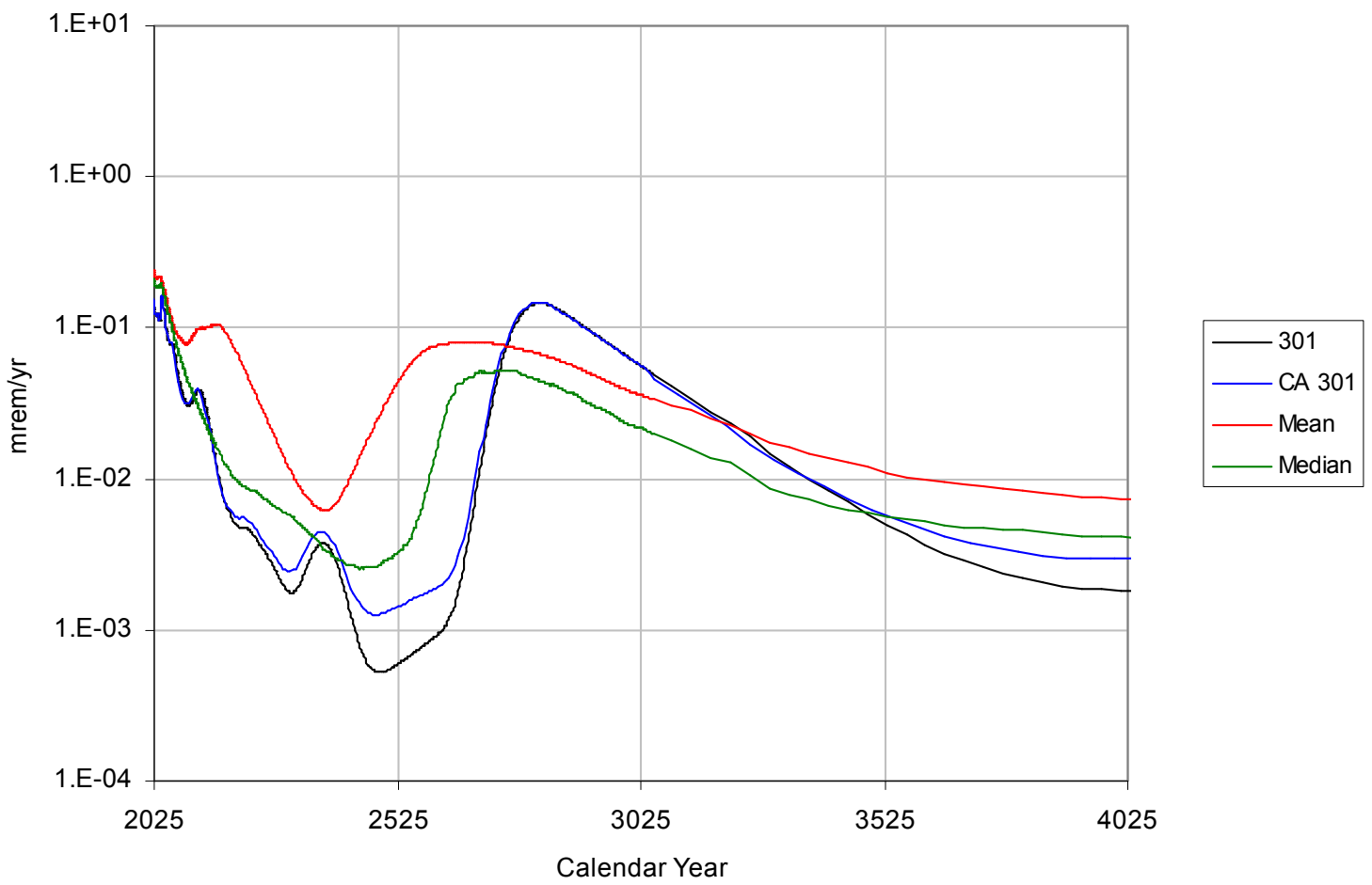

Figure 6.3-6. Mean, median and deterministic doses at 301 Bridge POA. 


\subsection{Separate Effects on Uncertainty}

To further examine the important factors in CA uncertainty, the uncertainty in $\mathrm{K}_{\mathrm{d}}$ and uncertainty in the four categories of stochastic parameters listed in Tables 5-1 through 5-4 were analyzed separately. Results from this analysis are presented for each POA in Sections 7.1 through 7.6. Figures in these subsections are limited to the time period 2025 to 4025 . The first plot in each subsection shows the overall uncertainty when all stochastic parameters are allowed to vary and subsequent plots show the impact from varying each category of parameters alone.

Some general trends can be seen in the results of this separate effects analysis:

1. Results for uncertainty in dose parameters, material properties, and surface water flow follow the shape of the deterministic calculations for each POA as shown in Figure 4-4, whereas results for $K_{d}$ and vadose and aquifer flow do not. This is because the $K_{d}$ values and vadose and aquifer flow rates change the radionuclide transport times. Dose parameters and surface water flows (which are so large that they in effect instantaneously transport the radionuclides from the point of outcrop to the POA) have effectively no impact on the transport time to the POA and material properties have only a secondary effect on transport time. By altering the transport time, $\mathrm{K}_{\mathrm{d}}$ and groundwater flow change the shape of the uncertainty response. If the transport time is not changed, uncertainty results spread about the deterministic calculation.

2. $\mathrm{K}_{\mathrm{d}}$ values have a large impact on the uncertainty distributions. As noted in Section 5.0, relatively large standard deviations are assumed for these distributions.

3. Groundwater flow uncertainty also has a significant impact on the uncertainty distributions. This is likely caused by the relatively large standard deviations used for the aquifer flow parameters shown in Table 5-4.

4. Material properties do not have a significant impact on the uncertainty distributions.

5. Surface water flows have a small impact on the uncertainty distributions. However, the stochastic distribution assigned to the surface water flows represents an estimate of the distribution of 1,000 year average values as recommended by Shine 2009. These distributions are very narrow and the uncertainty results may not completely reflect the expected response to variations in surface water flow. Alternatively, using a distribution of yearly average flows is not appropriate for evaluating the impact on the CA dose over a 1,000 year period of assessment, since it is unreasonable to assume that the flow would remain at a value selected from this distribution throughout the entire time period.

Another approach that could be considered in the next CA would be to use a yearly average flow distribution but to resample the distribution at each year or time step in the CA simulation. However, the representativeness of re-sampling at each time step would have to be evaluated closely due to the use of varying time steps. This approach would give a series of varying surface water flow rates that would simulate the expected yearly fluctuation in flow and give a better measure of uncertainty to flow during Monte Carlo runs. The feasibility of such an approach would have to be tested versus the potential increase in run times that might be incurred. 
SRNL-STI-2011-00365, Rev. 0

\subsection{Dose Uncertainty at Upper Three Runs POA}

\section{UTR Dose 1000 Realizations}

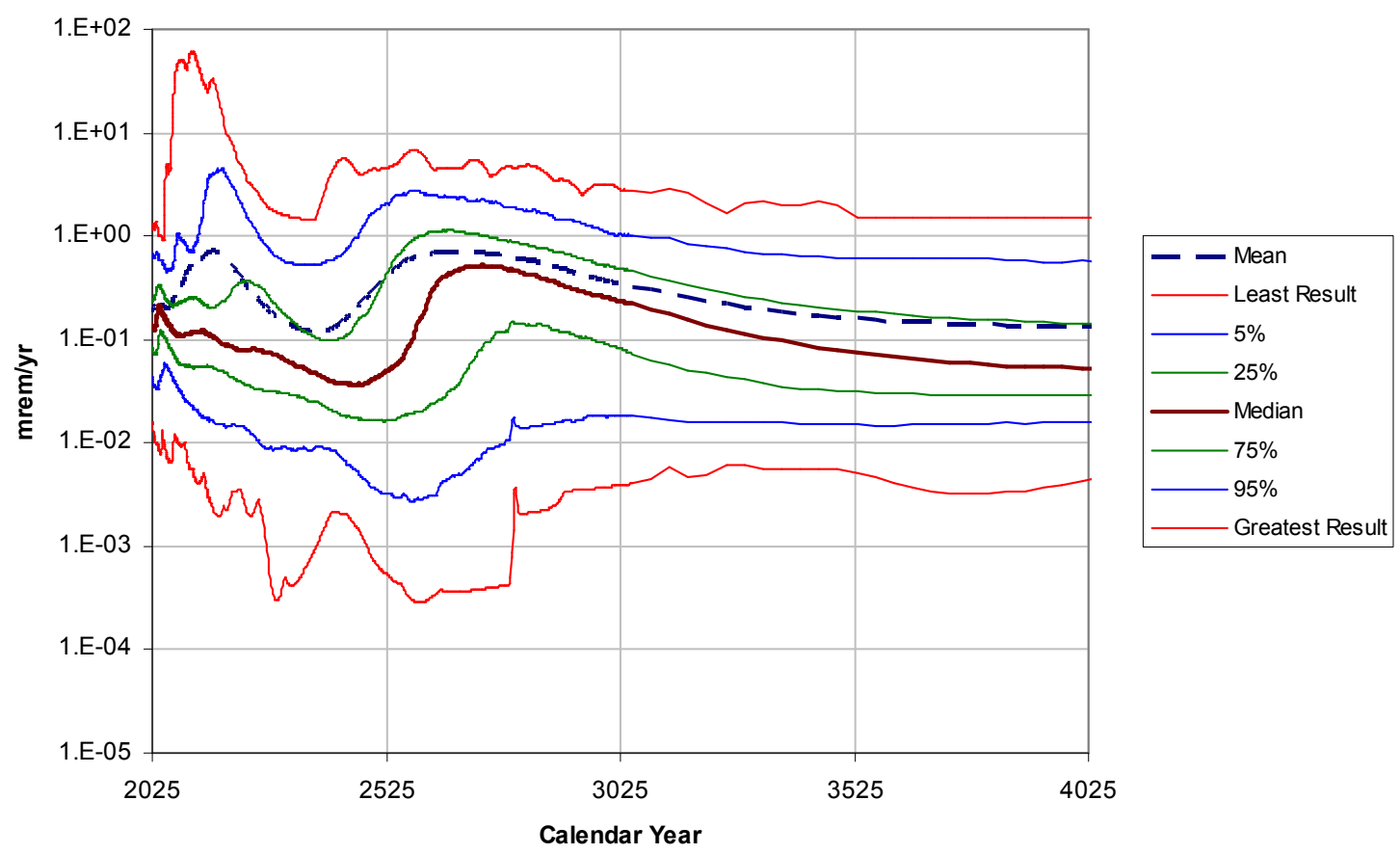

Figure 7.1-1. Overall uncertainty in dose at Upper Three Runs POA.

\section{UTR Dose 1000 Realizations}

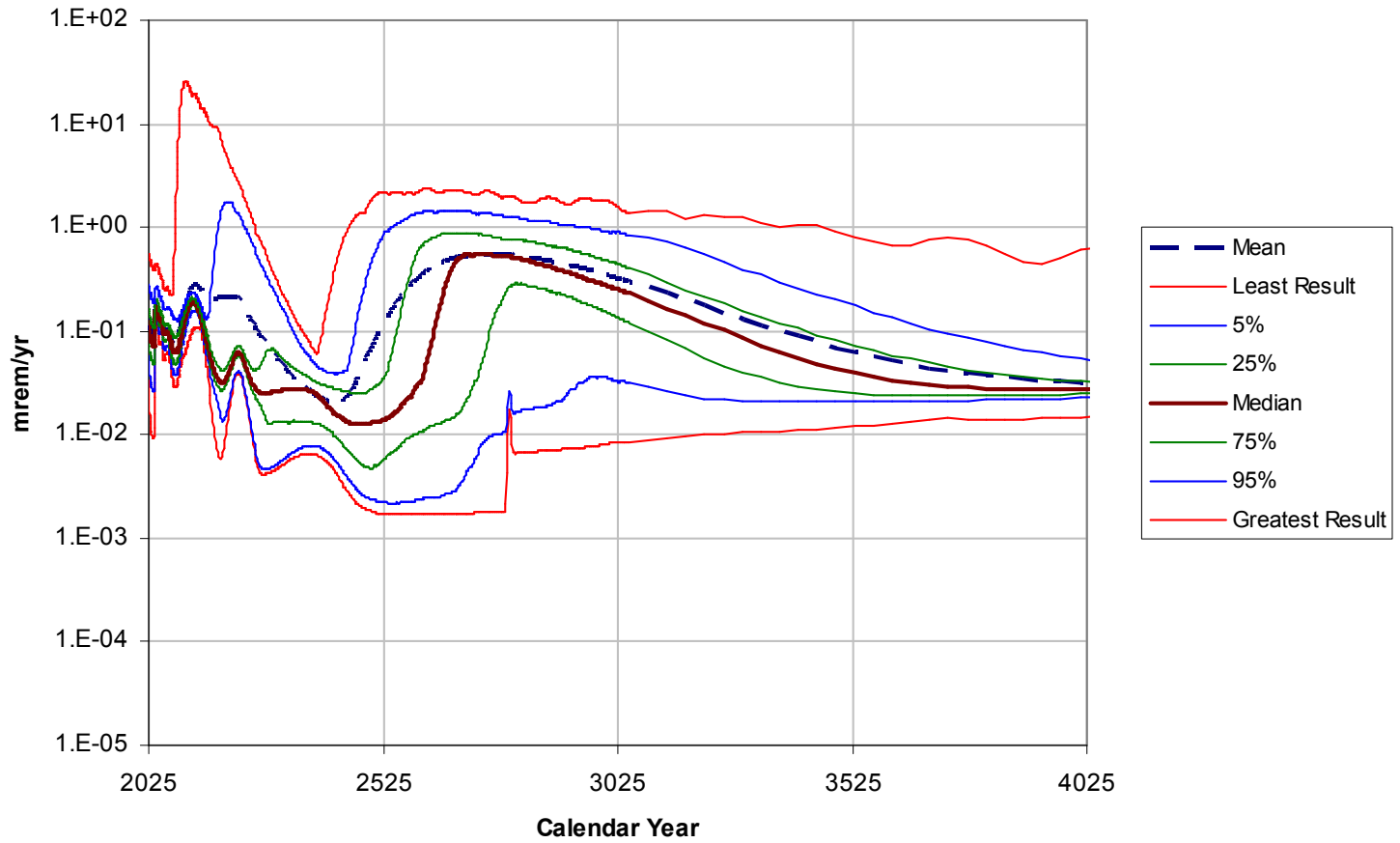

Figure 7.1-2. Uncertainty in dose at Upper Three Runs POA from variation in $\mathrm{K}_{\mathrm{d}}$. 
SRNL-STI-2011-00365, Rev. 0

UTR Dose 1000 Realizations

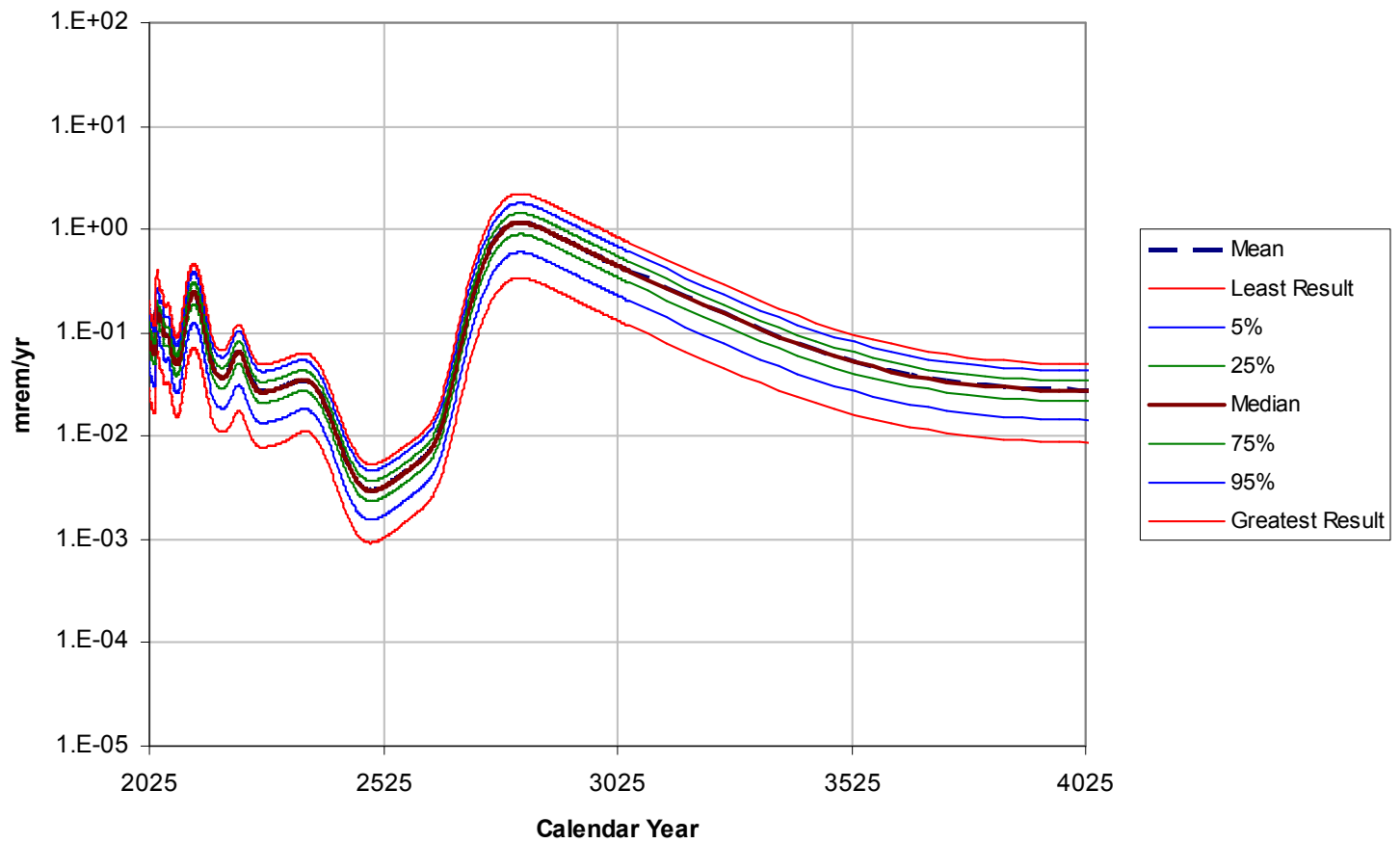

Figure 7.1-3. Uncertainty in dose at Upper Three Runs POA from variation in dose parameters.

UTR Dose 1000 Realizations

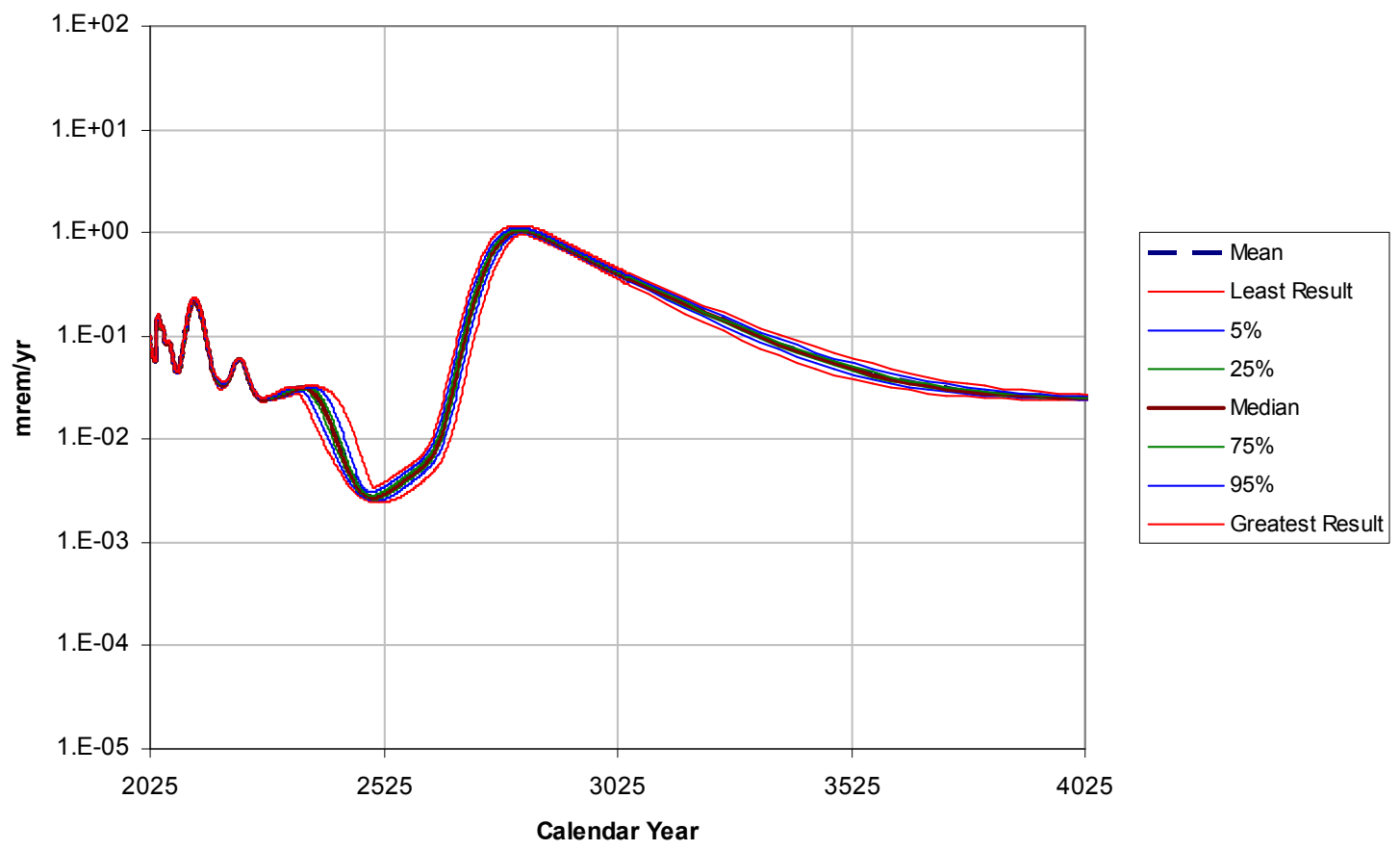

Figure 7.1-4. Uncertainty in dose at Upper Three Runs POA from variation in material properties. 
SRNL-STI-2011-00365, Rev. 0

UTR Dose 1000 Realizations

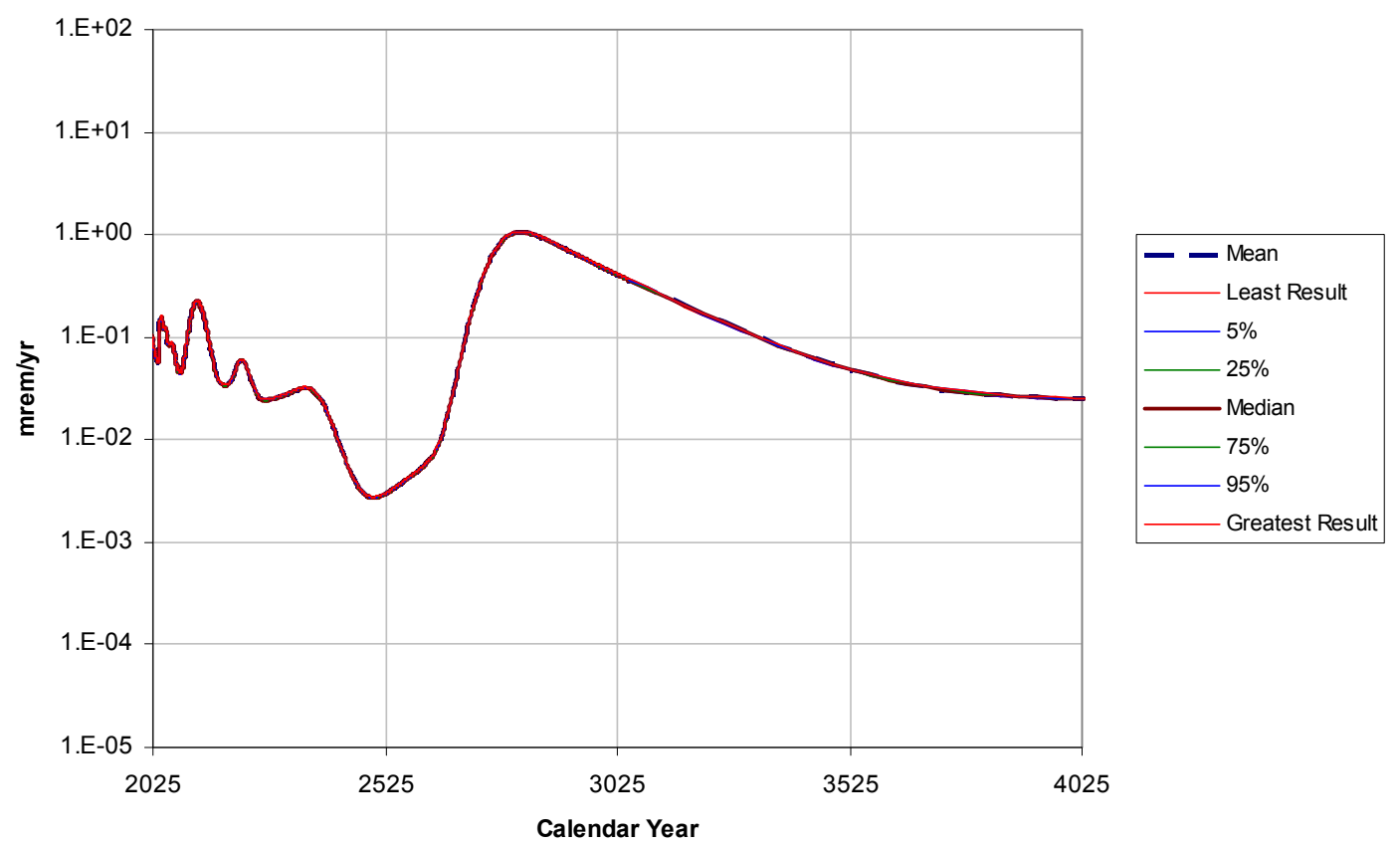

Figure 7.1-5. Uncertainty in dose at Upper Three Runs POA from variation in surface water flow.

UTR Dose 1000 Realizations

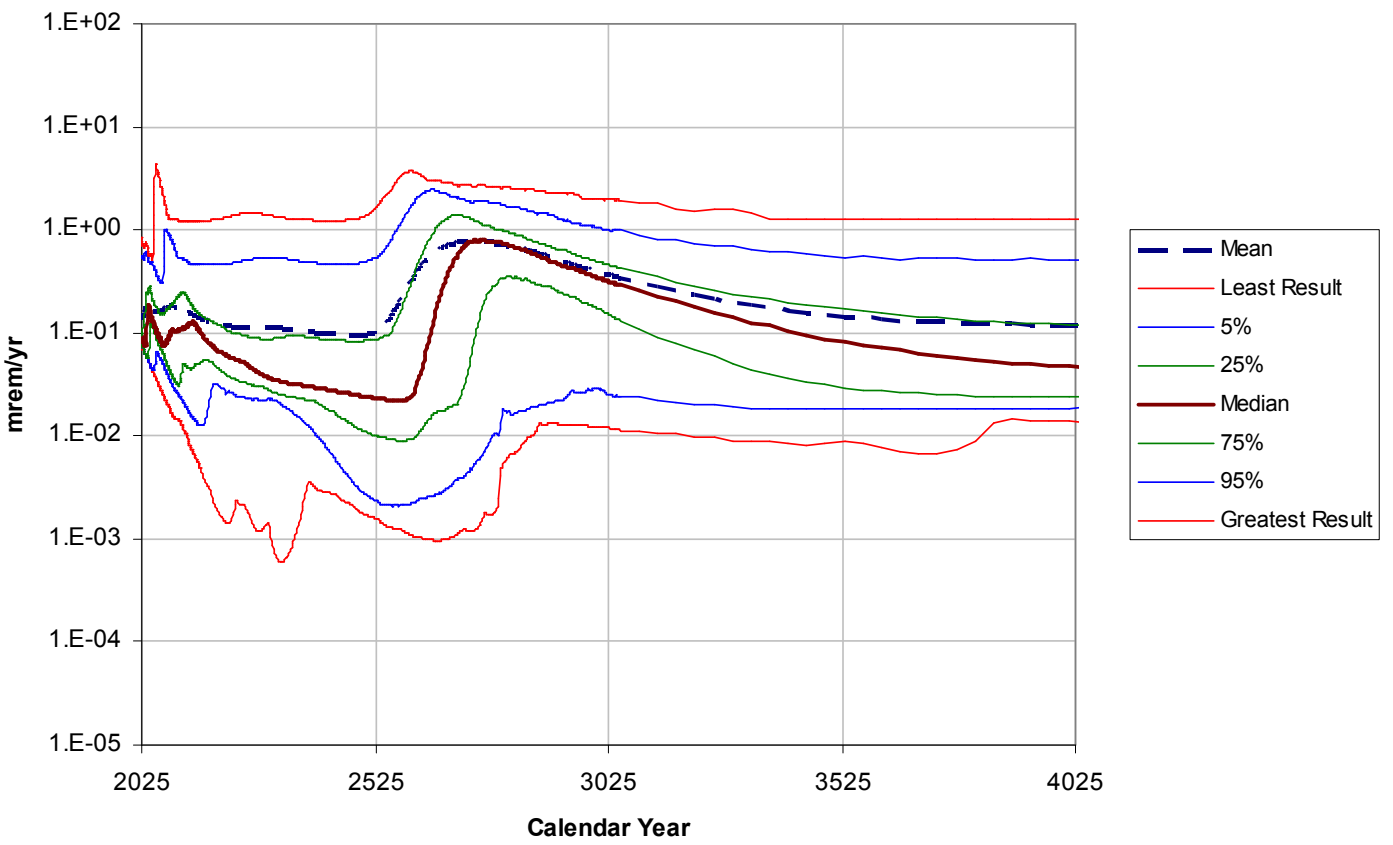

Figure 7.1-6. Uncertainty in dose at Upper Three Runs POA from variation in infiltration and aquifer flow. 


\subsection{Dose Uncertainty at Savannah River POA}

\section{SR Dose 1000 Realizations}

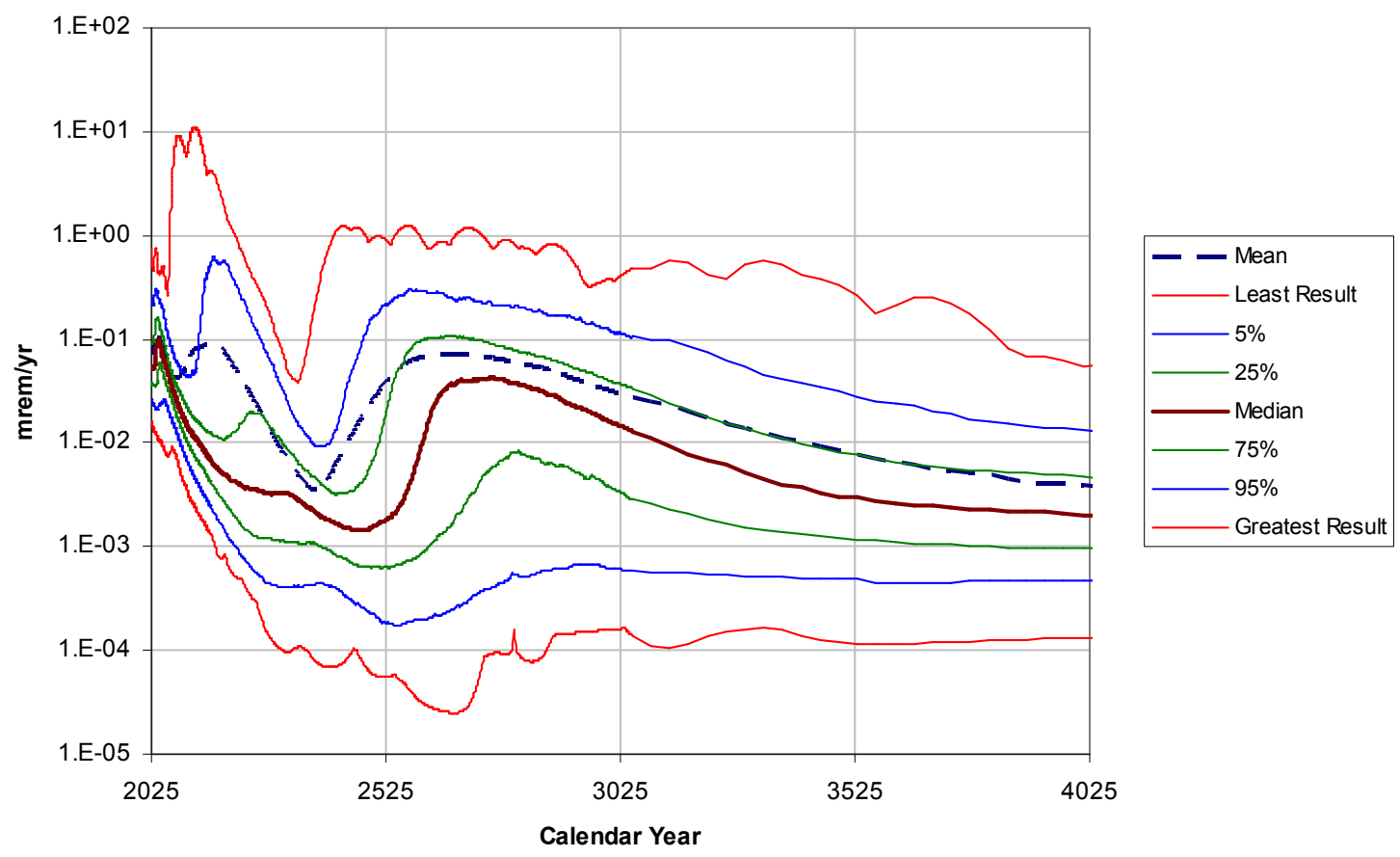

Figure 7.2-1. Overall uncertainty in dose at Savannah River POA.

\section{SR Dose 1000 Realizations}

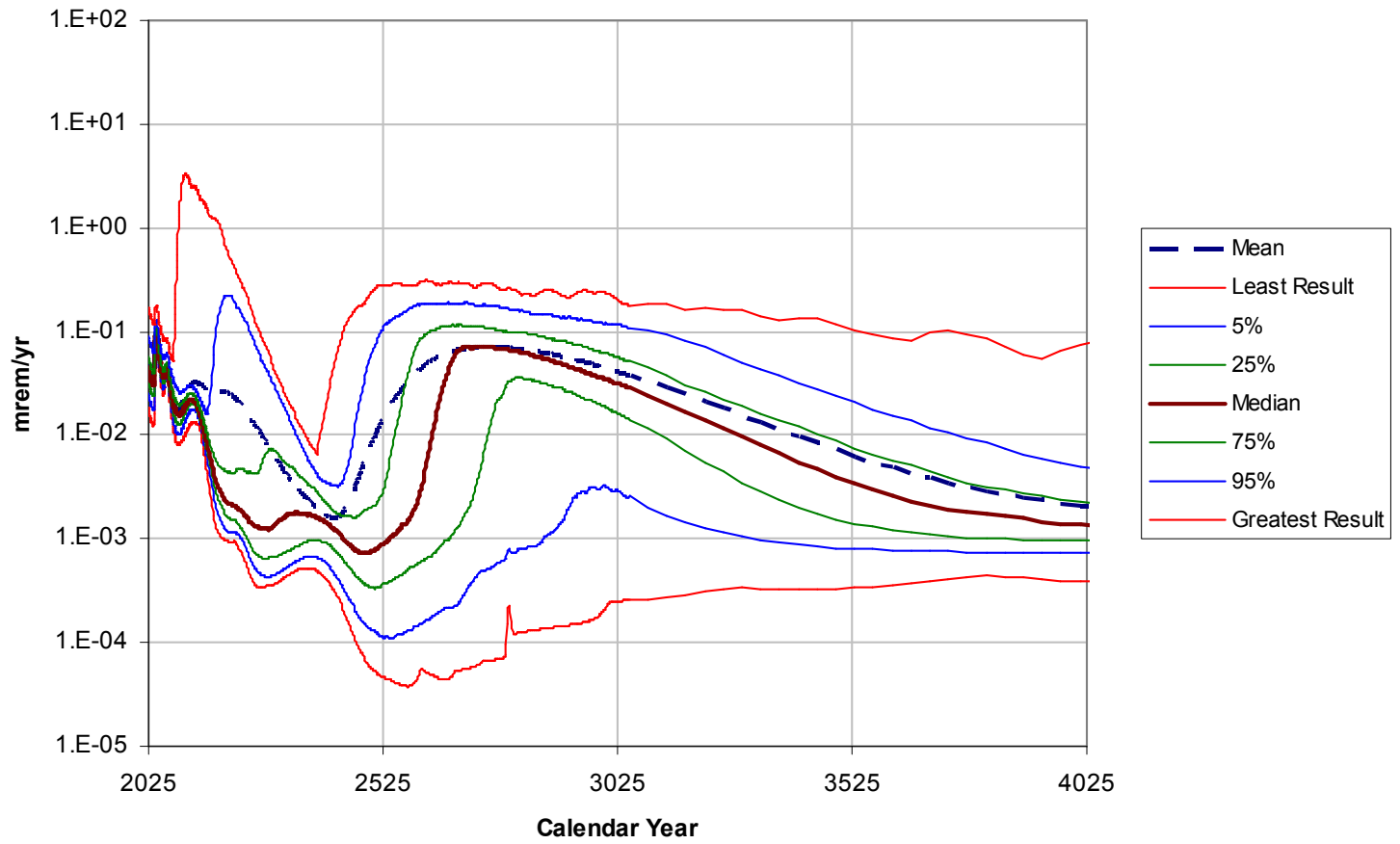

Figure 7.2-2. Uncertainty in dose at Savannah River POA from variation in $\mathrm{K}_{\mathrm{d}}$. 


\section{SR Dose 1000 Realizations}

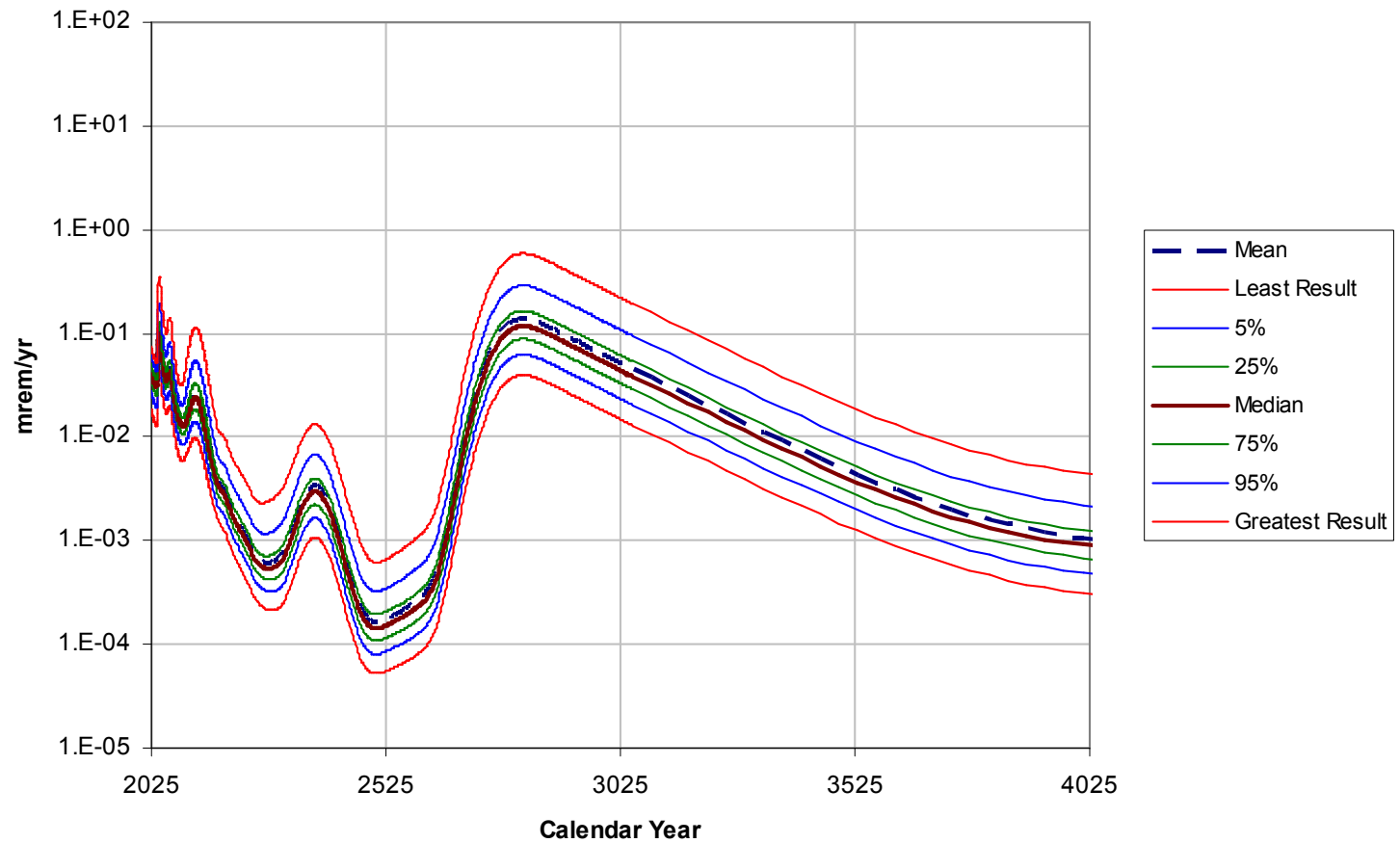

Figure 7.2-3. Uncertainty in dose at Savannah River POA from variation in dose parameters.

\section{SR Dose 1000 Realizations}

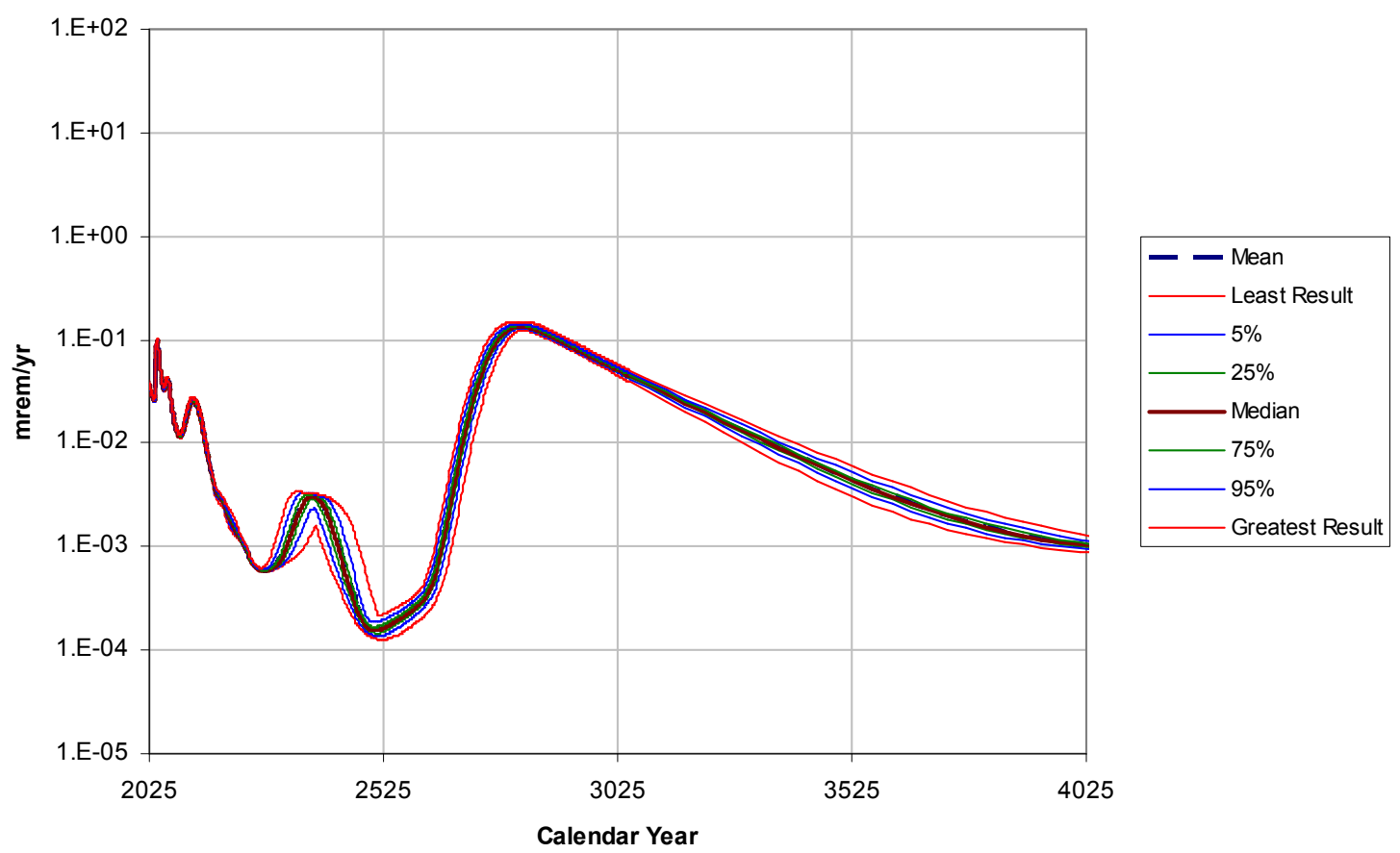

Figure 7.2-4. Uncertainty in dose at Savannah River POA from variation in material properties. 
SRNL-STI-2011-00365, Rev. 0

SR Dose 1000 Realizations

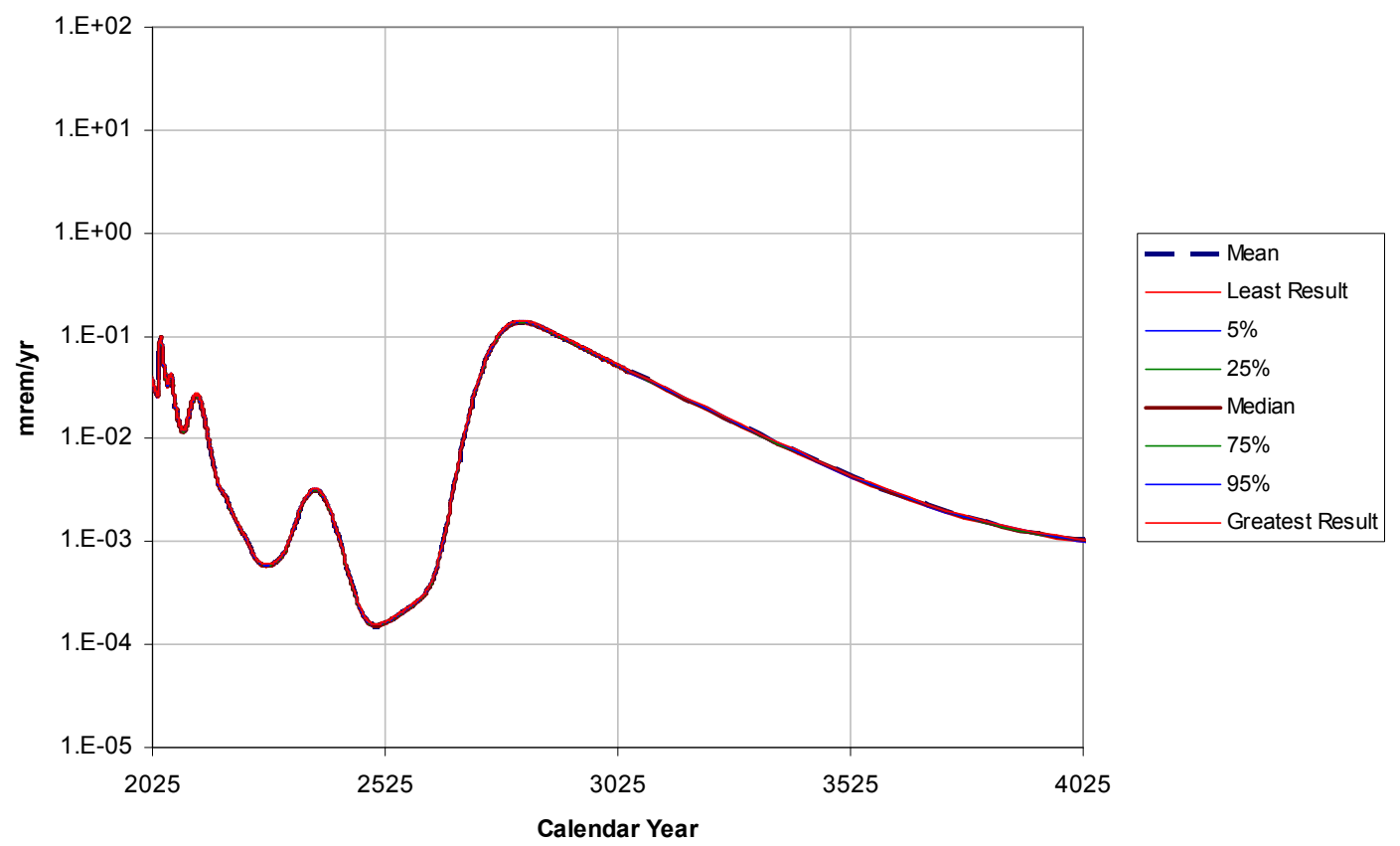

Figure 7.2-5. Uncertainty in dose at Savannah River POA from variation in surface water flow.

SR Dose 1000 Realizations

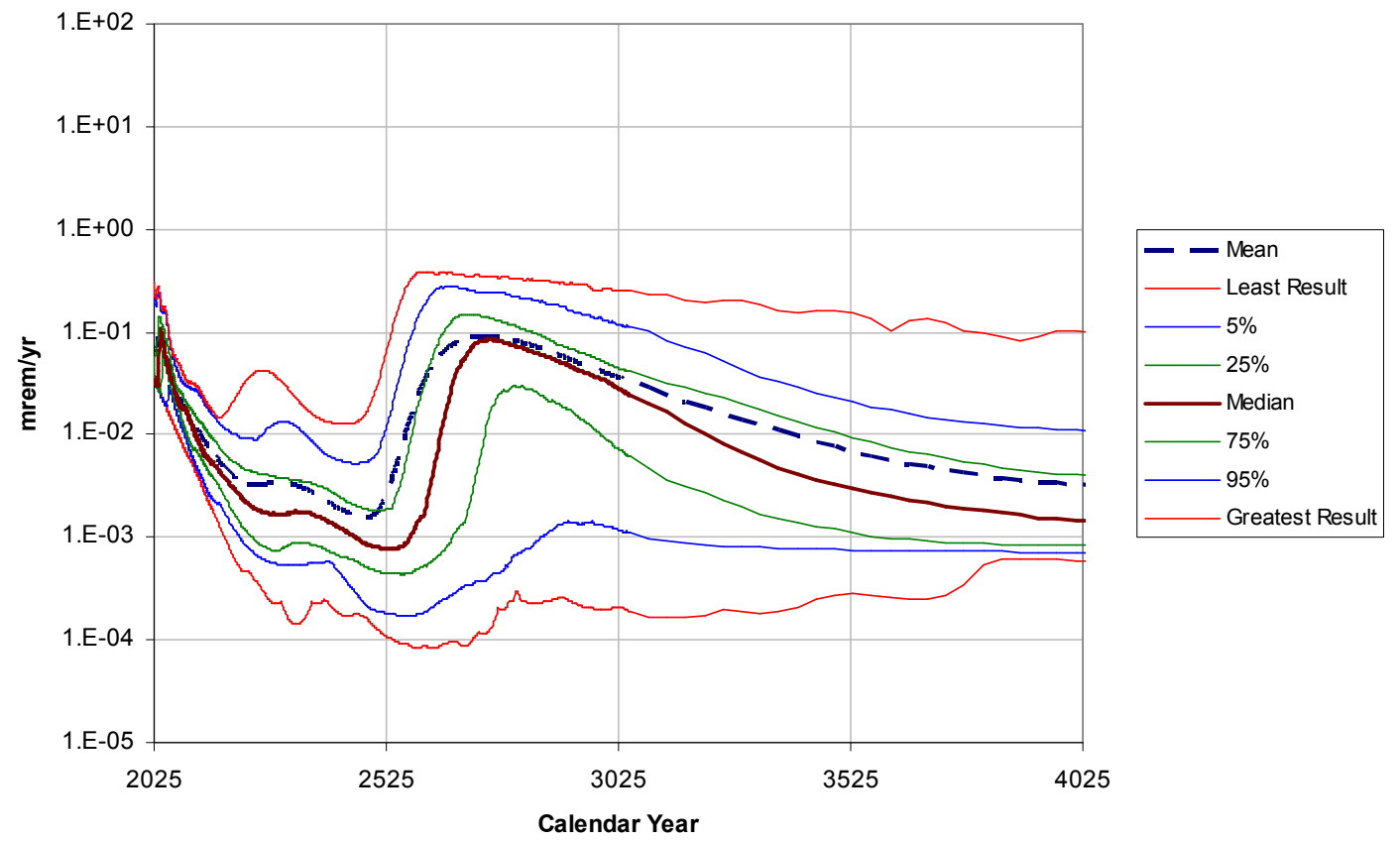

Figure 7.2-6. Uncertainty in dose at Savannah River POA from variation in infiltration and aquifer flow. 


\subsection{Dose Uncertainty at Fourmile Branch POA}

FMB Dose 1000 Realizations

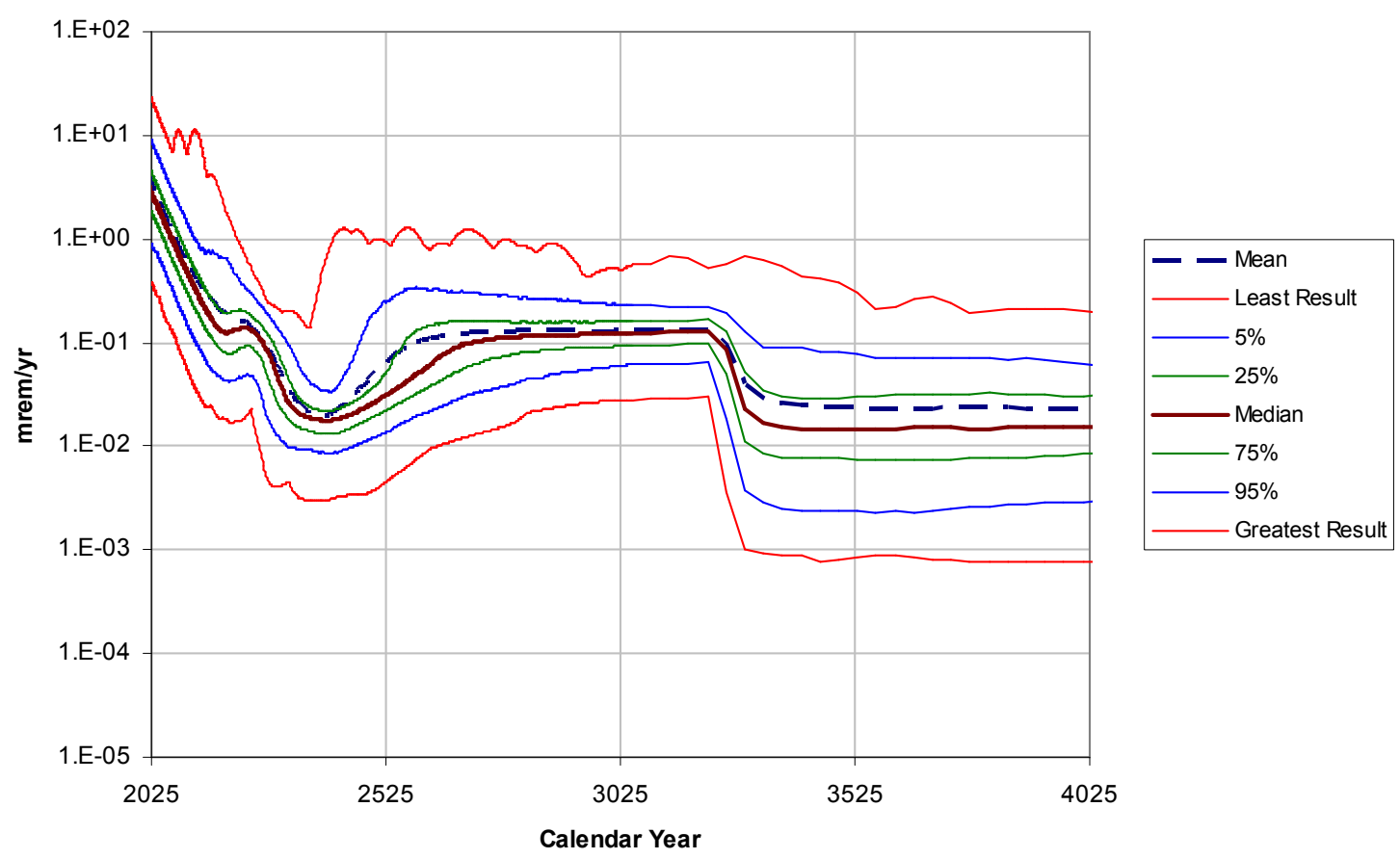

Figure 7.3-1. Overall uncertainty in dose at Fourmile Branch POA.

FMB Dose 1000 Realizations

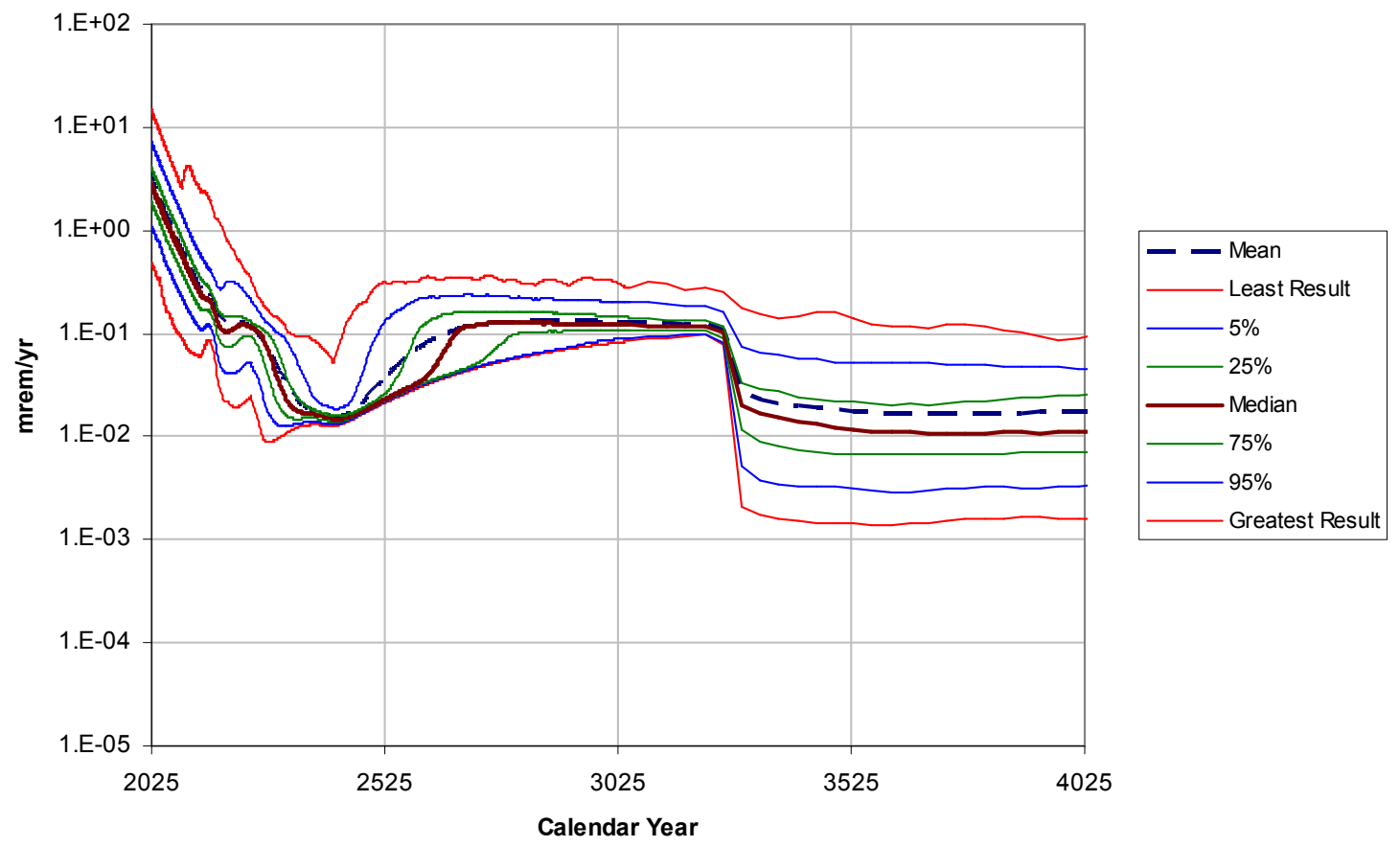

Figure 7.3-2. Uncertainty in dose at Fourmile Branch POA from variation in $\mathrm{K}_{\mathrm{d}}$. 
FMB Dose 1000 Realizations

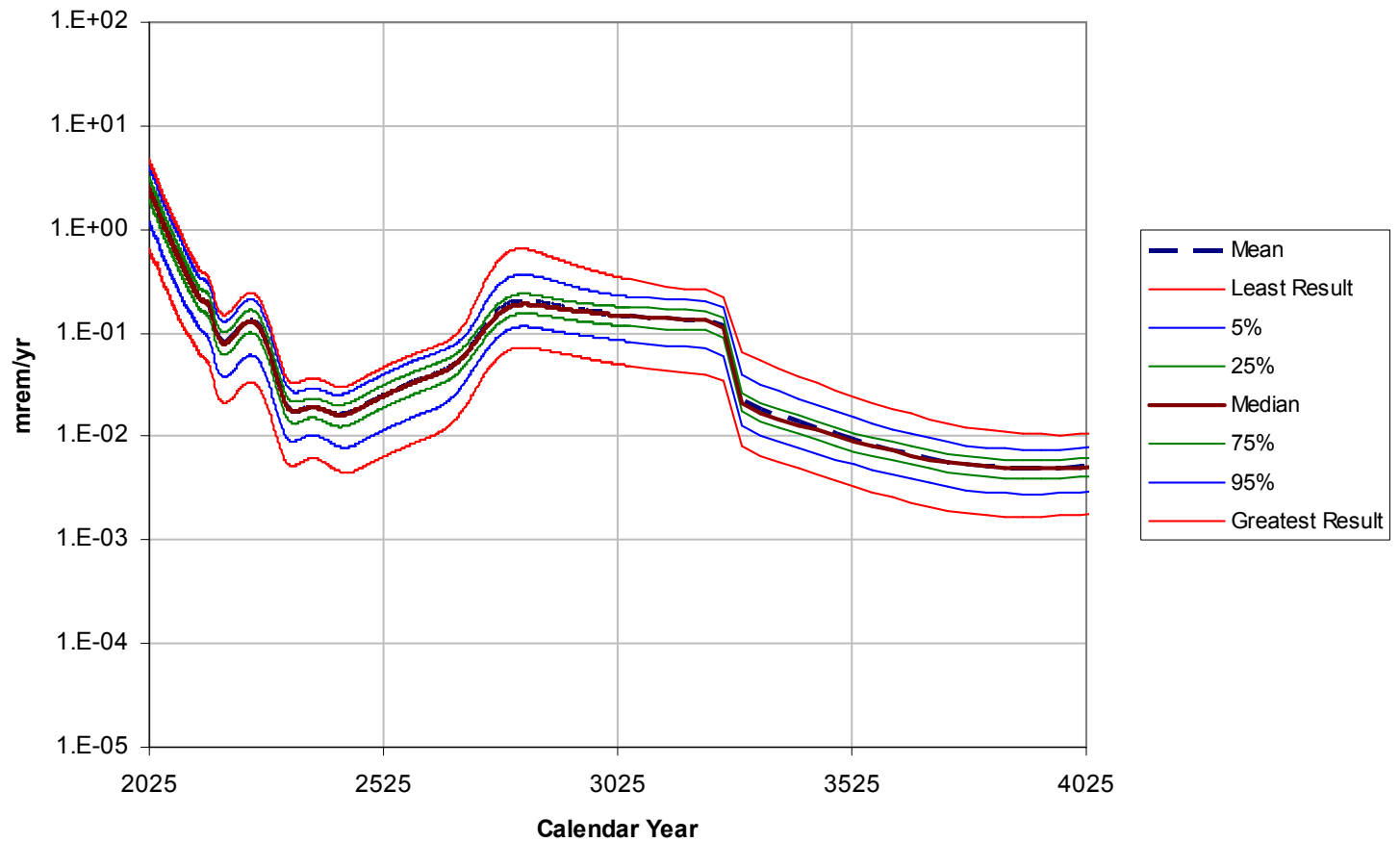

Figure 7.3-3. Uncertainty in dose at Fourmile Branch POA from variation in dose parameters.

FMB Dose 1000 Realizations

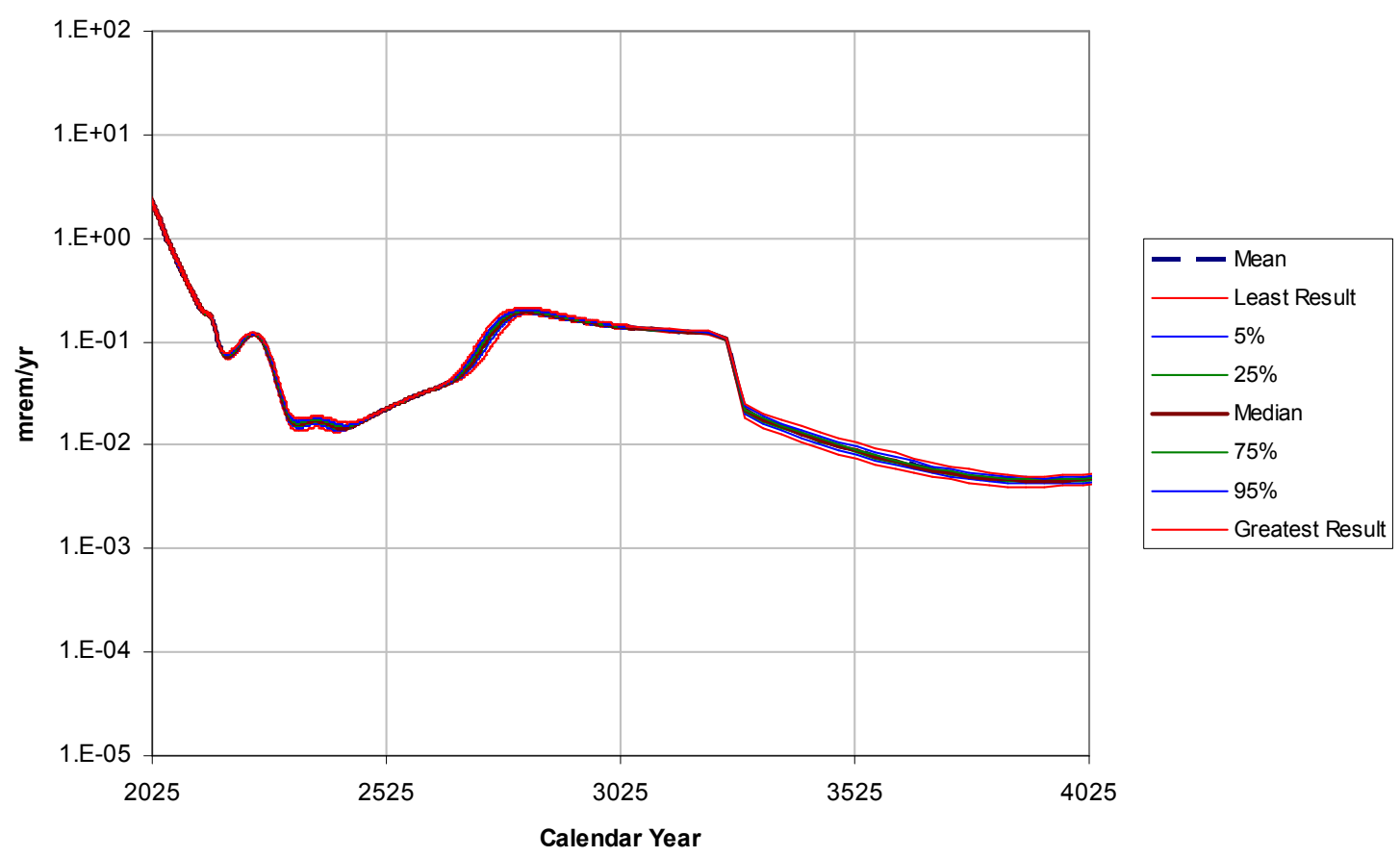

Figure 7.3-4. Uncertainty in dose at Fourmile Branch POA from variation in material properties. 
FMB Dose 1000 Realizations

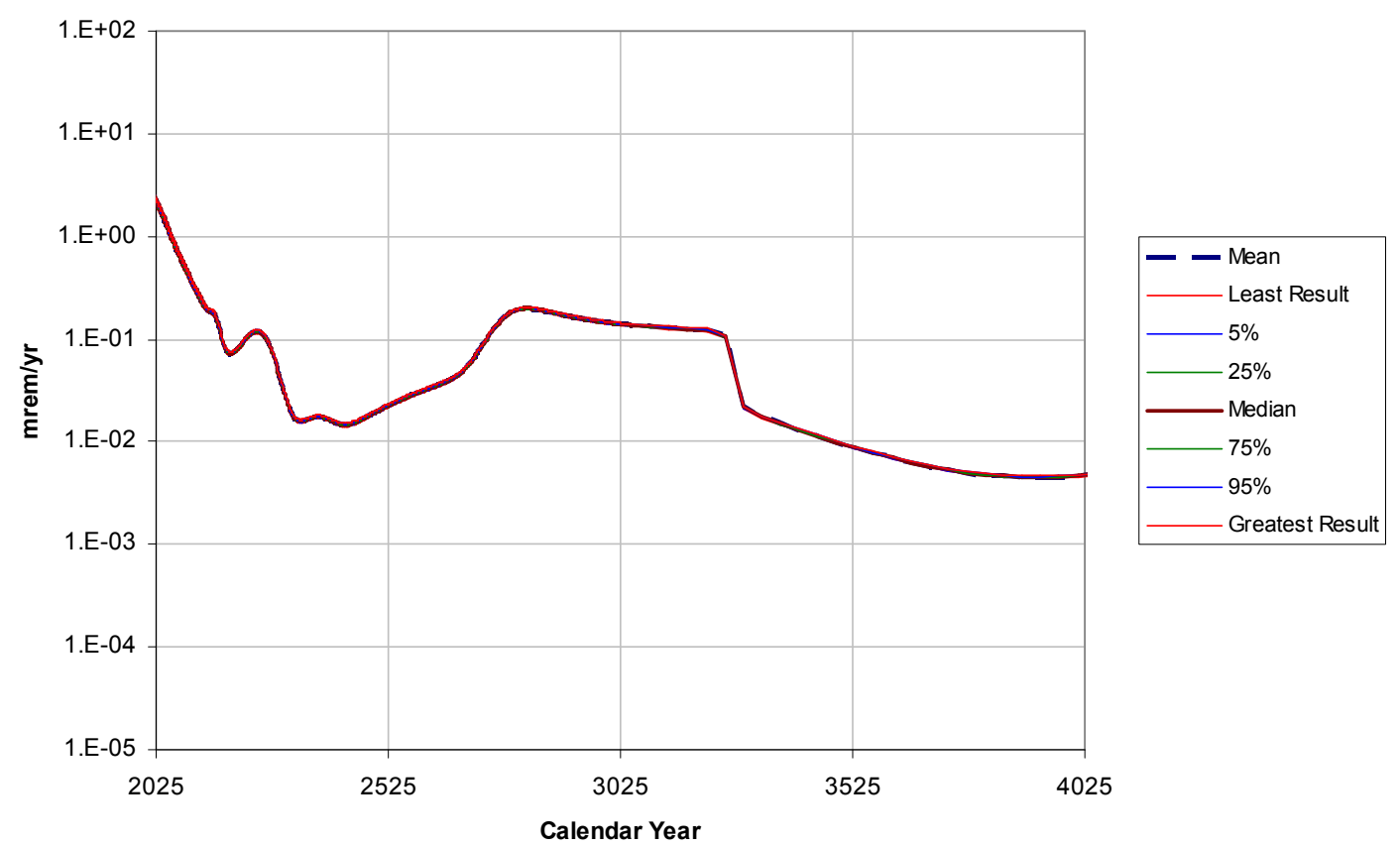

Figure 7.3-5. Uncertainty in dose at Fourmile Branch POA from variation in surface water flow.

FMB Dose 1000 Realizations

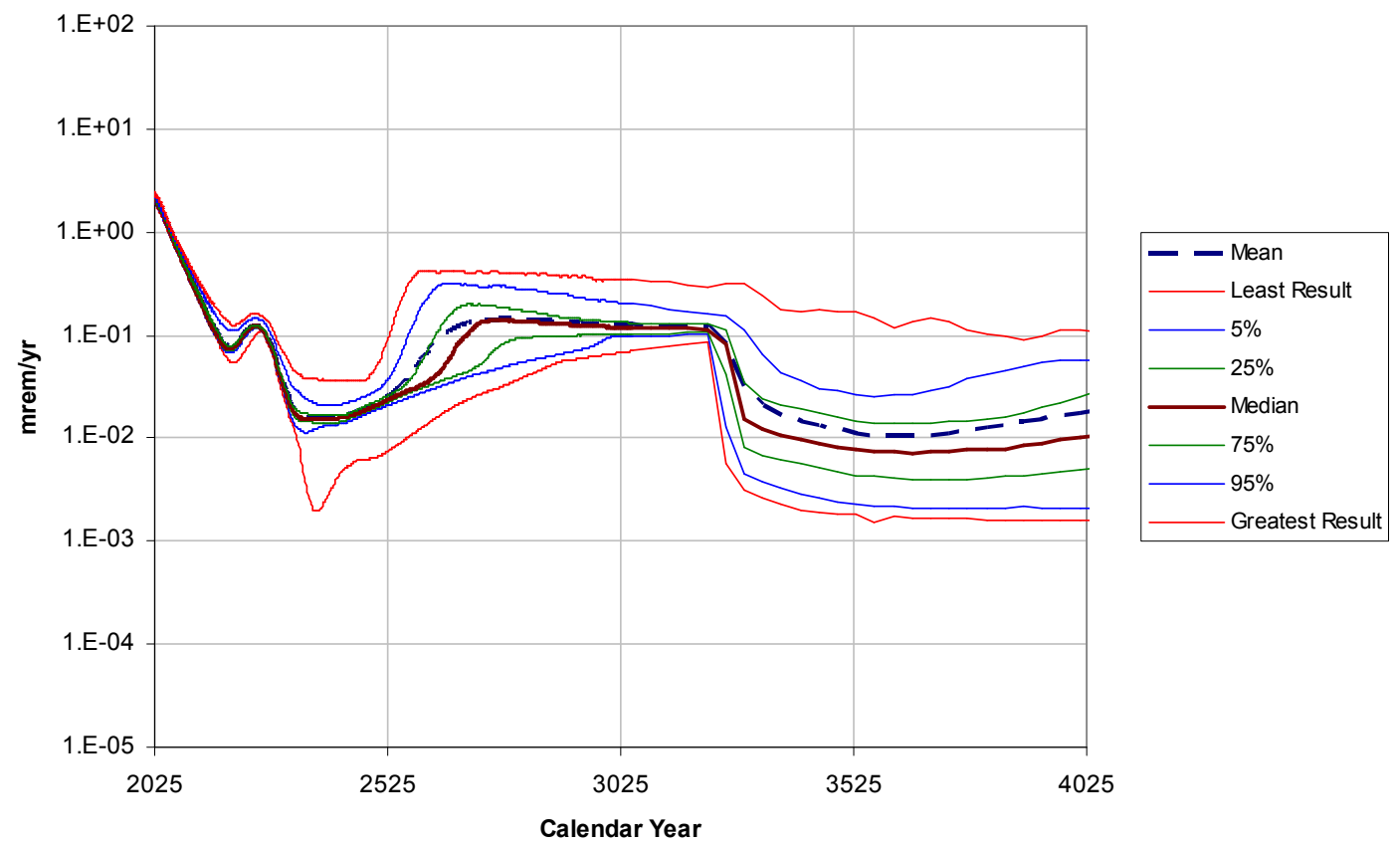

Figure 7.3-6. Uncertainty in dose at Fourmile Branch POA from variation in infiltration and aquifer flow. 
SRNL-STI-2011-00365, Rev. 0

\subsection{Dose Uncertainty at Steel Creek/Pen Branch POA}

SC Dose 1000 Realizations

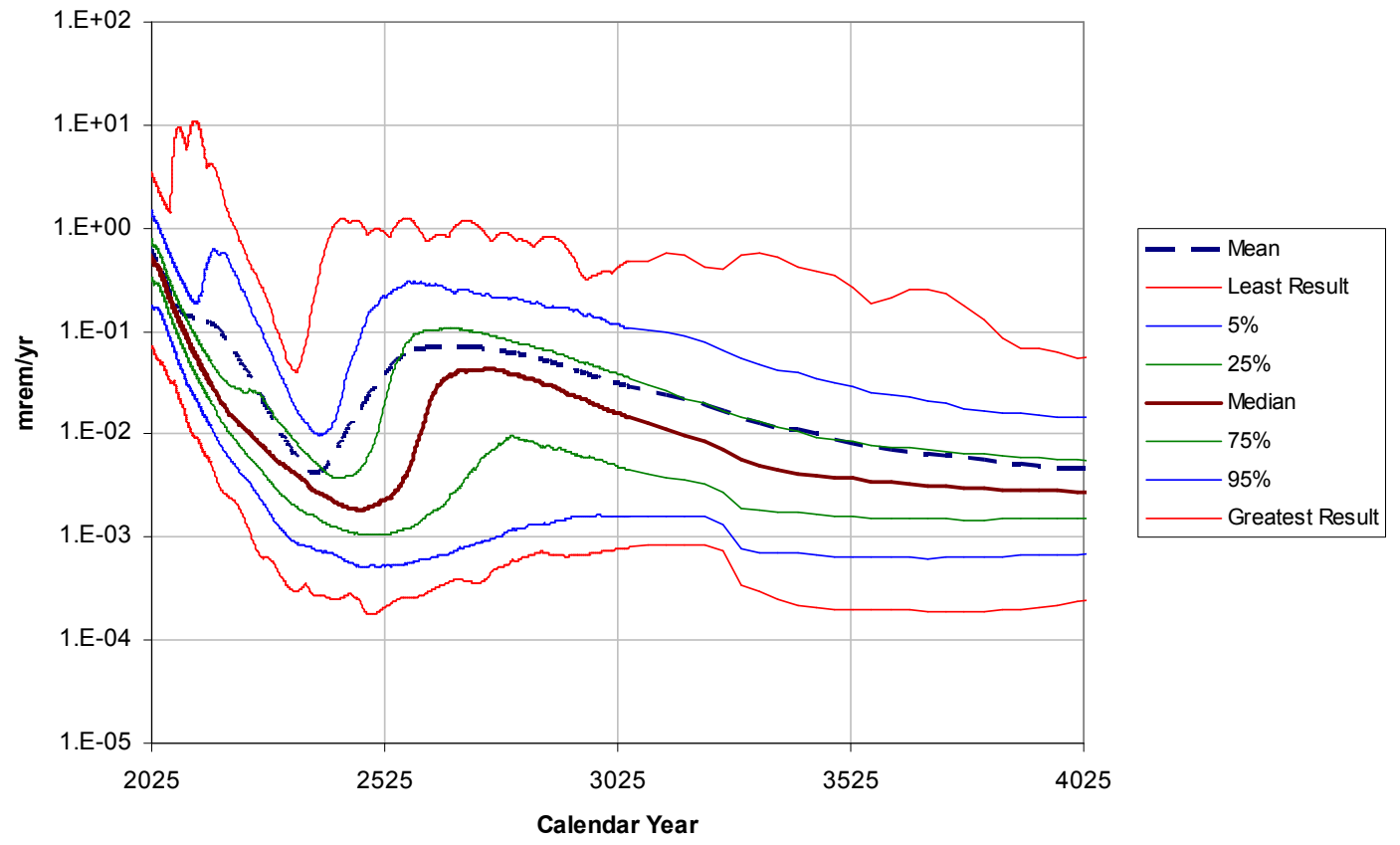

Figure 7.4-1. Overall uncertainty in dose at Steel Creek/Pen Branch POA.

\section{SC Dose 1000 Realizations}

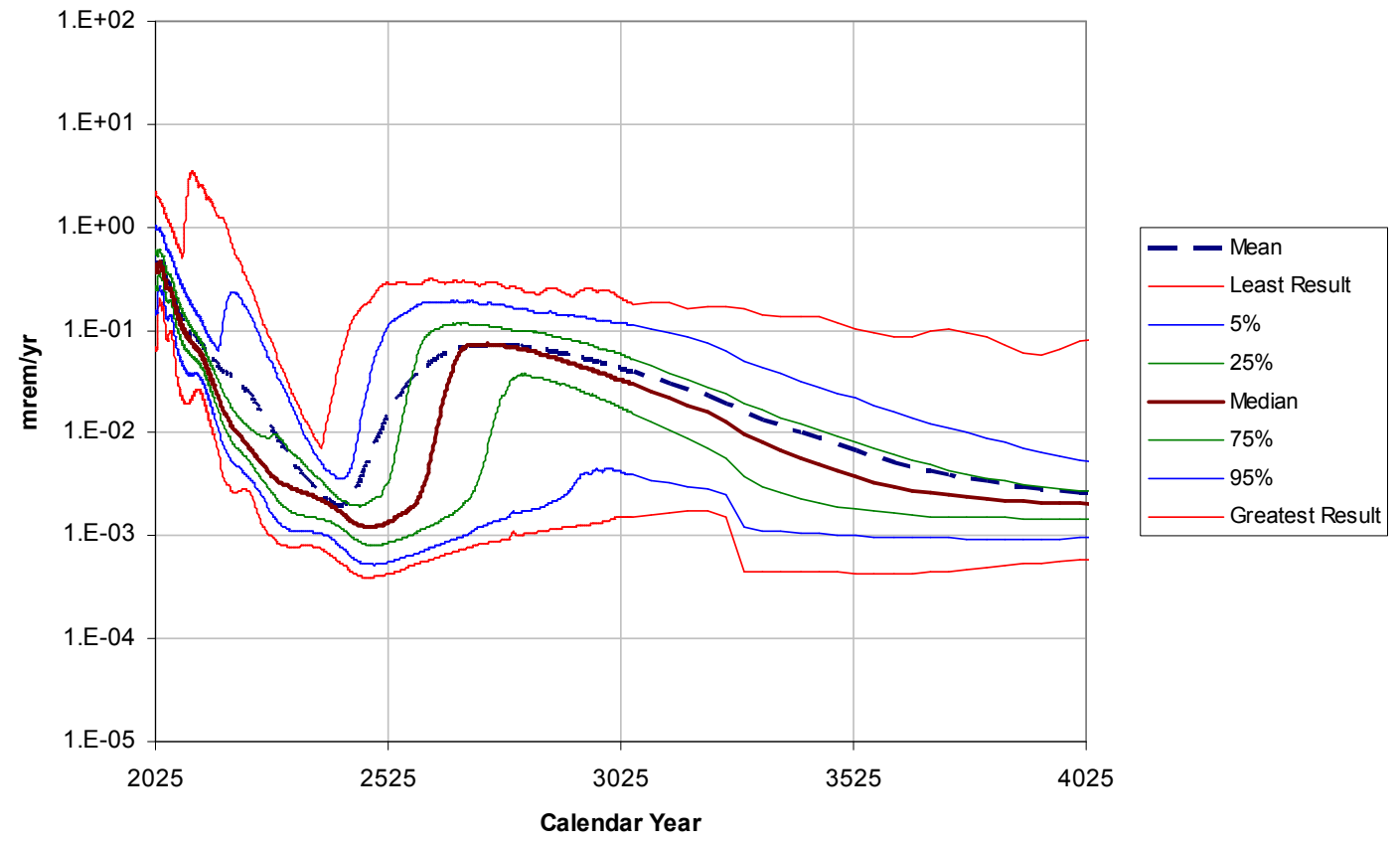

Figure 7.4-2. Uncertainty in dose at Steel Creek/Pen Branch POA from variation in $\mathrm{K}_{\mathrm{d}}$. 
SRNL-STI-2011-00365, Rev. 0

SC Dose 1000 Realizations

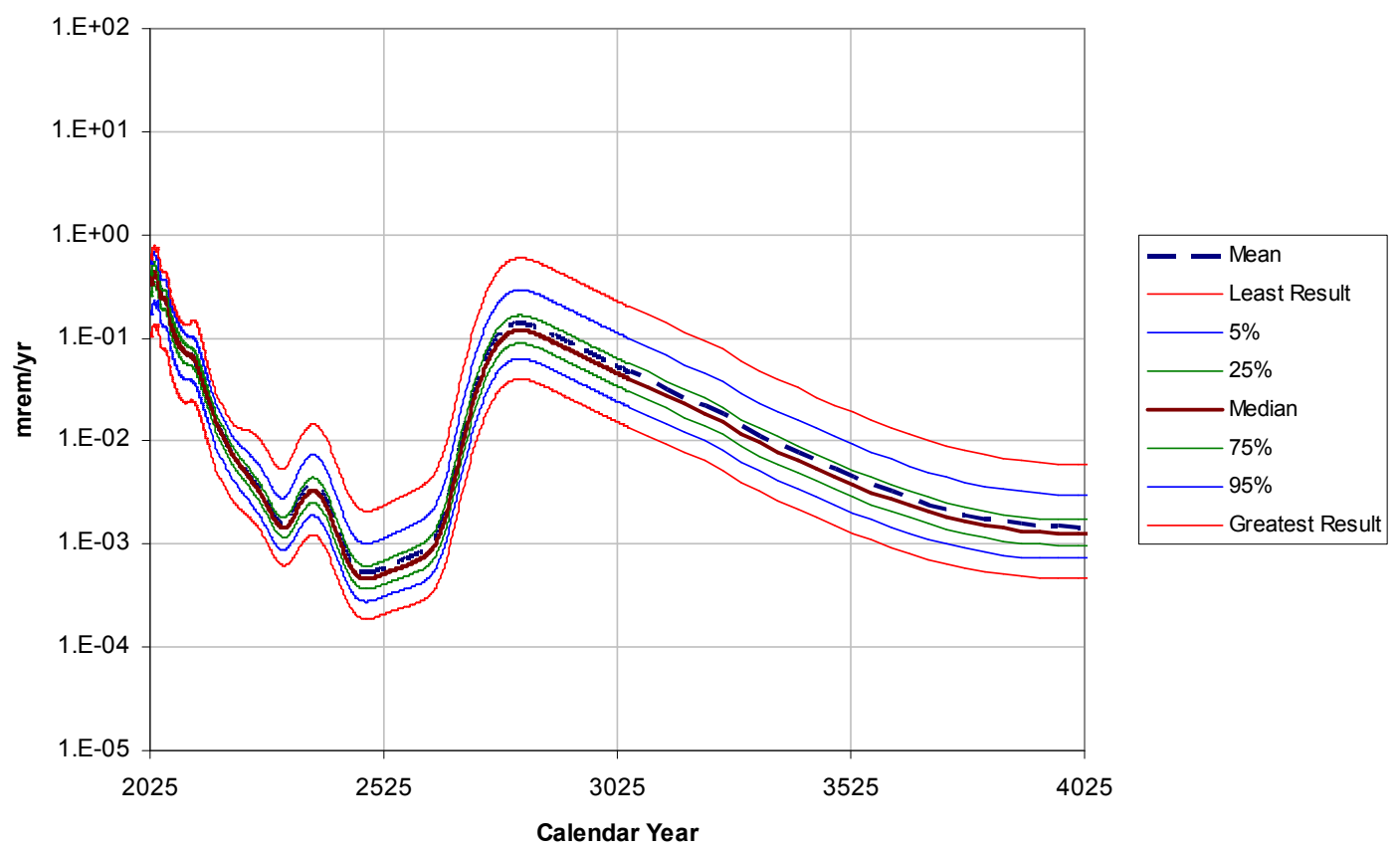

Figure 7.4-3. Uncertainty in dose at Steel Creek/Pen Branch POA from variation in dose parameters.

SC Dose 1000 Realizations

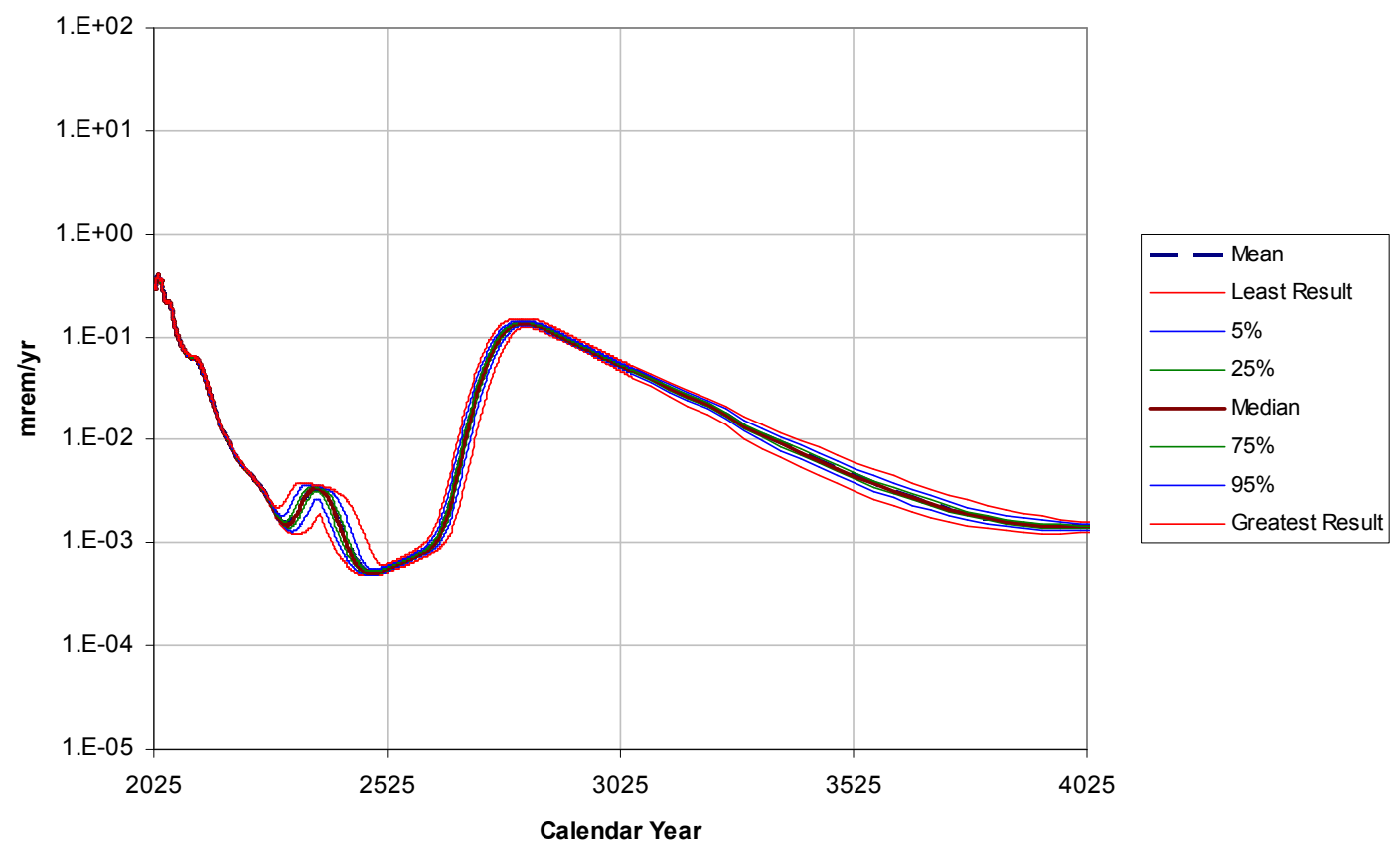

Figure 7.4-4. Uncertainty in dose at Steel Creek/Pen Branch POA from variation in material properties. 
SRNL-STI-2011-00365, Rev. 0

SC Dose 1000 Realizations

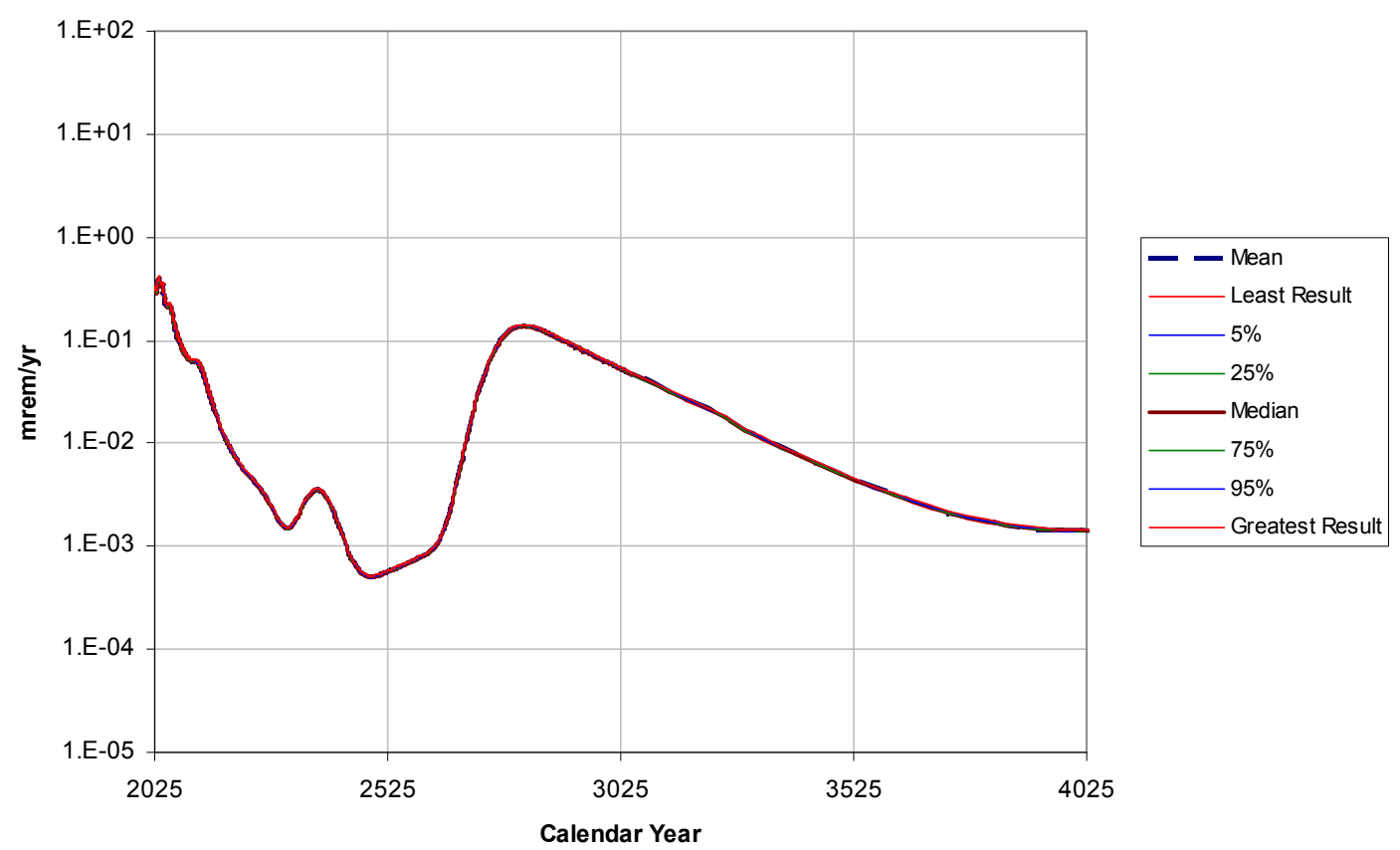

Figure 7.4-5. Uncertainty in dose at Steel Creek/Pen Branch POA from variation in surface water flow.

SC Dose 1000 Realizations

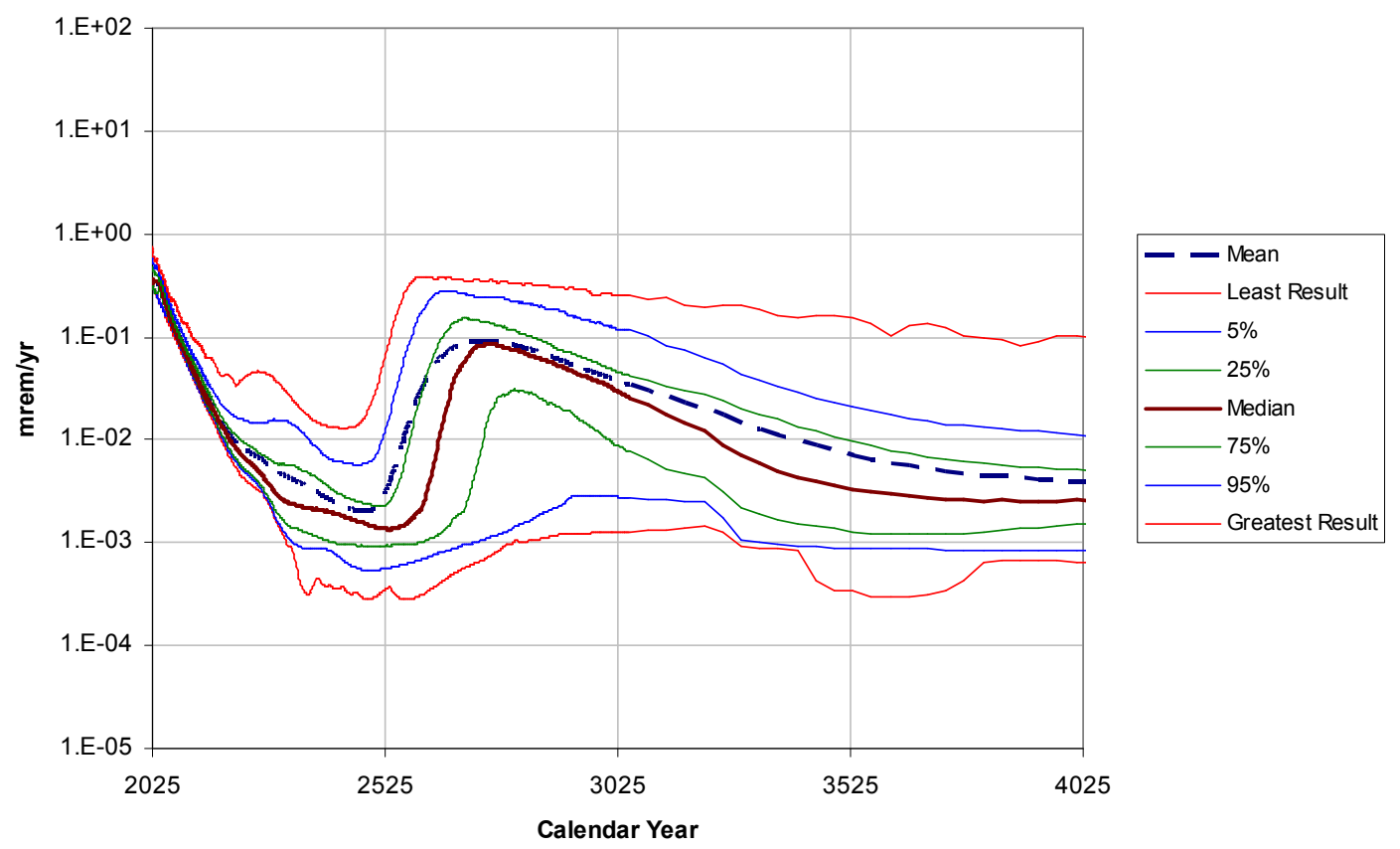

Figure 7.4-6. Uncertainty in dose at Steel Creek/Pen Branch POA from variation in infiltration and aquifer flow. 
SRNL-STI-2011-00365, Rev. 0

\subsection{Dose Uncertainty at Lower Three Runs POA}

LTR Dose 1000 Realizations

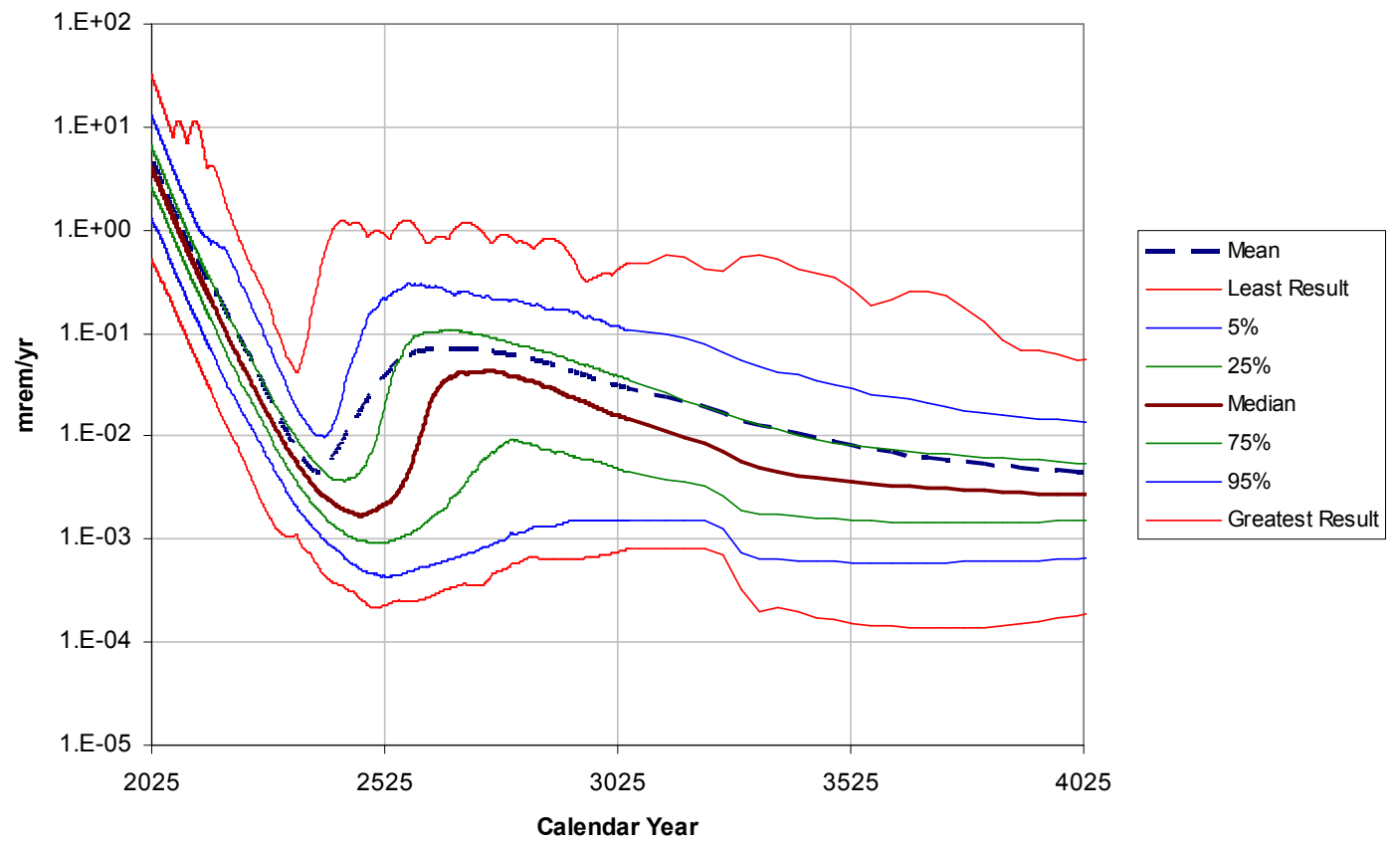

Figure 7.5-1. Overall uncertainty in dose at Lower Three Runs POA.

\section{LTR Dose 1000 Realizations}

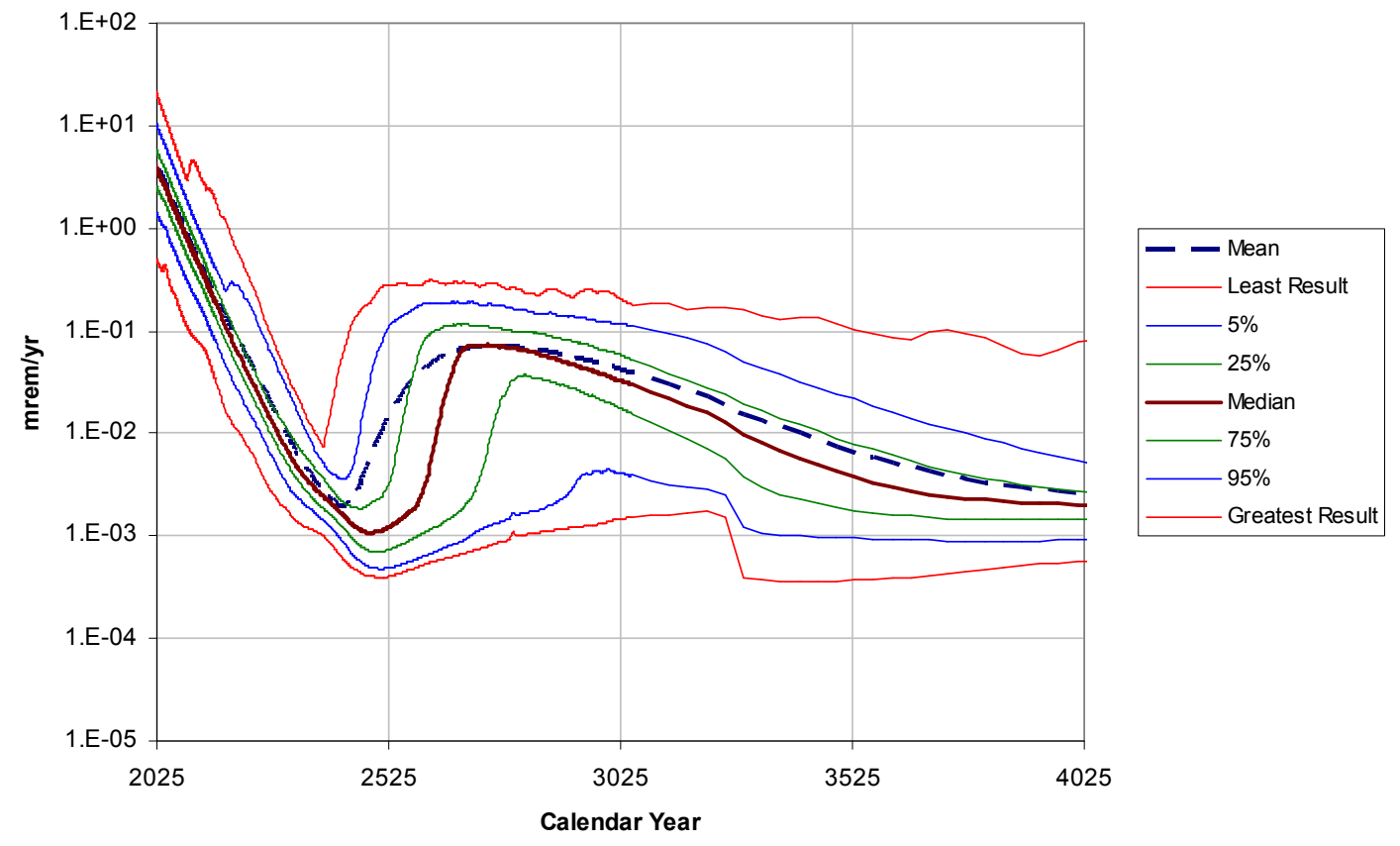

Figure 7.5-2. Uncertainty in dose at Lower Three Runs POA from variation in $\mathrm{K}_{\mathrm{d}}$. 
SRNL-STI-2011-00365, Rev. 0

\section{LTR Dose 1000 Realizations}

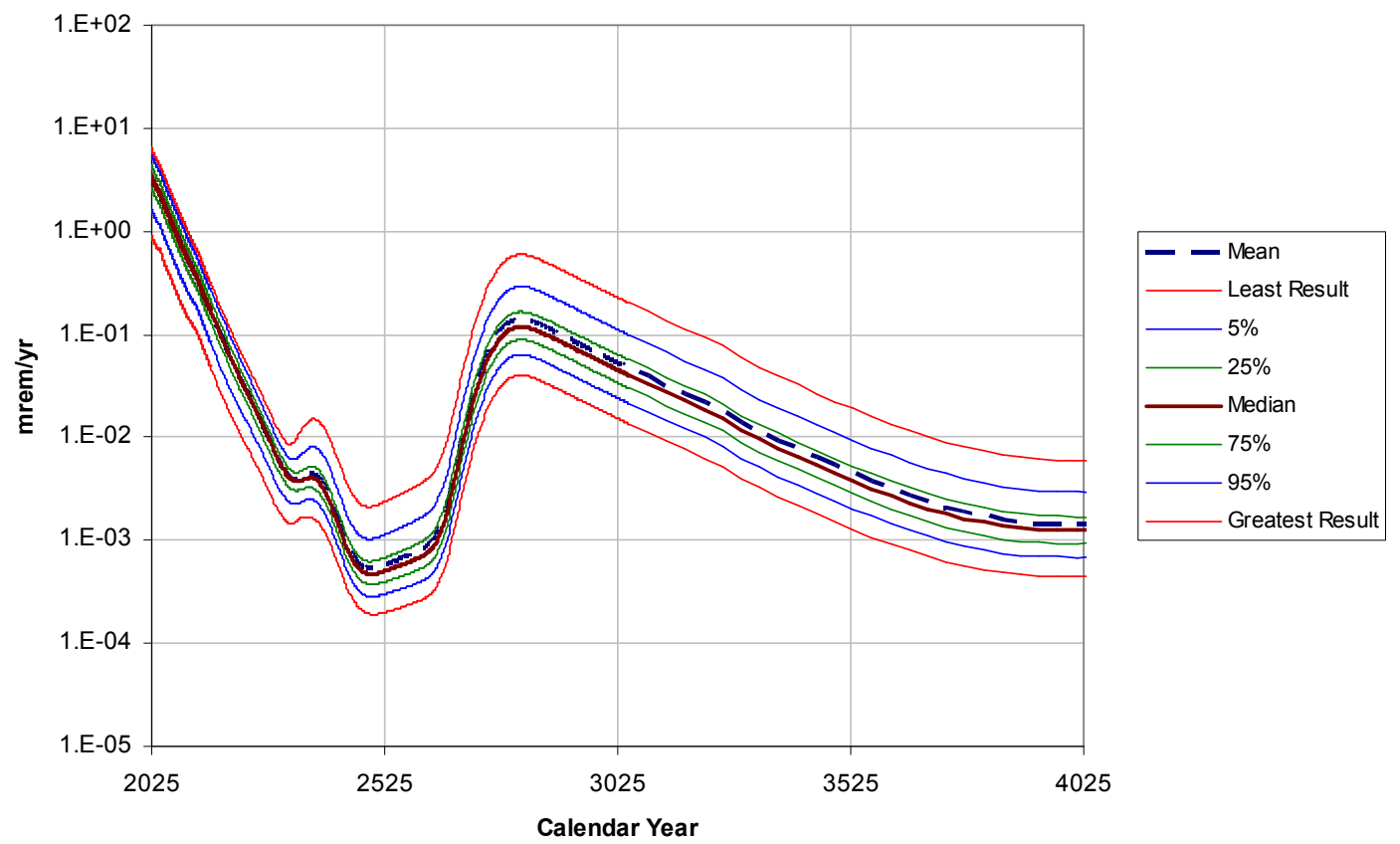

Figure 7.5-3. Uncertainty in dose at Lower Three Runs POA from variation in dose parameters.

LTR Dose 1000 Realizations

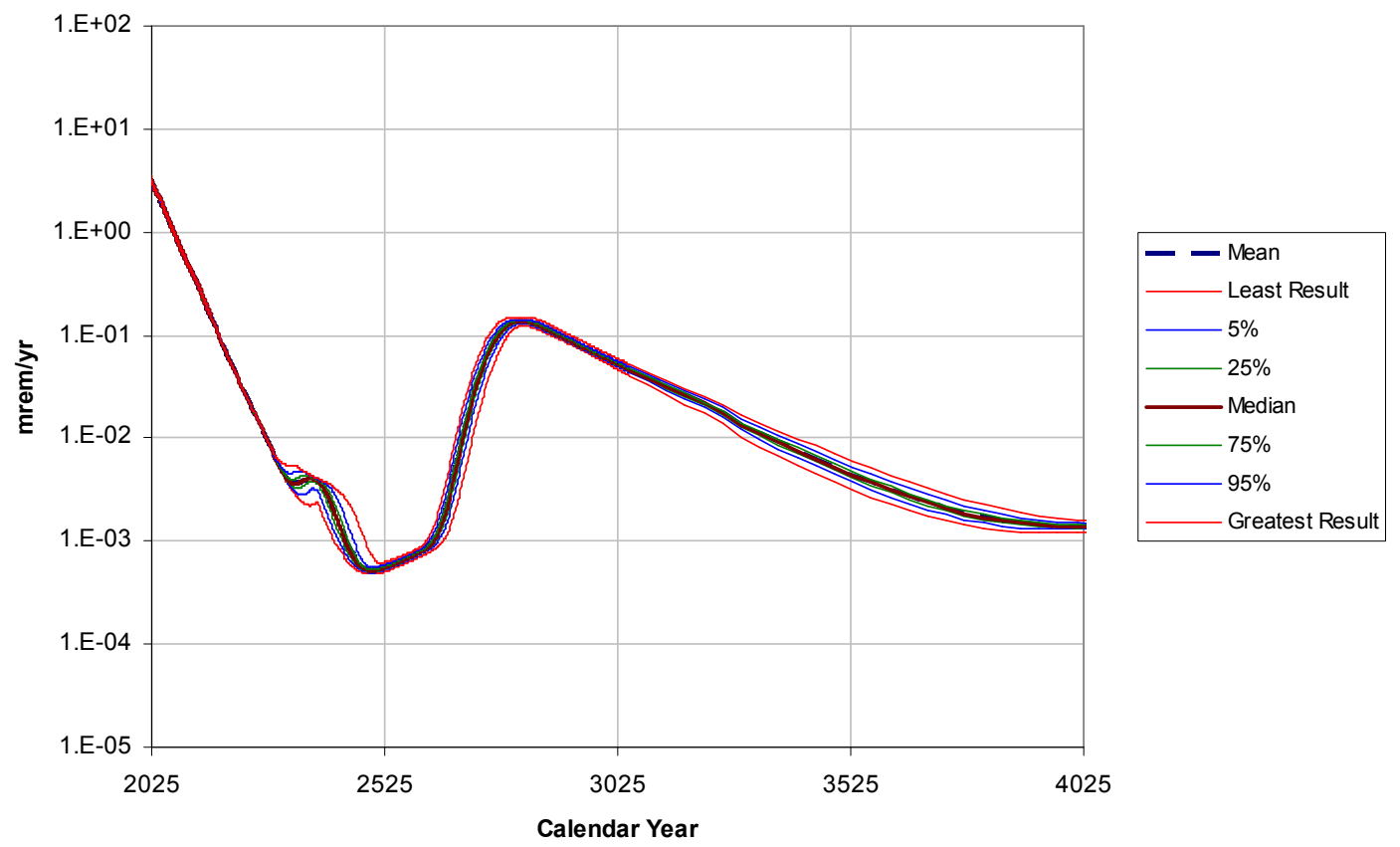

Figure 7.5-4. Uncertainty in dose at Lower Three Runs POA from variation in material properties. 


\section{LTR Dose 1000 Realizations}

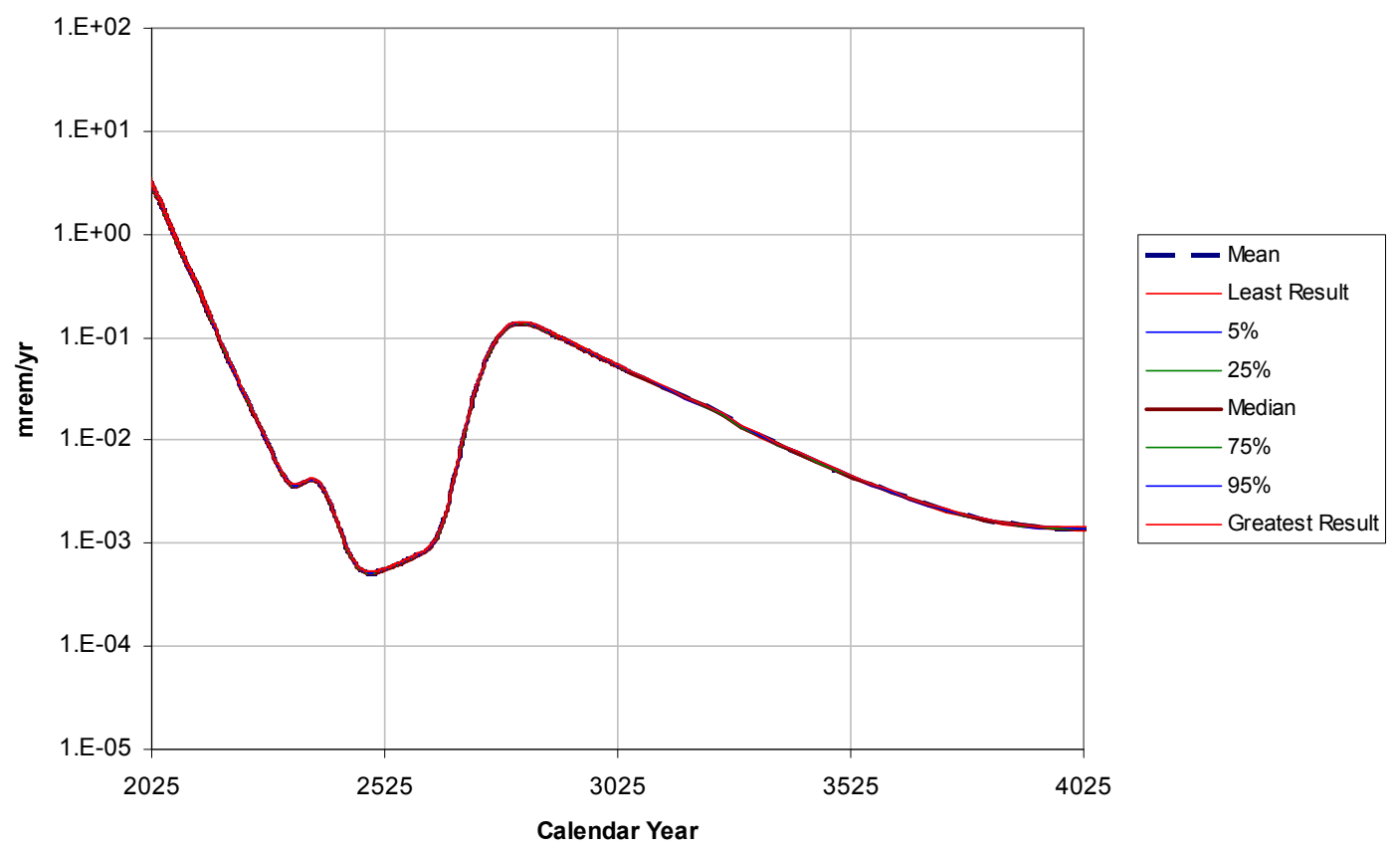

Figure 7.5-5. Uncertainty in dose at Lower Three Runs POA from variation in surface water flow.

\section{LTR Dose 1000 Realizations}

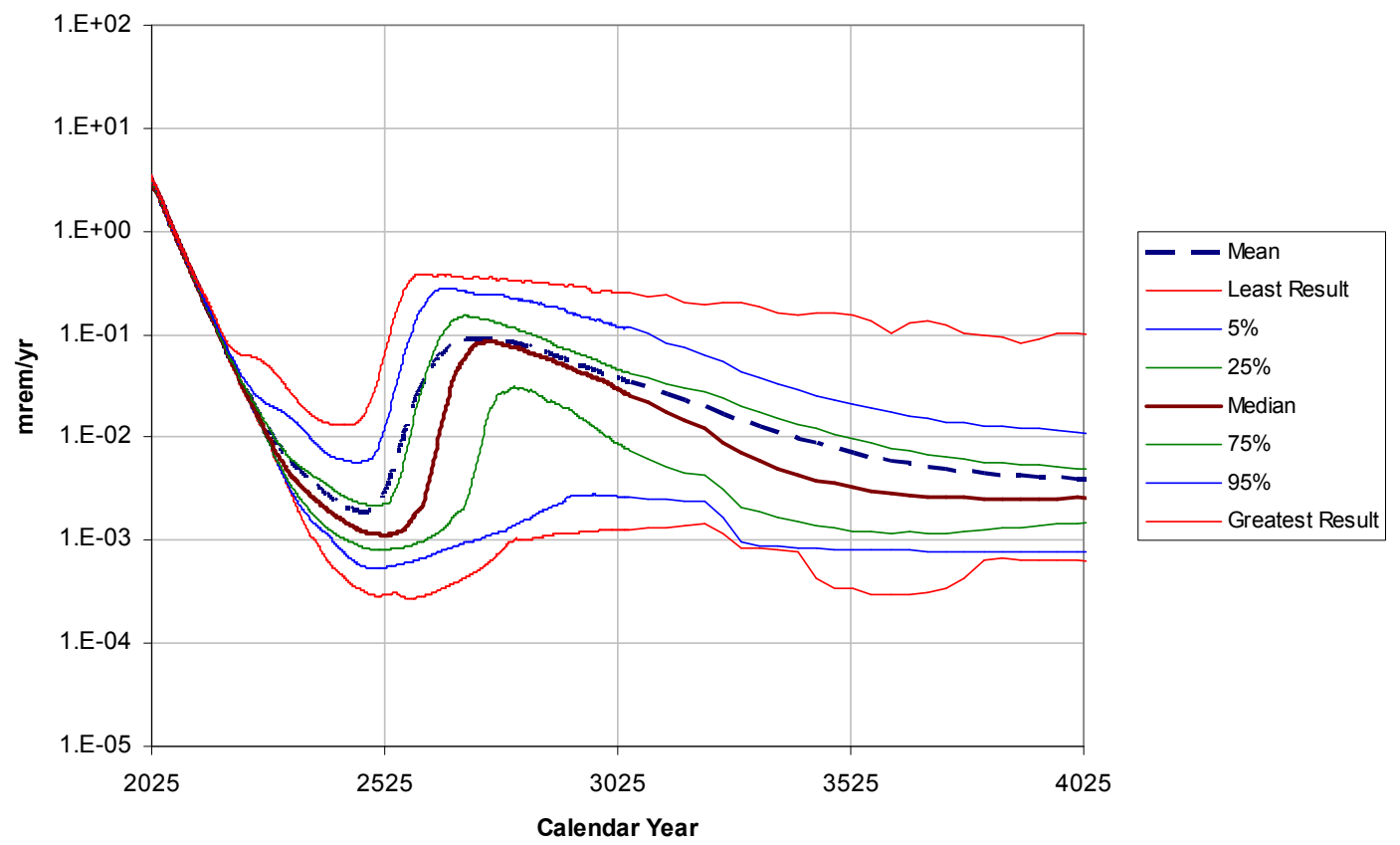

Figure 7.5-6. Uncertainty in dose at Lower Three Runs POA from variation in infiltration and aquifer flow. 


\subsection{Dose Uncertainty at 301 Bridge POA}

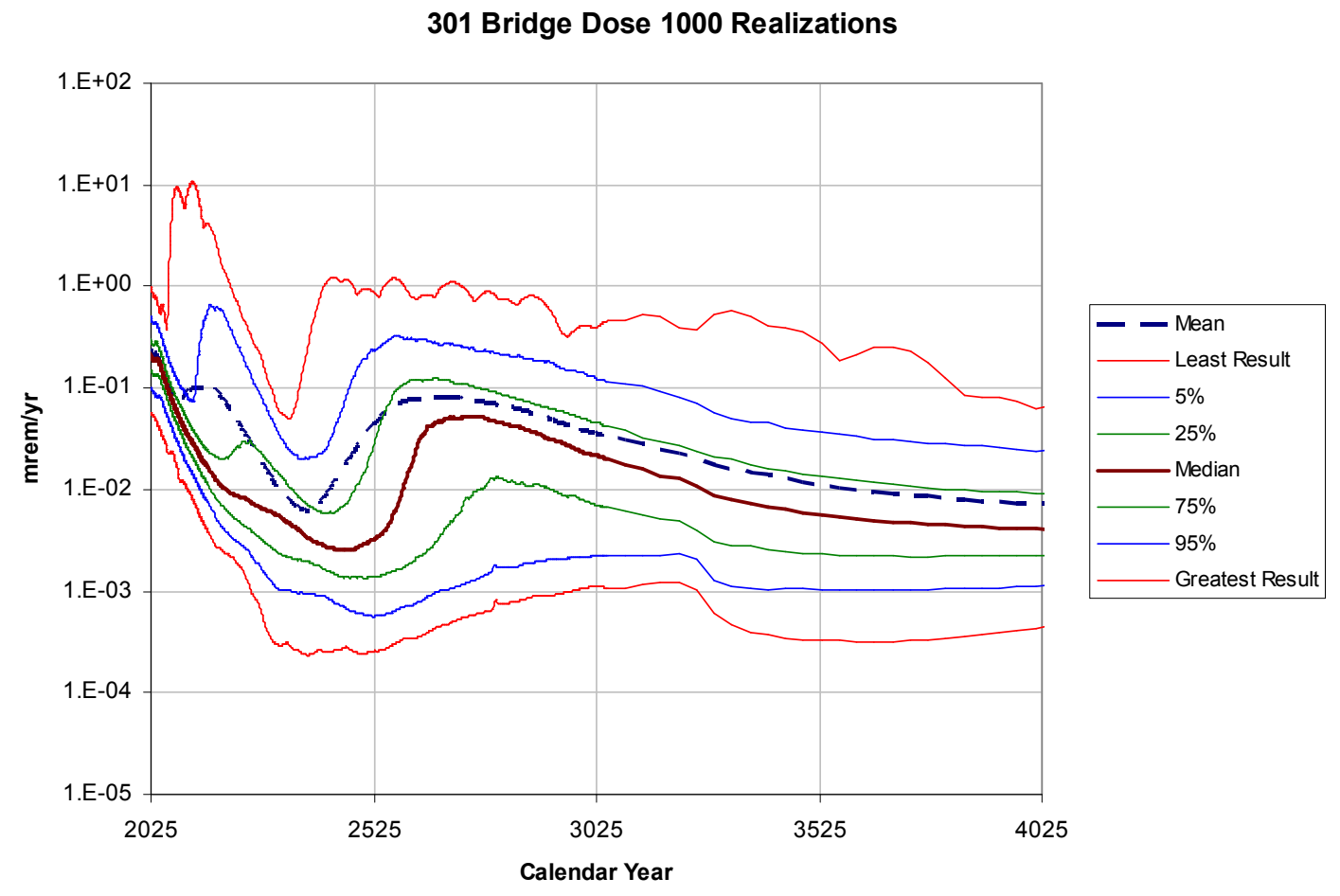

Figure 7.6-1. Overall uncertainty in dose at 301 Bridge POA.

\section{Bridge Dose 1000 Realizations}

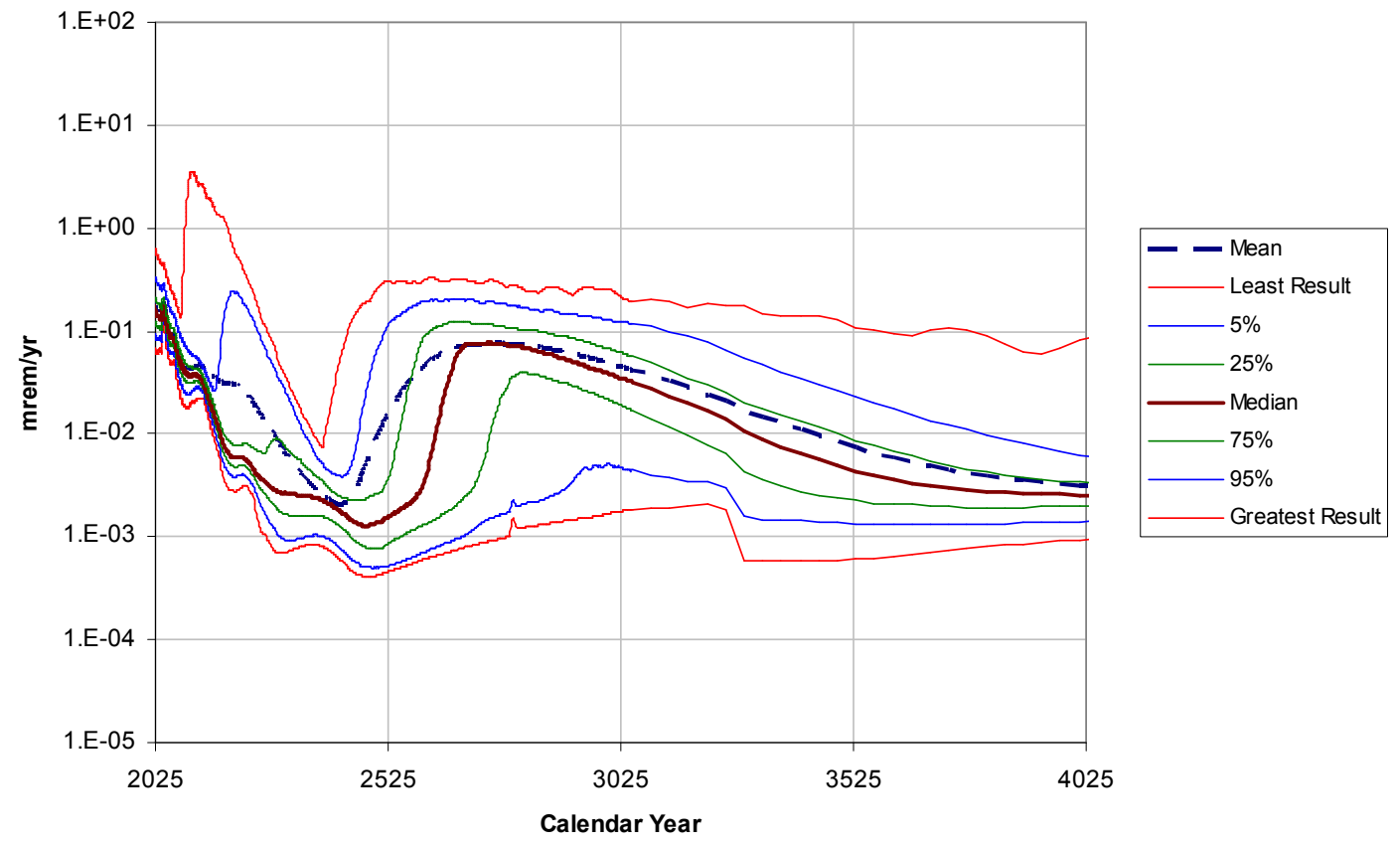

Figure 7.6-2. Uncertainty in dose at 301 Bridge POA from variation in $\mathrm{K}_{\mathrm{d}}$. 
SRNL-STI-2011-00365, Rev. 0

301 Bridge Dose 1000 Realizations

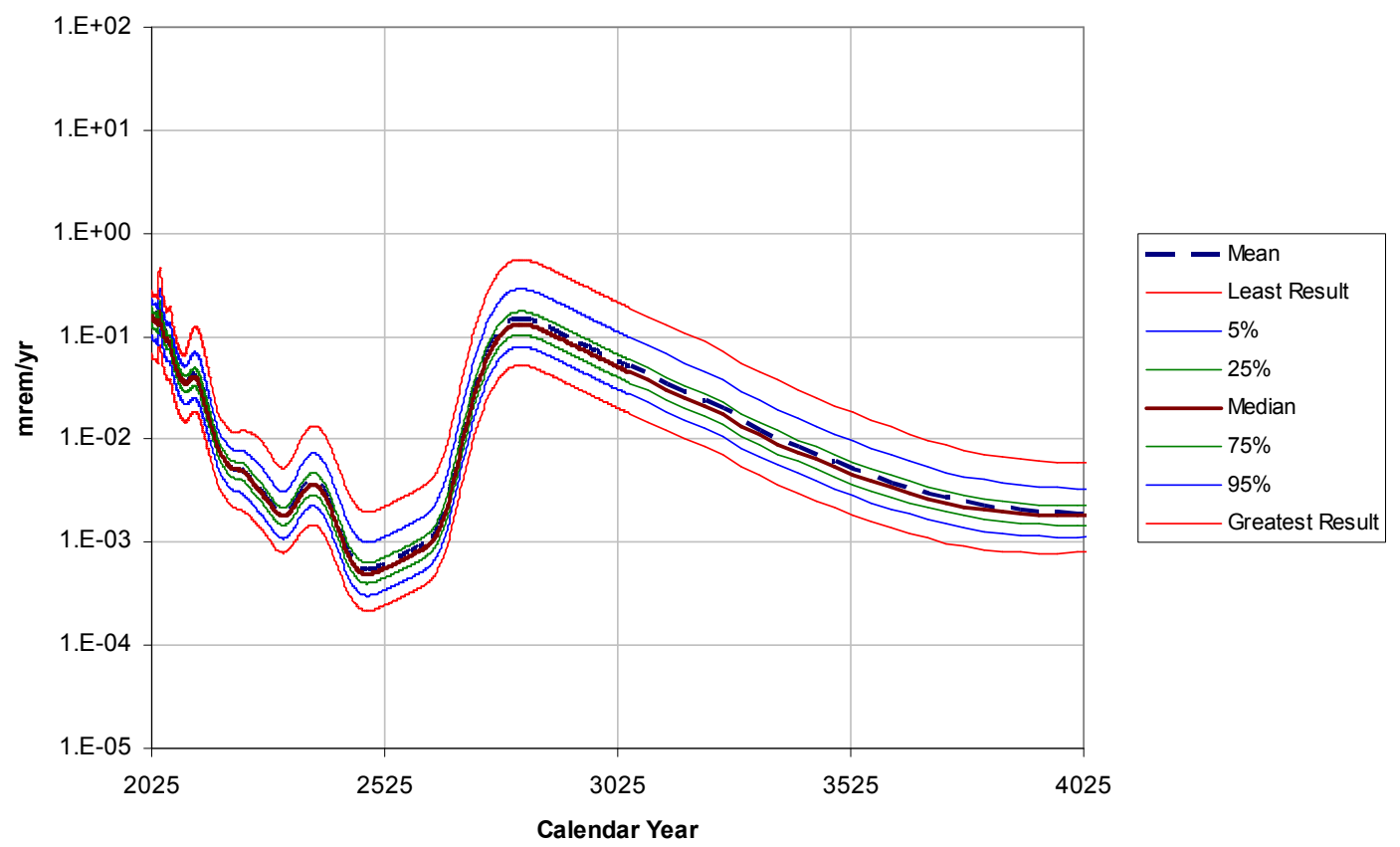

Figure 7.6-3. Uncertainty in dose at 301 Bridge POA from variation in dose parameters.

301 Bridge Dose 1000 Realizations

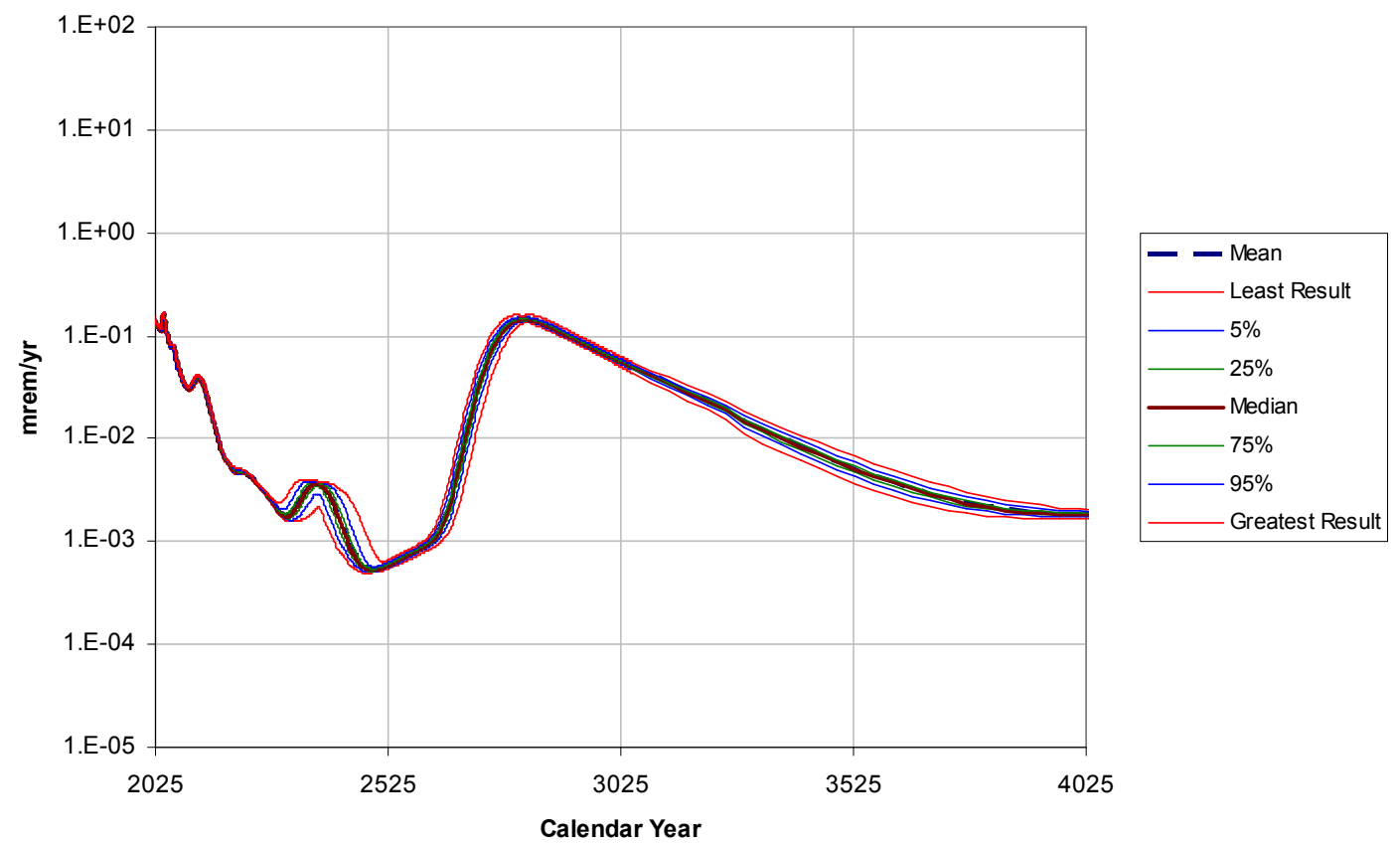

Figure 7.6-4. Uncertainty in dose at 301 Bridge POA from variation in material properties. 
SRNL-STI-2011-00365, Rev. 0

301 Bridge Dose 1000 Realizations

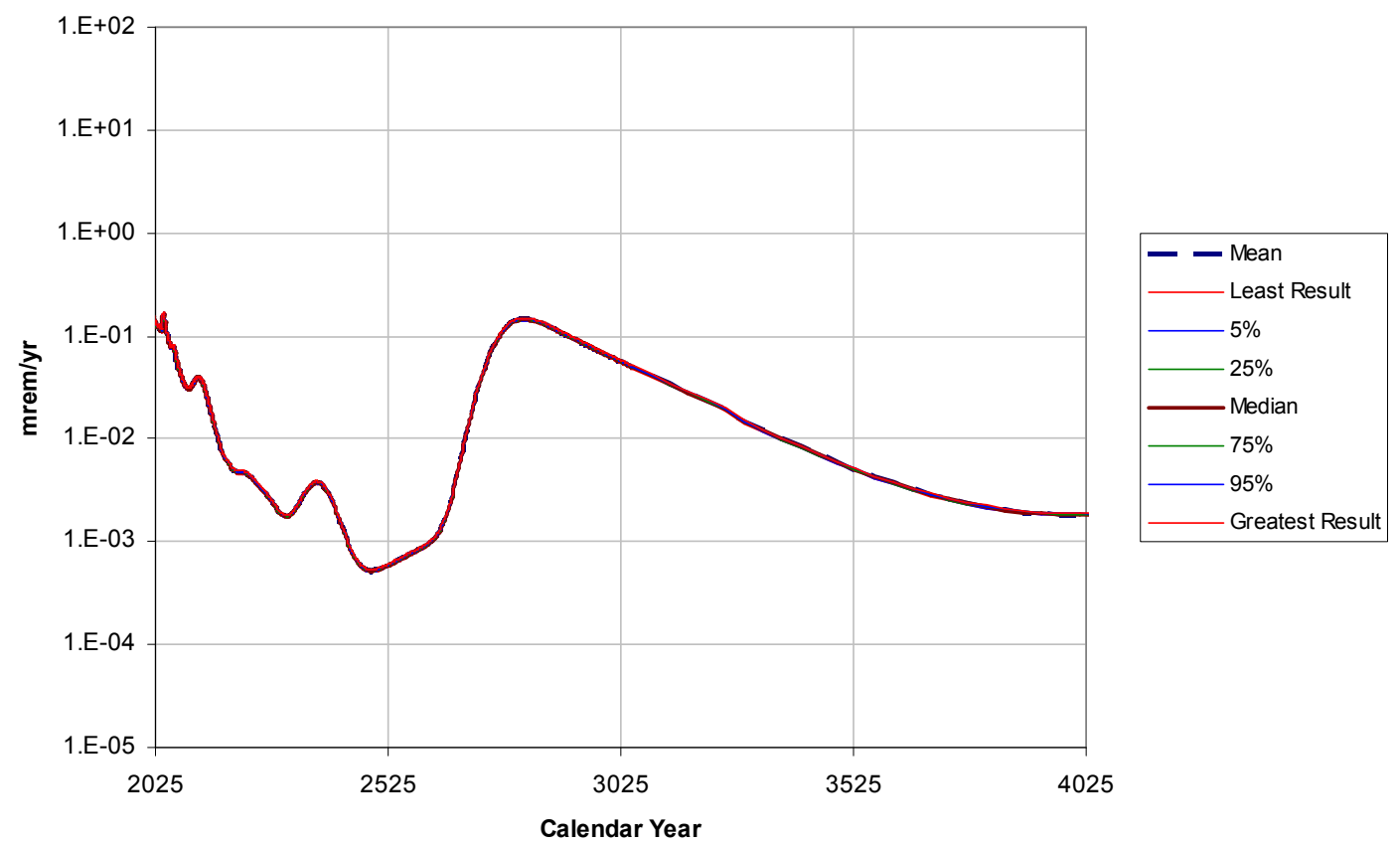

Figure 7.6-5. Uncertainty in dose at 301 Bridge POA from variation in surface water flow.

301 Bridge Dose 1000 Realizations

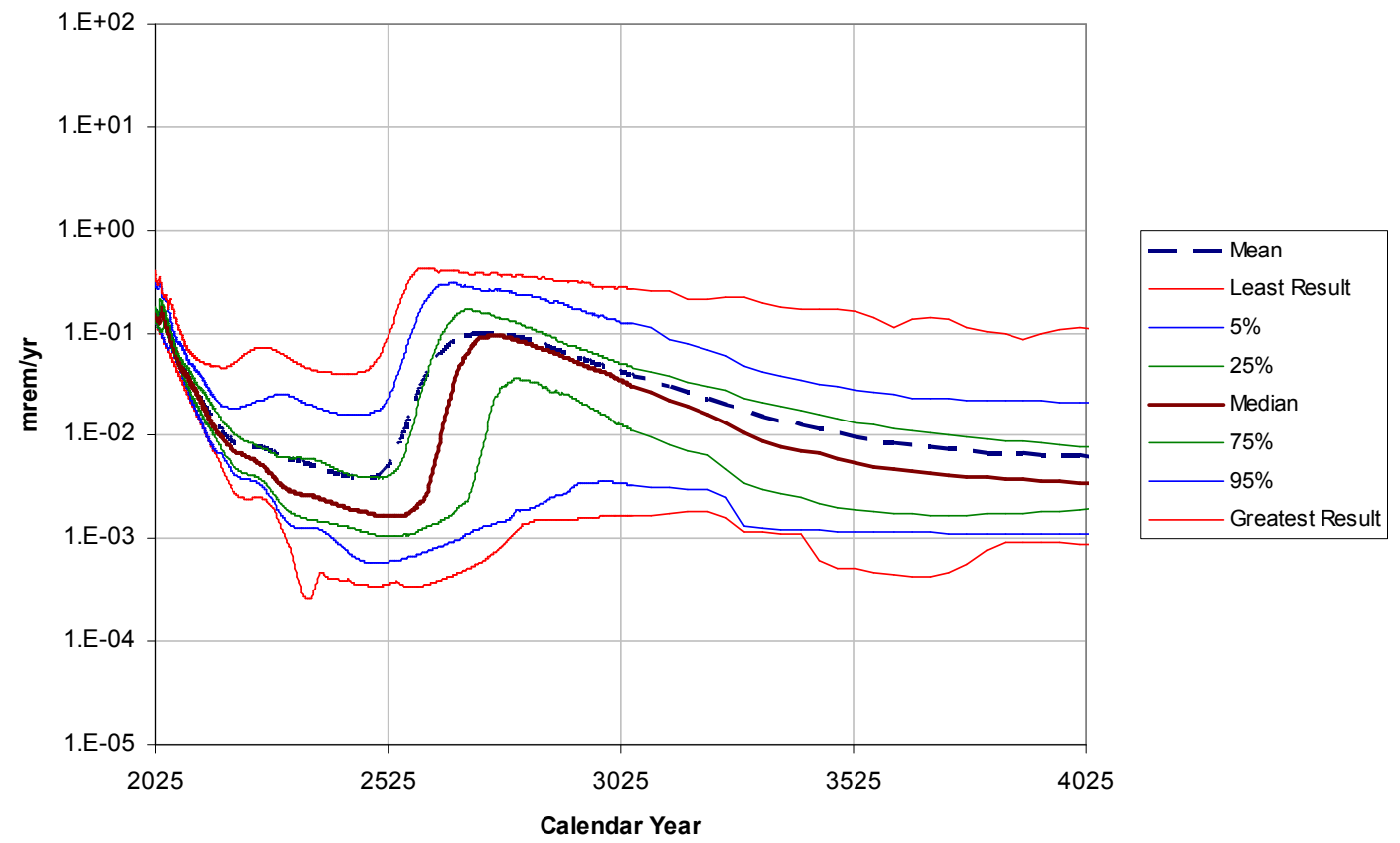

Figure 7.6-6. Uncertainty in dose at 301 Bridge POA from variation in infiltration and aquifer flow. 
SRNL-STI-2011-00365, Rev. 0

\subsection{Conclusions and Recommendations}

The GoldSim DP-Plus module in conjunction with dedicated servers providing up to 36 processors worked smoothly. A simulation modeling the performance of 32 surface and 7 IOU sources for 10,000 years using 1,000 realizations with reasonable time steps required about 20 hours to complete using 30 slave processes. This is a relatively convenient time in that a simulation started one work day would be completed before the end of the next work day allowing time to view the results and submit another job. The model appeared to run better on the servers than on a local workstation, which is likely caused by use of the GoldSim DP-Plus software on the servers.

Results from the expanded uncertainty analysis were in good agreement with those obtained in the original CA treatment. As shown in Table 6-1, the uncertainty analysis provided a high degree of confidence that peak doses at the POAs do not exceed the $30 \mathrm{mrem} / \mathrm{yr}$ dose constraint. The analysis found that variations in $\mathrm{K}_{\mathrm{d}}$ values and in infiltration and aquifer flow rates had the greatest impact on dose uncertainty. Both of these factors influence the transport timing. In most cases, the peak dose at a POA occurred in the early part of the transient where the dose is predominantly from Cs-137 released from streambed sediments.

\subsection{Future Work}

As shown by the dose distribution plotted in Figure 8-1 (see also Figure 3-1), of the 152 CA sources, 49 (41 surface sources and 8 IOUs) have peak doses greater than $0.001 \mathrm{mrem} / \mathrm{yr}$ in the time period from 2025 to 3025 . Based on the results obtained during this project, the GoldSim model could be expanded to include all of these sources in an uncertainty analysis. This model would scale up to about $280 \mathrm{Mb}$ in size and require about 30 hours to complete a simulation with 30 slave processors. This expansion is feasible although the resulting GoldSim file size of $20 \mathrm{~Gb}$ will be difficult to work with. Another 47 CA sources had peak doses less than $1.0 \mathrm{e}-6 \mathrm{mrem} / \mathrm{yr}$ and could reasonably be excluded from the uncertainty analysis. Some of the remaining sources with similar source locations, release mechanisms, and vadose and aquifer path parameters could perhaps be lumped together to improve the model accuracy with a modest increase in computational burden.

Since the CA supports the PA facilities (E-Area low level waste disposal facilities, F and H-Area tank farms, and Z-Area saltstone) it would be desirable to include as many PA sources in the uncertainty analysis as possible. The PA facilities accounted for 46 of the 152 CA sources and ten of the 46 PA sources were included in the current uncertainty analysis. More PA sources could be included by lumping ones with similar transport paths into single composite sources. For example, source lumping could be applied to the eight H-Area tank farm sources that discharge to the Upper Three Runs POA which were not included in the present analysis.

Other modifications to the model that should be considered for future uncertainty analysis are:

- Bioaccumulation factors and source inventory were not included in the uncertainty analysis. Stochastic distributions need to be developed for these variables. Cook et al. (2011) reviewed two approaches for estimating inventory uncertainty.

- Surface water flow distributions used in the uncertainty analysis were based on estimates of the variability in the 1,000 year average flow which gave a very narrow distribution. Other methods of estimating the uncertainty in surface water flow should be evaluated. 
- In the current model, stochastic parameters are the same in each source and each dose calculation. This approach significantly reduces the number of uncertainty parameters that must be analyzed; however, an argument could be made that each instance of a stochastic parameter should be allowed to vary independently.

- The model should be modified to output the stochastic parameter values used for each realization along with full results from each realization for a statistical analysis. A statistical analysis could be employed to identify the stochastic parameters having the most impact on peak doses with a single run of the uncertainty model.

Cumulative Distribution of Peak Doses in Years 2025 - 3025

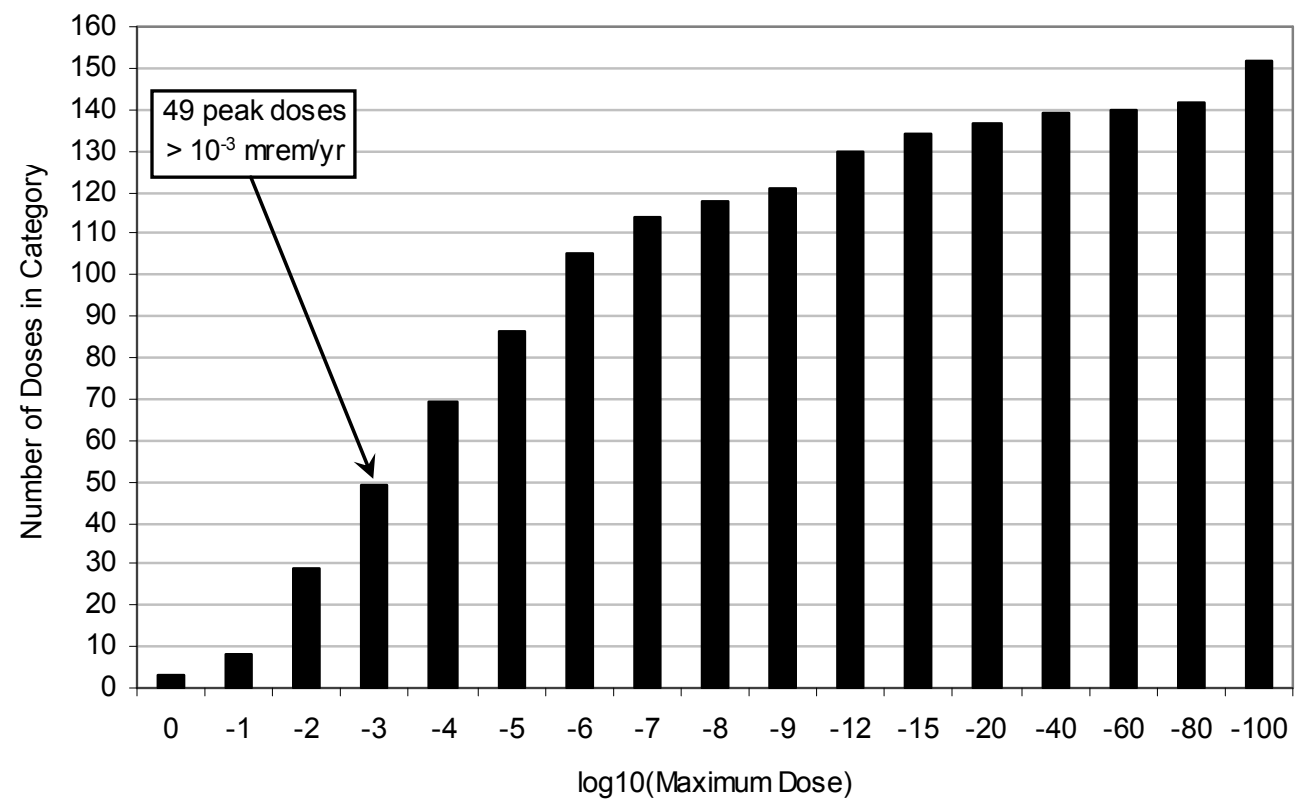

Figure 8-1. Cumulative distribution of peak doses from all CA sources during the years $2025-$ 3025. 


\subsection{References}

Cook, J.R., McDowell-Boyer, L., Roddy, N.S. 2011. Methods for Estimating Inventory Uncertainty in SRS Performance Assessments, SRNL-STI-2010-00666, Rev. 0, Savannah River National Laboratory, Aiken, SC, May 2011.

Hamm, L.L., Smith, F.G. III, Phifer, M.A. and Collard, L.B. 2009. Savannah River Site Composite Analysis: Aquifer Flow Path Parameters, SRNL-STI-2009-00438, Rev. 0, Savannah River National Laboratory, Aiken, SC, August 2009. [OUO]

McDowell-Boyer, L. and Kaplan, D.I. 2009. Distribution Coefficients (Kds), Kd Distributions, and Cellulose Degradation Product Correction Factors for the Composite Analysis, SRNL-STI2009-00150, Rev. 1, Savannah River National Laboratory, Aiken, SC, April 2009.

Phifer, M.A. and Dixon, K.L. 2009. Material Property, Infiltration, and Saturation Estimates and Distributions, SRNL-STI-2009-00316, Savannah River National Laboratory, Aiken, SC, May 2009.

Phifer, M.A., McDowell-Boyer, L., Young, K.E., and Cook, J.R. 2009. Savannah River Site Composite Analysis: Dose Module, SRNL-STI-2009-00424, Rev. 0, Savannah River National Laboratory, Aiken, SC, August 2009.

Shine, E.P. 2009. Distributions of the Means of Stream Flows in the Savannah River Site Vicinity over One-Year and 1,000-Years, SRNL-L5100-2009-00009, Savannah River National Laboratory, Aiken, SC, March 9, 2009.

Smith, F.G. III, Hiergesell, R.A., Swingle, R.F., Hamm, L.L., and Phifer, M.A. 2009a. Savannah River Site Composite Analysis: Base Case Deterministic Calculations, SRNL-STI-2009-00390, Rev. 0, Savannah River National Laboratory, Aiken, SC, July 22, 2009.

Smith, F.G. III, Hiergesell, R.A., Swingle, R.F., Hamm, L.L., and Phifer, M.A. 2009b. Savannah River Site Composite Analysis: Sensitivity and Uncertainty Calculations, SRNL-STI-2009-00436, Rev. 0, Savannah River National Laboratory, Aiken, SC, July 30, 2009.

SRS CA, 2009. Savannah River Site DOE 435.1 Composite Analysis, SRNL-STI-2009-00512, Rev. 0, Vols. I and II, Savannah River National Laboratory, Aiken, SC, June 10, 2010. 


\section{Distribution:}

R. S. Aylward, 773-42A

L. A. Bagwell, 773-42A

D. L. Beeler, 704-60E

H. H. Burns, 773-41A

B. T. Butcher, 773-43A

L. B. Collard, 773-43A

D. A. Crowley, 773-43A

G. P. Flach, 773-42A

F. L. Fox, 704-59E

W. T. Goldston,705-3C

J. C. Griffin, 773-A

L. L. Hamm,703-41A

M. A. Heitkamp, 999-W

S. J. Hensel, 703-41 A

R. A. Hiergesell, 773-43A

G. K. Humphries, 705-3C

J. M. Jordan, 703-41A

D. I. Kaplan, 773-43A

D. Li, 773-43A

M. G. Looper, 704-36E

J. J. Mayer, 773-42A

M. R. Millings, 773-42A

T. O. Oliver, 773-42A

M. A. Phifer, 773-42A

L. K. Pressley, 705-1C

S. R. Reed, 704-56E

K. A. Roberts, 773-43A

K. H. Rosenberger, 705-1C

R. R. Seitz, 773-43A

D. F. Sink, 704-56E

F. G. Smith, 703-41A

F. M. Smith, Jr., 703-1C

R. F. Swingle, 773-43A

G. A. Taylor, 773-43A

K. L. Tempel, 704-56E

C. Wilson (1 file copy \& 1 electronic copy), 773-43A - Rm. 213 